UNIVERSIDADE DE SAO PAULO

INSTITUTO DE QUÍMICA

\title{
ESTUDO DE ALGUNS SULFÓXIDOS $\alpha$-TIO-SUBSTITUIDOS: MEDIDAS DE BASICIDADE RELATIVA, E REAÇŌES COM COMPOSTOS DE GRIGNARD AROMÁTICOS
}

FRANCISCO A. C. ANDRADE Tese de Doutoramento 


\section{UNIVERSIDADE DE SAO PAULO \\ INSTITUTO DE QUIMICA}

ESTUDO DE ALGUNS SULFOXIDOS $\alpha$-TIO-SUBSTITUIDOS:

MEDIDAS DE BASICIDADE RELATIVA, E REAÇÕES COM COMPOSTOS DE GRIGNARD AROMATICOS

FRANCISCO A. C. ANDRADE

Tese de Doutoramento orientada pela Profa. Dra. BLANKA WLADISLAW

São Paulo 
A meus pais 
A Dora

A. Paulinho 
A Profa. Dra, Blanka ll1adislaw, o meu profundo reconhecimento pela orientação e interēsse dispensados à execução dēste trabalho. 


\section{AGRADECIMENTOS}

Aos amigos e Professores do Instituto de Quimica que di reta ou indiretamente colaboraram na realização dēste trabalho.

Aos Drs. Paulo 01ivato e Liliana Harzoratti, pela doação de a gumas de suas amostras.

Aos Srs. Laerte $V$. da Silva e Josē Neiva, funcionärios do laboratório, pela boa vontade com que me auxiliaram.

A Srta. Valdete C. 01 iveira pela dedicação com que executou os serviços datilogräficos.

Ao Instituto de Quĩmica da Universidade Federal da Bahia, pela licença concedida. 


\section{INDICE}

pag s

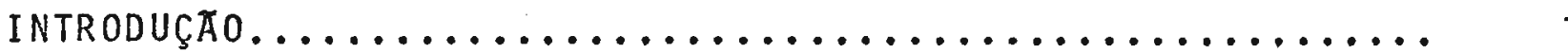

CAPITULO 1 - BASICIDADE DE SULFOXIDOS E REAÇOES COM COMPOS-

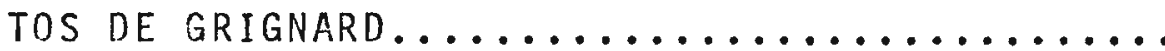

1.1. Basicidade de surfóxidos.....................

1.2. Reações de sulföxidos com compostos de Grignard......

CAPITULO 2 - APRESENTAÇÃO DOS RESULTADOS E DISCUSSÄO......

2.1. Hedidas comparativas de basicidade pelo emprêgo do mē-

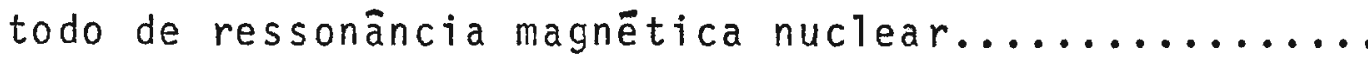

2.2. Reações de B-tia-sulföxidos com compostos de Grignard.

CAPITULO 3 - PARTE EXPERIMENTAL................. 36

3.1. Instrumentos........................ 36

3.2. Determinação de constantes de associação de sulfōxidos com fenol, em tetracloreto de carbono.............. 36

3.2 .1 . Notações............................ 36

3.2.2. Descrição geral do mëtodo empregado nas medidas dos

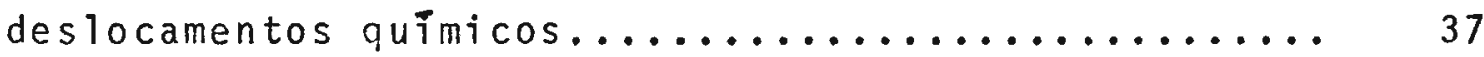

3.2.2.1. Preparação das amostras................. 37

3.2.2.2. Medidas dos deslocamentos quîmicos (v) ........ 38

$3 \cdot 2,2.3$. Determinação da variação do deslocamento químico do pröton fenōlico $(\Delta v) \ldots \ldots \ldots \ldots \ldots \ldots . \ldots \ldots$

3.2.2.4. Determinação da variação do deslocamento quĩmico do pröton fenōlico, quando em presença de concen -

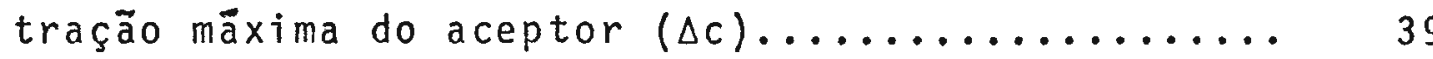

3.2.2.5. Relações entre os deslocamentos descritos....... 40 
pag:

3.2.3. Determinação das constantes de associação (Kass $) \ldots .41$

3.2.4. Experiēncias realizadas................... 41

3.2.4.1. Determinação da constante de associação do metil metiltiometil sulföxido com fenol, em tetracloreto

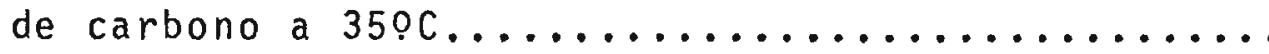

3.2.4.2. Determinação da constante de associação do metil propil sulfōxido com fenol, em tetracloreto de car

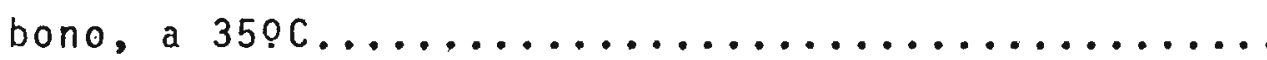

3.2.4.3. Determinação da constante de associação do etil etiltiometil sulföxido com fenol, em tetracloreto de carbono, a $350 \mathrm{C} \ldots \ldots \ldots \ldots \ldots \ldots \ldots \ldots \ldots \ldots \ldots$

3.2.4.4. Determinação da constante de associação do etil butil sulfōxido coln fenol, em tetracloreto de car-

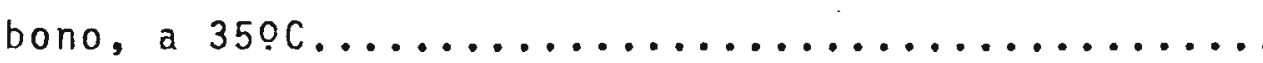

3.3. Reações de sulföxidos com compostos de Grignard...... 51

3.3.1. Procedimentos gerais..................... 51

3.3.1.1. Preparação e dosagem dos compostos de Grignard... 51

3.3.1.2. Reações de sulfōxidos com compostos de Grignard... 52

3.3.1.3. Identificações e anāitises dos produtos das reações de sulfóxidos com compostos de Grignard......... 52

3.3.2. Experiēncias realizadas................... 56

3.3.2.1. Reação do etil etiltiometil sulfōxido com um equivalente de brometo de fenilmagnēsio.

3.3.2.2. Reação do etil etiltiometil sulfōxido com dois equivalentes de brometo de fenilmagnēsio.........

3.3.2.3. Reação do etil etiltiometil sulföxido com o brometo de p-tolilmag̣nēsio. 
pag.

3.3.2.4. Reação do etil etiltiometil sulfóxido com o brometo de p-metoxifenilmagnēsio.

$3.3 .2,5$. Reação do etil feniltiometil sulföxido com o brometo de fenilmagnēsio.

3.3.2.6. Reação do fenil feniltiometil sulfōxido com o brome to de fenilmagnēsio.

3.3.2.7. Reação do 1,3-ditiolano-1-ōxido com o brometo de fe ni 1 magnësio.

3.4. Preparaçōes e reações de carbānions do etiletiltiome -

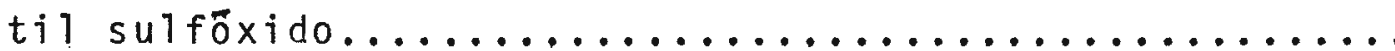

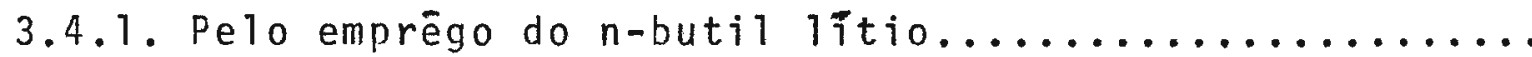

3.4.1.1. Preparação do carbânion.

3.4.1.2, Reação com um equivalente de brometo de fenilmagnésio.

3.4.1.3. Reação com dois equivalentes de brometo de feni1 magnēsio.

3.4.1.4. Reaçāo com brometo de fenilmagnësio, em presença de brometo de magnësio

3.4.1.5. Reação com āgua deuterada.

3.4.2. Pelo emprégo de hidreto de sōdio.

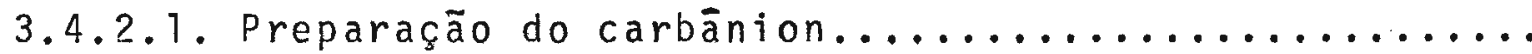

3.4.2.2. Reação com um equivalente de brometo de fenilmagnēsio

$3.4 .2,3$, Reação com dois equivalentes de brometo de fenilmag

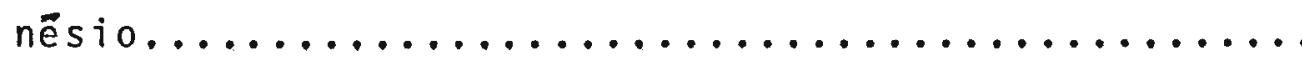

$3 \cdot 4 \cdot 2.4$. Reação com āgua deuterada.

3.4.3. Pelo emprêgo do brometo de etilmagnēsio........... 
pag.

3.4.3.1. Preparação e reação com āgụa deuterada.......... 67

3.4.4. Pelo emprègo do brometo de fenilmagnēsio.......... 68

3.4.4.1. Preparação e reação com ãgua deuterada.......... 68

3.5. Compostos disponiveis...................... 69

3.5.1. Solventes e reagentes não purificados............. 69

3.5.2. Solventes e reagentes purificados............... 69

3.6. Preparações de sulföxidos..................... 70

3.6.1. Preparação do metil metiltiometil sulföxido....... 70

3.6.1.1. Metilmercaptal do formaldeido............... 70

3.6.1.2. Netil metiltiometil sulföxido................ 71

3.6.2. Preparação do etil etiltiometil sulfōxido.......... 71

3.6.2.1. Etilmercaptal do formaldeido............... 71

3.6.2.2. Etil etiltiometil sulföxido................. 72

3.6.3. Preparação do metil propil sulfõxido............. 72

3.6 .3 .1 . ifetil propil sulfeto.................... 72

3.6.3.2. Hetil propil sulföxido.................. 73

3.6.4. Preparação do fenị feniltiometil sulföxido........ 73

3.6.4.1. Fenilmercaptal do formaldeido.............. 73

3.6.4.2. Fenil feniltiometil sulföxido............... 74

3.6.5. Preparaçāo do etil feniltiometil sulfóxido........ 75

3.6.5.1. Etil clorometil sulfeto.................. 75

3.6.5.2. Etil feniltiometil sulfeto................. 75

3.6.5.3. Etil feniltiometil sulfóxido............... 76

3.6.6. Preparação do 1,3-ditiolano-1-ōxido............. 77

$3.6 .6 .1 .1,3-$ Ditiolano......................... 77

$3.6 .6 .2 .1,3-$ Ditiolano-1-öxido.................. 77

3.7. Preparações de compostos para fins comparativos....... 78 
pag:

3.7.1. Preparação do etilmercaptal do p-metoxibenzaldeido.. 78

3.7.2. Preparação do etilmercaptal do o-metoxibenzaldeido.. 79

3.7.3. Preparação do etilmercaptal do p-tolualdeido...... 79

3.7.4. Preparação do fenilmercaptal do benzaldeido....... 80

3.7.5. Preparação do etilfenilmercaptal do benzaldeido.... 80

3.7.5.1. Benzil fenil sulfeto.................... 80

3.7.5.2. $\alpha-C 1$ orobenzil fenil sulfeto................. 80

3.7.5.3. Etilfenilmercaptal do benzaldeido............. 80

3.7.6. Preparação do 2 -fenil-1,3-ditiolano............ 82

3.7.7. Preparação do eti1 p-metoxifenil sulfeto......... . 83

3.7.8. Preparação do etil p-metoxibenzil sulfeto......... 83

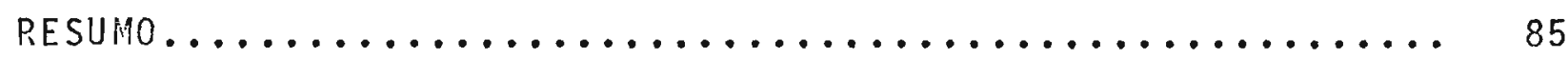

ABSTRACT ............................. 87

REFERENCIAS BIBLIOGRAFICAS.................. 89 


\section{INTRODUCAO}

0 presente trabalho faz parte de duas linhas de pesquisa em desenvolvimento no grupo dirigido pela profa. Wladislaw : interações eletrōnicas e reações de sulfõxidos B-tia-substitui dos.

A primeira parte da tese, tratando de medidas de basici dade relativa de sulfóxidos $\beta$-tia-substituidos, constitue-se em uma ponte comum entre estas duas linhas, pois, os resultados, de um lado indicam a existência de interação eletrōnica no siste ma $-\mathrm{S}-\mathrm{CH}_{2}-\mathrm{SO}$ - e por outro lado explicam a modificação de reativi dade destes compostos, observada paralelamente em nosso laborató rio ${ }^{1}{ }^{2}$.

As reações dos mesmos compostos com reagentes de Grig nard, tratadas na segunda parte da tese, que, em parte, jā tinham sido relatadas numa comunicação prēvia ${ }^{3}$, alēm de fornecerem re sultados de aplicação sintētica, possibilitam uma discussão dos mecanismos envolvidos.

Esta tese compōe-se de trēs capĩtulos: o primeiro traz uma revisão bibliogrãfica sobre basicidade de sulfōxidos, e reações de sulföxidos com compostos de Grignard. No segundo capitu10 são relatados e discutidos os resultados experimentais. O ter ceiro capītulo contēm a parte experimental. 


\section{BASICIDADE DE SULFOXIDOS E REACOES}

COH COMPOSTOS DE GRIGNARD

\subsection{EASICIDADE DE SULFOXIDOS}

A basicidade de sulfóxidos tem sido estimada por dife rentes mētodos, atravēs dos valores de constantes de protonação $\left(K_{B H+}\right)$ obtidos em àcidos fortes, ou dos valores de constantes de associação ( $k_{\text {ass }}$ ) com doadores de prötons.

Trataremos, inicialmente, dos resultados de $\mathrm{pK}_{\mathrm{BH}}$ obtidos em ảcidos fortes, que se referem ao equilỉbrio:

$$
\mathrm{BH}^{+} \rightleftarrows \mathrm{B}+\mathrm{H}^{+}
$$

Por titulação potenciomētrica de uma sērie de aminas, $\underline{u}$ sando ăcido perclōrico em äcido acētico glacial como titulante e anidrido acëtico como solvente, Streuli ${ }^{4}$, em 1958, observou uma boa correlação dos valores de potenciais de neutralização obtidos, com os valores conhecidos de constantes de protonação em āgua. 0 gräfico destes valores conhecidos de $\mathrm{kK}_{\mathrm{BH}}$ contra os potenciais de neutralização foj utilizado para a determinação de p $K_{B H+}$ de ou tras aminas, e, por extrapolação, de outros compostos. 0 dimetilsulfōxido $\left(\mathrm{pK}_{\mathrm{BH}+}=1,0\right)$ apresentou-se mais básico que a acetamida $\left(p_{B H+}=-1,05\right)$ e acetanilida $\left(p K_{B H+}=-2,9\right)$, e com basicidade seme 1hante à da urēia $\left(p K_{B H+}=0,64\right)$ e da meti1-urēia $\left(n K_{B H+}=1,05\right)$. Utilizando o mesmo mētodo, Andersen e col. ${ }^{5}$, em 1966 , 
determinaram valores de $\mathrm{pK}_{\mathrm{BH}}$ para uma sērie de metil fenil sulfō xidos substituidos obtendo valores numa faixa de 0,55 ( $p$-anisil metil sulfôxido) a $-3,51$ ( $p$-nitrofenil metil sulfōxido). 0 valor de $\rho=-3,79$ encontrado indica uma grande sensibilidade da basicida de dos sulfōxidos ãs modificações estruturais. Comparando com o valor encontrado por Stewart e Yates ${ }^{6}$ para acetofenonas $(\rho=-2,17)$ observa-se uma maior sensibilidade dos sulfōxidos que dos compostos carbonilicos, aos efeitos dos substituintes.

Em 1968. Haake e Cook ${ }^{7}$ determinaram $\mathrm{pK}_{\mathrm{BH}+}$ de $-2,78$ para 0 dimetilsulföxido e de $-3,38$ para o metil fenil sulfóxido, em ācido sulfūrico aquoso, por ressonāncia magnētica nuclear, atravēs de uma tëcnica de medida que os mesmos autores propuseram em $1967^{\circ}$. Tal técnica consistiu na determinação dos deslocamentos quĩmicos dos prōtons metîlicos do sulfóxido quando em presença de diferentes concentrações da solução ācida, em relação ao deslocamento quīmico dos prötons metīlicos do ion trimetilamōnio, utilizado como padrão. o grä́fico dos deslocamentos quĩmicos $\Delta(e m \mathrm{~Hz}$ ) versus tio produziu uma curva sigmóide da qual foram determinados os valores dos deslocamentos que correspondiam à forma protonada $\left(\Delta_{B H_{+}}\right)$e à não protonada $\left(\Delta_{B}\right)$ do sulfōxido. Utilizando a equação: $\log (B H+/ B)=M\left(p K_{B H_{+}}-H_{0}\right)$, construiu-se um gräfico de log $(B H+/ B)$ versus $H o$, do qual os valores de pKa foram determinados dividindo-se a interseç̧ão pela inclinação da reta obtida. 0 fator $\|$ foi introduzido à equação de Hammett para correção do efeito do meio sobre bases que não se comportam como bases de Hammett. os valores das intersecções encontrados foram: -1,72(DMSO) e $-2,09(\operatorname{meS} 0 \phi)$.

Em 1969, Landini e col. 'determinaram valores de $\mathrm{pK}_{\mathrm{BH}}+\mathrm{p} \underline{\mathrm{a}}$ 
ra diferentes metil sulfóxidos em soluções aquosas de äcido sulfü. rico e de ācido perclōrico, utilizando técnicas espectroscōpicas tanto do ultravioleta como da ressonância magnētica nuclear. Por ressonāncia magnētica nuclear ${ }^{7}$, os deslocamentos quïmicos dos hidrogēnios metīlicos dos sulfōxidos foram medidos em relação ao Fon trimetilamônio em soluções âcidas. Os deslocamentos químicos $(\Delta)$ foram colocados em um gräfico contra os valores de Ho das soluçōes ãcidas, obtendo-se curvas sigmōides, das quais foram deter minados os valores de Ho ā meia protonação. Pelo ultravioleta ${ }^{10}$ fo ram medidas as densidades öticas dos sulföxidos nas soluções ãcidas em dois comprimentos de onda correspondentes às formas protonadas e não protonadas. Ns diferenças entre as atividades ōticas de cada forma foram colocadas em gräfico contra os valores de Ho das correspondentes soluções äcidas, obtendo-se tambēm curvas sig möides, e valores de Ho à meia protonação, concordantes com os ob tidos por ressonāncia magnētica nuclear. A meia protonação a fração de sulföxido protonado ë igual à do sulföxido livre, e o valor de Ho seria igual ao $\mathrm{pK}_{\mathrm{BH}+}$. Entretanto, a protonação completa dos sulföxidos foi alcançada com uma faixa maior que quatro unida des de Ho, indicando que os sulföxidos não se comportam como bases de Hammett, e que, consequentemente, seus valores de $\mathrm{pK}_{\mathrm{B} H+}$ não podiam ser avaliados diretamente do gräfico de $\log \left(B H^{+} / B\right)$ contra a função Ho. Os valores de $\mathrm{pK}_{\mathrm{BH}}$ foram, entäo, obtidos utilizando a equaçāo proposta por Bunnett e 01 sen $^{11}$ :

$\log (B H+/ B)+H_{0}=\emptyset\left(H_{0}+\log H^{+}\right)+p K_{B H+}$, determinando-se a intersecção da reta obtida pelo gräfico de $\log (S O H+/ S O)$ + Ho ver sus $H_{0}+\log H^{+}$. A inclinação $\varnothing$ variou na faixa de 0,4 a 0,6 indi cando, tambēm, que os sulfōxidos não são bases de Hammett. Deter- 
-minando os $\mathrm{pK}_{\mathrm{BH}}$ de diferentes fenil metil sulföxidos substituidos estes autores obtiveram valores na faixa de $-2,05$ (p-anisil metil sulfôxido) a $-2,96$ (p-nitrofenil metil sulfōxido). o valor de $\rho=-0,85$ encontrado mostra que os efeitos estruturais sôbre a basicidade dos sulfōxidos não são tão grandes como sugerido pelos resultados de Andersen e col.

As discrepancias observadas foram atribuidas ao fato de que os resultados de Andersen e col. foram avaliados por extrapo lações de medidas em meio não aquoso, em relação a dados de $\mathrm{pK}_{\mathrm{BH}}$ encontrados para bases de Hammett em meio aquoso diluido.

Os valores de $\mathrm{pK}_{\mathrm{BH}}$ encontrádos para o t-butil metil sulfōxido $(-1,62)$; dimetilsulfōxido $(-1,80)$; metil fenil sulfōxi do $(-2,27)$ e difenilsulföxido $(-2,54)$, correlacionaram-se com os dados de $\Delta \nu_{O H}\left(\mathrm{~cm}^{-1}\right)$ do fenol com estes sulföxidos em tetracloreto de carbono $\left(393,366,330\right.$ e $305 \mathrm{~cm}^{-1}$, respectivamente), com $r=0,9936$.

Determinando as basicidades de diferentes sulfōxidos em äcido sulfürico aquoso, por medidas no ultravioleta, Harziano e col. 12 em 1969, encontraram valores de $\mathrm{pK}_{\mathrm{BH}+}$ semelhantes aos obtidos por Landini e col., utilizando, tambēm, a equacão de Bunnett e 01sen. 0 mëtodo de medida consistiu na determinação da densidade ötica para o sistema em diferentes soluçōes äcidas, em um sō comprimento de onda prēviamente escolhido, obtendo o $\mathrm{pK}_{\mathrm{BH}}$ pela intersecçāo da reta do gräfico de $\log (B H+/ B)+$ Ho contra Ho $+\log \mathrm{H}^{+}$. A escolha do comprimento de onda foi feita plotando-se os valores de $\varepsilon$ contra Ho, em um comprimento de onda no qual se observou a menor absorção da forma protonada. Da curva sigmóide obtida escolheu-se para as medidas o comprimento de onda corres- 
pondente ā densidade ōtica no ponto de inflexão.

Os dados obtidos foram tambēm tratados por outros mētodos de cālculo, observando-se diferenças de atē duas unidades de pK $K_{B H+}$ Considerando os sulföxidos como bases de Hammett ${ }^{23}, \log (B H+/ B)+$ $H_{0}=p K_{B H+}$, a fração $\mathrm{BH}+/ \mathrm{B}$ no ponto de inflexão da curva sigmōide é igual à unidade, e o valor de $\mathrm{Fk}_{\mathrm{BH}+}$ serā içual ao Ho neste ponto. Corrigindo conforme aproximação de Yates ${ }^{14}$,

$\log (B H+/ B)+m H o=p K_{B H_{+}}$, o valor do $p K_{B H+}$ é encontrado determi nando-se o valor de mHo quando $\log (B H+/ B)$ è igual a zero. Foram encontrados, por exemplo, os seguintes $\mathrm{pK}_{\mathrm{BH}}$ para o metil fenil sulföxido: $-3,68$ (Ho no ponto de inflexão; $-1,92$ (mētodo de Yates) e $-2,26$ (mëtodo de Bunnett e 01 sen). Neste mesmo ano, oae e col. ${ }^{15}$ obtiveram valores de $\mathrm{pK}_{\mathrm{BH}}$ para difenilsulfōxidos substituidos, em ācido sulfūrico aquoso, por medidas no ultravioleta, utilizando o método descrito por Davis e Geissmann ${ }^{10}$. A equação utilizada para o cālculo das constantes era semelhante à utilizada por Hake e Cook ${ }^{8}$ : $p K_{B H+}=H o-n \log (B H+/ B)$. Os valores encontrados variaram de $-3,67$ (fenil p-metoxifenil sulföxido) a-5,74 (fenil m-clorofenil sulfóxido), e deram boa correlação com valores de $\sigma^{+}$, obtendo-se $\rho=-2,00$. A utilização desta equação, bem como daquela utilizada por Haack e Cook, fornece resultados de pk $K_{B+}$ bem menores que os obtidos pela utilização da equação de Yates e McClelland ${ }^{14}$. Na tabela I reunimos os dados de $\mathrm{pK}_{\mathrm{BH}+}$ da literatura. 
TABELA I

$\mathrm{pK}_{\mathrm{BH}+}$ de alguns sulfōxidos

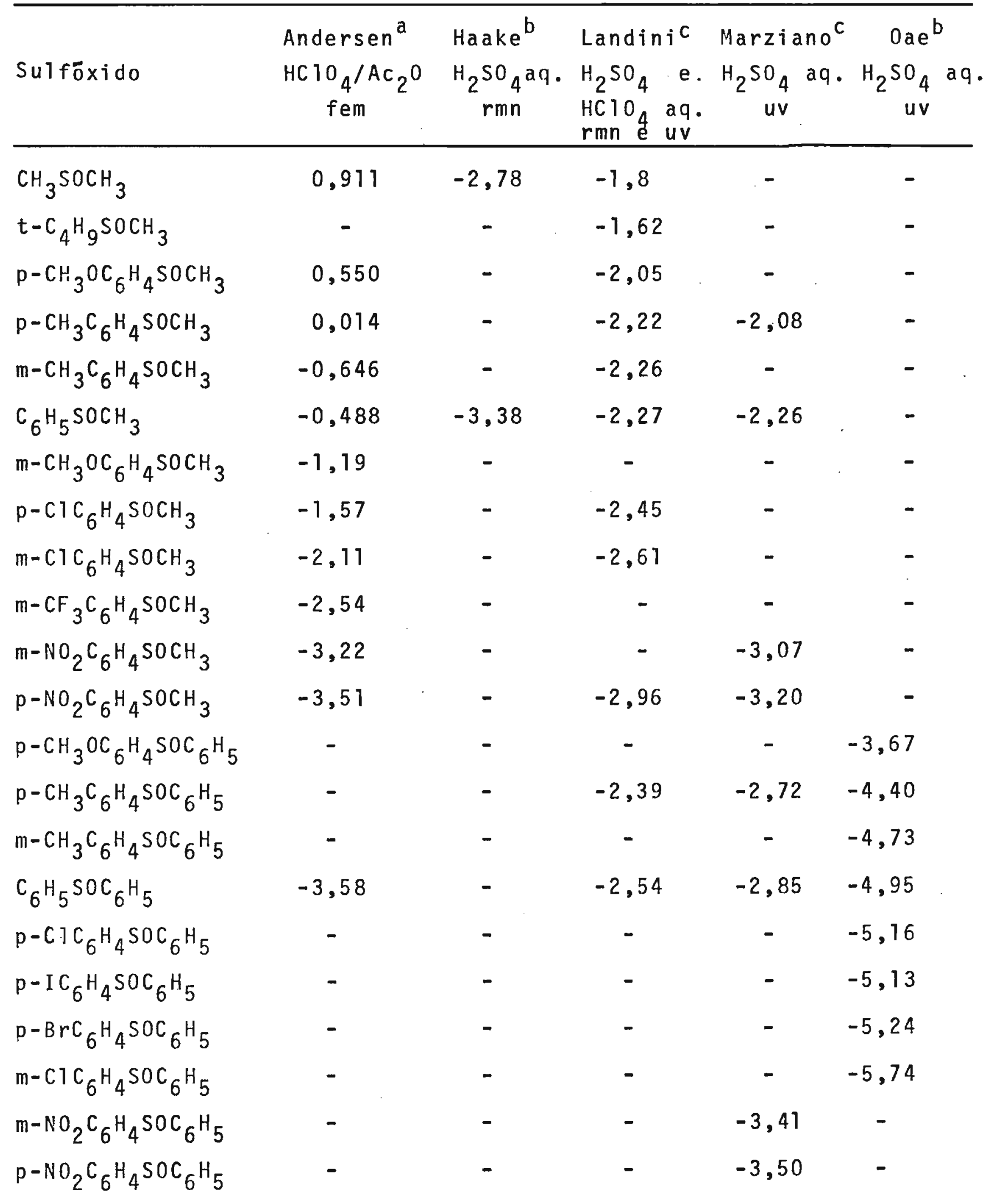

${ }^{a}$ Valor de Ho no ponto de inflexão, segundo eq.: $\log \frac{B H+}{B}=p K_{B H+}-H_{0}$ ${ }^{b}$ Interseç̧ão/inclinação, segundo eq.; $\log \frac{B H+}{B}=M\left(p K_{B H+}-H_{0}\right)$

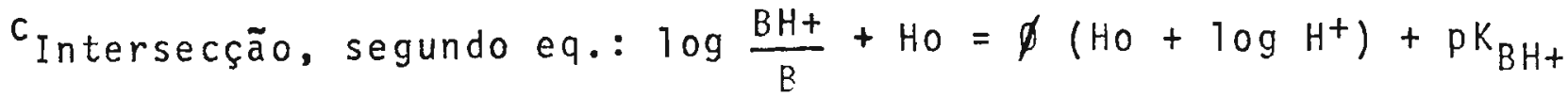


Pode ser observado que, por medidas em meio aquoso, são relatados resultados de $\mathrm{pK}_{\mathrm{BH}+}$ principalmente para sulfōxi dos aromãticos.

As determinaçōes de basicidade de sulfōxidos alifäticos foram efetuadas principalmente por medidas de constantes de associação ( $\mathrm{K}_{\text {ass }}$ ) com doadores de protons, que relacionam as concentraçōes do equilïbrio:

$$
\mathrm{A}-\mathrm{H}+\mathrm{B} \rightleftarrows \mathrm{A}-\mathrm{H}--\mathrm{B}
$$

Em 1963, Gramstad ${ }^{26}$, por medidas no infraverme 1 ho prō ximo, determinou constantes de associação de alguns sulföxidos alifáticos, alicíclicos e aromáticos, com fenol, em tetracloreto de carbono, nas temperaturas de 20 e 500C. Paralelamente, o autor efetuou medidas dos deslocamentos da frequência de estira mento ( $\Delta \nu$ em $\mathrm{cm}^{-1}$ ) correspondentes ao fenol associado, encontran do uma boa correlação entre estes valores e os de $\log \mathrm{K}_{\text {ass }}$. Os dados de $\Delta v$ foram obtidos utilizando uma solução $0,06 \mathrm{M}$ do doador e $0,03 \mathrm{M}$ do aceptor. Foram calculados os valores de $\Delta \mathrm{F}$, $\Delta H$ e $\Delta S$, que também se correlacionaram com os resultados de $\Delta \nu$, observando-se que os gräficos de $\Delta S$ versus $\Delta \nu$ para sulföxidos e para outros compostos forneciam retas paralelas, e a seguinte or dem de decrêscimo de entropia em relação a $\Delta \nu$ : compostos organofosforados > amidas $N, N$-substituidas > sulfóxidos > esteres > cetonas > nitrosocompostos > aldeidos > eteres > piridinas e ami nas terciärias.

No mesmo ano, Biscarini e col. ${ }^{17}$ mediram os deslocamen tos $\Delta \nu$ em soluções contendo $0,01 \mathrm{H}$ de fenol e $0,01 \mathrm{M}$ de sulfóxido, em tetracloreto de carbono, a $250 \mathrm{c}$. Estes deslocamentos se 
correlacionaram com os valores de log kass obtidos por medidas do coeficiente de extinção a $3615 \mathrm{~cm}^{-1}$, Os autores observaram que ta1 correlação indicava que a variação de entropia padrão associàda ã ligação de hidrogēnio nestes sistemas ou é muito pequena em relação ã variação de entalpia padrão, ou ẽ constante.

Em 1966, Figueroa e Szmant ${ }^{18}$ determinaram constantes de associação entre sulfóxidos e fenol, em tolueno, a 270̣, por medi das da absorbāncia da banda situada em $3535 \mathrm{~cm}^{-1}$.

Por ressonāncia magnētica nuclear, Gurka e Taft ${ }^{19}$, em 1969, mediram constantes de associação do p-fluorofenol com alguns sulföxidos, em tetracloreto de carbono, a 250̣, usando o p-fluoroanisol como referência interna. A constante de associação foi calculada utilizando a expressão:

$$
K_{a s s}=\frac{A_{0}(\delta / \Delta)}{A_{0}\{1-(\delta / \Delta)\}\left\{B_{0}-A_{0}(\delta / \Delta)\right\}}
$$

onde $A_{0}$ e $B_{0}$ são as concentrações iniciais de fenol e base, respec tivamente, $\delta$ é o deslocamento observado em relação ao p-fluorofe nol livre, e $\Delta$ é o deslocamento limite em relação ao p-fluorofenol, correspondente ao do complexo completamente formado.

A tabela que segue (Tabela II) reune os resultados de $k_{\text {ass }}$ e $\Delta \nu\left(\mathrm{cm}^{-1}\right)$ ou $\Delta(\mathrm{ppm})$ encontrados para a associação de sulfó xidos com doadores de prötons. 
Dados de $K_{a s s}(1 / \mathrm{mol})$ e $\Delta v\left(\mathrm{~cm}^{-1}\right)$ ou $\Delta(\mathrm{ppm})$ para associação de sulföxidos com doadores de prötons

\begin{tabular}{|c|c|c|c|c|c|c|c|c|c|}
\hline \multirow{3}{*}{ Sulföxidos } & \multirow{2}{*}{\multicolumn{2}{|c|}{$\begin{array}{c}\text { Biscarini e col. } \\
\mathrm{C}_{6} \mathrm{H}_{5} \mathrm{OH} / \mathrm{CCl}_{4}\end{array}$}} & \multirow{2}{*}{\multicolumn{3}{|c|}{$\begin{array}{c}\text { Gramstad } \\
\mathrm{C}_{6} \mathrm{H}_{5} \mathrm{OH} / \mathrm{CC}_{4}\end{array}$}} & \multirow{2}{*}{\multicolumn{2}{|c|}{$\begin{array}{c}\text { Figueroa e Szmant } \\
{ }_{\mathrm{C}_{6}} \mathrm{H}_{5} \mathrm{OH} / \mathrm{C}_{6} \mathrm{H}_{5} \mathrm{CH}_{3}\end{array}$}} & \multirow{2}{*}{\multicolumn{2}{|c|}{$\begin{array}{l}\text { Gurka e Taft } \\
\mathrm{p}-\mathrm{FC}_{6} \mathrm{H}_{4} \mathrm{OH}^{\mathrm{OCCT}} 4\end{array}$}} \\
\hline & & & & & & & & & \\
\hline & $\Delta v$ & $k_{a s s}^{25}$ & $\Delta v$ & $k_{a s s}^{20}$ & $k_{a s s}^{50}$ & $\Delta v$ & $k_{\text {ass }}^{27}$ & $\Delta$ & $\begin{array}{l}k_{25}^{25} \\
\text { ass }\end{array}$ \\
\hline $\mathrm{CH}_{3} \mathrm{SOCH}_{3}$ & 366 & 216 & 350 & 230,2 & 64,2 & 340 & 55 & 2,71 & 338 \\
\hline$\left(\mathrm{C}_{2} \mathrm{H}_{5}\right)_{2} \mathrm{SO}$ & 385 & 250 & - & - & - & - & - & - & - \\
\hline$\left(\mathrm{n}-\mathrm{C}_{3} \mathrm{H}_{7}\right)_{2} \mathrm{SO}$ & 387 & 306 & - & - & - & - & - & - & - \\
\hline$\left(\mathrm{n}-\mathrm{C}_{4} \mathrm{H}_{9}\right)_{2} \mathrm{SO}$ & - & - & 373 & 264,3 & 96,7 & - & - & - & 398 \\
\hline$\left(\mathrm{i}-\mathrm{C}_{3} \mathrm{H}_{7}\right)_{2} \mathrm{SO}$ & 405 & 238 & 360 & 209,7 & 83,2 & - & - & - & - \\
\hline$i-\mathrm{C}_{3} \mathrm{H}_{7} \mathrm{SOCH}_{3}$ & 380 & 199 & - & - & - & - & - & - & - \\
\hline$t-\mathrm{C}_{4} \mathrm{H}_{9} \mathrm{SOCH}_{3}$ & 393 & 230 & - & - & - & - & - & - & - \\
\hline$\left(\mathrm{CH}_{2}\right)_{3} \mathrm{SO}$ & 320 & 94 & - & - & - & - & - & - & - \\
\hline$\left(\mathrm{CH}_{2}\right)_{4} \mathrm{SO}$ & 390 & 323 & 370 & 233,5 & 77,6 & - & - & 2,80 & 166 \\
\hline$\left(\mathrm{CH}_{2}\right)_{5} \mathrm{SO}$ & 390 & 307 & - & - & - & - & - & - & - \\
\hline$\left(\mathrm{C}_{6} \mathrm{H}_{5} \mathrm{CH}_{2}\right)_{2} \mathrm{SO}$ & - & - & 330 & 131,4 & 52,2 & - & - & - & 190 \\
\hline $\mathrm{C}_{6} \mathrm{H}_{5} \mathrm{SOCH}_{3}$ & 330 & 105 & - & - & - & - & - & 2,67 & 141 \\
\hline$\left(\mathrm{C}_{6} \mathrm{H}_{5}\right)_{2} \mathrm{SO}$ & 305 & 70 & 294 & 70,4 & 28,1 & 256 & 19 & 2,70 & 106 \\
\hline$\left(\mathrm{p}-\mathrm{CH}_{3} \mathrm{OC}_{6} \mathrm{H}_{4}\right)_{2} \mathrm{SO}$ & - & - & - & - & - & 299 & 29 & - & - \\
\hline$\left(p-\mathrm{CH}_{3} \mathrm{C}_{6} \mathrm{H}_{4}\right)_{2} \mathrm{SO}$ & - & - & 320 & 105,1 & 39,4 & 278 & 26 & - & - \\
\hline$\left(p-\mathrm{BrC}_{6} \mathrm{H}_{4}\right)_{2} \mathrm{SO}$ & - & - & - & - & - & 235 & 6,5 & - & - \\
\hline$\left(p-\mathrm{NO}_{2} \mathrm{C}_{6} \mathrm{H}_{4}\right)_{2} \mathrm{SO}$ & - & - & - & - & - & 179 & - & - & - \\
\hline
\end{tabular}




\subsection{REAÇOES DE SULFOXIDOS COM COMPOSTOS DE GRIGNARD}

Grignard e Zorn ${ }^{20}$, em 1910, por reação de cloreto de tio nila com o brometo de isoamilmagnésio, obtiveram di-isoamilsulfö xido, ao lado de di-isoamilsulfeto e de àlcool isoamīlico. Como a formação destes sub produtos foi tambêm verificada na reação do di-isoamilsulföxido com o brometo de isoamilmagnēsio, os auto res sugeriram que estes produtos secundārios decorriam da ação posterior do organomagnësiano sōbre o sulfōxido, atravēs da formação e decomposição de um "complexo de sulfōnio" intermediā rio (1)

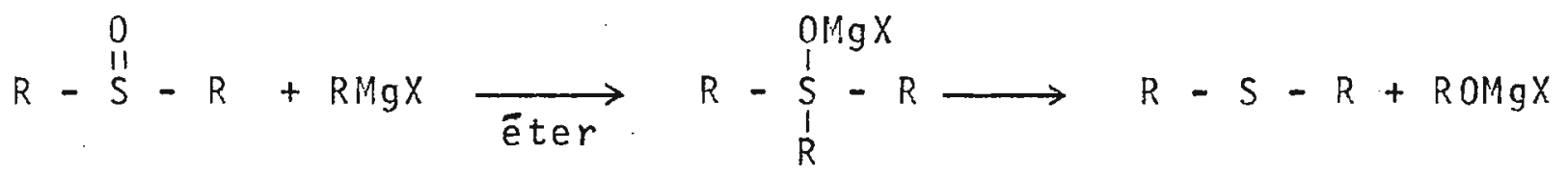

$\mathrm{R}=\left(\mathrm{CH}_{3}\right)_{2} \mathrm{CHCH}_{2} \mathrm{CH}_{2}-$

$\mathrm{X}=\mathrm{Br}$

Quando foi efetuada a reação do dietilsulföxido com o brometo de etilmagnésio os autores obtiveram etileno ao lado de pequena quantidade de dietilsulfeto. Sugeriram, neste caso, que o complexo $\underline{2}$ se decompõe segundo a equação:

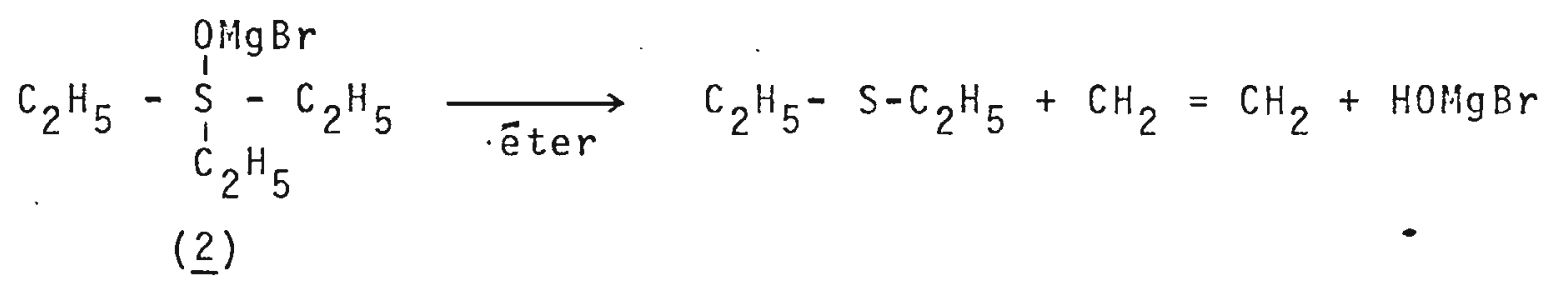


Da reação do cloreto de tionila com organomagnesianos aro māticos não foram obtidos produtos secundārios ao lado dos aril sulfōxidos. Estes se mostraram inertes ã ação posterior do reagen te nas condições empregadas.

Foi demonstrado, posteriormente, por Hepworth e Clapham ${ }^{21}$ que, sulfóxidos arîlicos, apesar de menos reativos, quando aqueci dos sob refluxo em tolueno, tambēm reagiam com compostos de Grignard. Os resultados de suas reações podem ser resumidos pelas seguintes equações:

$$
\begin{aligned}
& \left(\mathrm{C}_{6} \mathrm{H}_{5}\right)_{2} \mathrm{SO} \stackrel{\mathrm{CH}_{3} \mathrm{lgI} \text { exc. }}{\longrightarrow} \quad\left(\mathrm{C}_{6} \mathrm{H}_{5}\right)_{2} \mathrm{~S}+\left(\mathrm{C}_{6} \mathrm{H}_{5}\right)_{2} \mathrm{SO} \\
& 54 \% \quad 44 \% \\
& \left(\mathrm{C}_{6} \mathrm{H}_{5}\right)_{2} \mathrm{SO} \stackrel{\mathrm{C}_{6} \mathrm{H}_{5} \mathrm{MgPr} \text { exc. }}{\longrightarrow}\left(\mathrm{C}_{6} \mathrm{H}_{5}\right)_{2} \mathrm{~S} \\
& 33 \%
\end{aligned}
$$

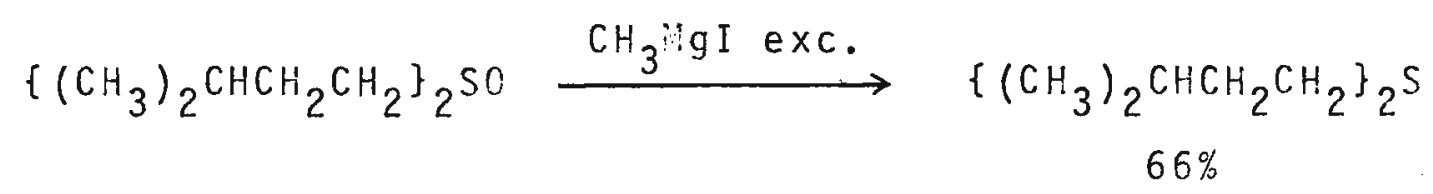

$$
\begin{aligned}
& \mathrm{C}_{6} \mathrm{H}_{5}\left(\mathrm{C}_{6} \mathrm{H}_{5} \mathrm{CH}_{2}\right) \mathrm{SO} \stackrel{\mathrm{CH}_{3} \mathrm{MgI} \text { exc. }}{\longrightarrow} \underset{43 \%}{\mathrm{C}_{6} \mathrm{H}_{5} \mathrm{SCH}_{2} \mathrm{C}_{6} \mathrm{H}_{5}+\mathrm{C}_{6} \mathrm{H}_{5} \mathrm{SOCH}_{2} \mathrm{C}_{6} \mathrm{H}_{5}}
\end{aligned}
$$

ilais recentemente $11 i l d i$ e col. ${ }^{22}$ por aquecimento sob re fluxo, em benzeno, do difenilsulfäxido com brometo de arilmagné sio, obtiveram os seguintes sais de sulfónio: 
$\left(\mathrm{C}_{6} \mathrm{H}_{5}\right)_{3} \mathrm{~S}^{+} \mathrm{Br}-(49,4 \%) ; \quad 3-\mathrm{CH}_{3} \mathrm{C}_{6} \mathrm{H}_{4}\left(\mathrm{C}_{6} \mathrm{H}_{5}\right)_{2} \mathrm{~S}^{+} \mathrm{Br}^{-}(23,4 \%)$

$4-\mathrm{CH}_{3} \mathrm{C}_{6} \mathrm{H}_{4}\left(\mathrm{C}_{6} \mathrm{H}_{5}\right)_{2} \mathrm{~S}^{+} \mathrm{Br}-(34,1 \%)$ e $2,4\left(\mathrm{CH}_{3}\right)_{2} \mathrm{C}_{6} \mathrm{H}_{3}\left(\mathrm{C}_{6} \mathrm{H}_{5}\right)_{2} \mathrm{~S}^{+} \mathrm{Br}^{-}(12,1 \%)$

Substituindo o composto de Grignard por fenilitio os autores ob tiveram um "rendimento negligivel" do brometo de trifenilsulfó. nio.

Com sulfóxidos $\alpha, \beta$-insaturados foi observado por Kohler e Potter ${ }^{23}$ um comportamento bem diferente. Estes autores obtiveram $80 \%$ do 1,4-difenilbutadieno, ao lado de etil tolil sulfeta, pela reação do benzalmetil tolil sulfōxido (3) com um largo excesso de brometo de etilmagnësio. Quando utilizaram o brometo de fenilmagnésio, obtiveram $0 \beta, \beta, \beta-t r i f e n i l e t i l p-t o l i l$ sulfeto ().

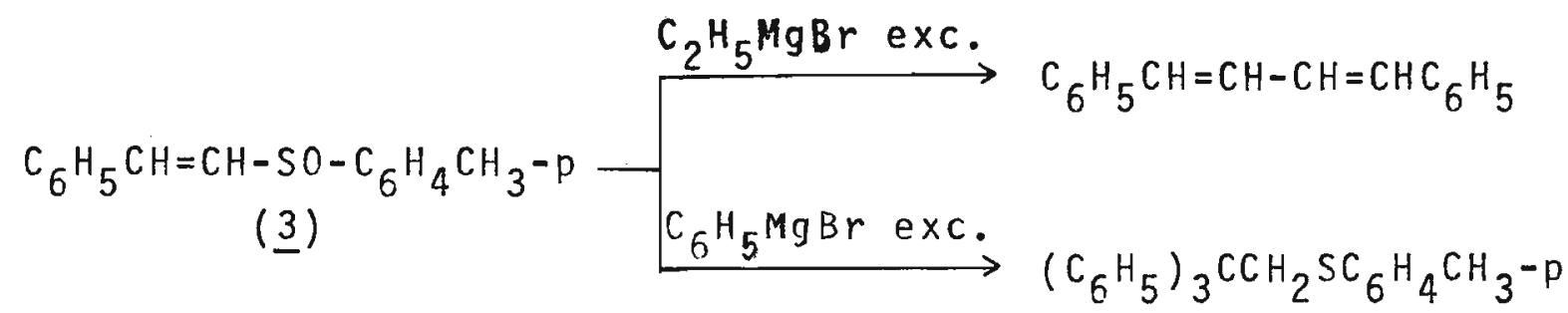

(4)

Em 1960, Potter ${ }^{24}$ verificou que a reação de sulfóxidos, contendo hidrogēnio em alfa, com excesso de brometo de fenilmagnésio, segue um curso diferente, resultando na redução do sulfōxido e substituição concomitante de um hidrogēnio do carbo no alfa pelo grupo fenila do organomagnesiano. Seus resultados. foram os seguintes:

$\mathrm{p}-\mathrm{CH}_{3} \mathrm{C}_{6} \mathrm{H}_{4} \mathrm{SOCH}_{3} \underset{\text { eter }}{\stackrel{\mathrm{C}_{6} \mathrm{H}_{5} \mathrm{MgBr}}{\longrightarrow}} \mathrm{p}-\mathrm{CH}_{3} \mathrm{C}_{6} \mathrm{H}_{4} \mathrm{SCH}_{2} \mathrm{C}_{6} \mathrm{H}_{5}$ 
$\mathrm{p}-\mathrm{CH}_{3} \mathrm{C}_{6} \mathrm{H}_{4} \mathrm{SOCH}_{2} \mathrm{C}_{6} \mathrm{H}_{5} \stackrel{\mathrm{C}_{6} \mathrm{H}_{5} \mathrm{MgBr}}{\bar{e} \text { ter }} \mathrm{p}-\mathrm{CH}_{3} \mathrm{C}_{6} \mathrm{H}_{4} \mathrm{SCH}\left(\mathrm{C}_{6} \mathrm{H}_{5}\right)_{2}$

$p-\mathrm{CH}_{3} \mathrm{C}_{6} \mathrm{H}_{4} \mathrm{SOCH}{ }_{2} \mathrm{CH}\left(\mathrm{C}_{6} \mathrm{H}_{5}\right)_{2} \underset{\text { èter }}{\stackrel{\mathrm{C}_{6} \mathrm{H}_{5} \mathrm{MgBr}}{\longrightarrow}} \mathrm{p}-\mathrm{CH}_{3} \mathrm{C}_{6} \mathrm{H}_{4} \mathrm{SCH}_{2} \mathrm{C}\left(\mathrm{C}_{6} \mathrm{H}_{5}\right)_{3}$

Reaçöes semelhantes foram observadas por Oda e Yamamo$t_{0}{ }^{25}$ em 1961, entre o dimetilsulfōxido e um equivalente de diferentes compostos de Grignard. Na tabela III são apresentados os resultados obtidos. Com os três ültimos reagentes de Grignard alifáticos, os autores observaram a evolução de considerāvel quan tidade de olefina.

\section{$\underline{\text { TABELA III }}$}

Reação do dimetilsuiföxido com reagentes de Grignard

REND. (\%)

$\mathrm{C}_{6} \mathrm{H}_{5} \mathrm{MgBr}$

$\mathrm{C}_{6} \mathrm{H}_{5} \mathrm{CH}_{2} \mathrm{SCH}_{3}$

$\mathrm{C}_{6} \mathrm{H}_{5} \mathrm{CH}_{2} \mathrm{HgBr}$

$$
0-\mathrm{CH}_{3} \mathrm{C}_{6} \mathrm{H}_{4} \mathrm{CH}_{2} \mathrm{SCH}_{3}
$$

$0-\mathrm{CH}_{3} \mathrm{C}_{6} \mathrm{H}_{4} \mathrm{MgBr}$

$$
\mathrm{o}-\mathrm{CH}_{3} \mathrm{C}_{6} \mathrm{H}_{4} \mathrm{CH}_{2} \mathrm{SCH}_{3}
$$

$\mathrm{P}-\mathrm{CH}_{3} \mathrm{C}_{6} \mathrm{H}_{4} \mathrm{MgBr}$

$$
\mathrm{p}-\mathrm{CH}_{3} \mathrm{C}_{6} \mathrm{H}_{4} \mathrm{CH}_{2} \mathrm{SCH}_{3}
$$

$\mathrm{p}-\mathrm{CH}_{3} \mathrm{OC}_{6} \mathrm{H}_{4} \mathrm{HigBr}$

$\mathrm{p}-\mathrm{CH}_{3} \mathrm{OC}_{6} \mathrm{H}_{4} \mathrm{CH}_{2} \mathrm{SCH}_{3}$

$\mathrm{C}_{6} \mathrm{H}_{5} \mathrm{CH}_{2} \mathrm{CH}_{2} \mathrm{MgBr}$

$\mathrm{C}_{6} \mathrm{H}_{5}\left(\mathrm{CH}_{2}\right)_{3} \mathrm{SCH}_{3}$

$\mathrm{p}-\mathrm{BrC}_{6} \mathrm{H}_{4} \mathrm{MgBr}$

$\mathrm{p}-\mathrm{BrC}_{6} \mathrm{H}_{4} \mathrm{CH}_{2} \mathrm{SCH}_{3}$

Baixo

$\mathrm{C}_{2} \mathrm{H}_{5} \mathrm{MgBr}$

$n-\mathrm{C}_{3} \mathrm{H}_{7} \mathrm{SCH}_{3}$

$\mathrm{n}-\mathrm{C}_{3} \mathrm{H}_{7} \mathrm{HgBr}$

$n-\mathrm{C}_{4} \mathrm{H}_{9} \mathrm{SCH}_{3}$

26

$n-\mathrm{C}_{4} \mathrm{H}_{9} \cdot \mathrm{lgBr}$

$$
\mathrm{n}-\mathrm{C}_{5} \mathrm{H}_{11} \mathrm{SCH}_{3}
$$


A reação entre o dimetilsulfōxido e o brometo de fenilmagnësio descrita por Oda e Yamamoto foi reexaminada em 1965 por Sekera e col. ${ }^{26}$. Pelo emprêgo de cromatografia de gäs estẹs autores identificaram, na mistura final da reação, os seguintes compostos: dimetilsulfeto, benzeno, bromobenzeno, dimetilsulfona, metil fenil sulfeto, etil fenil sulfeto e metil benzil sulfeto. A formação do dimetilsulfeto, do metil fenil sulfeto e do fenol foi explicada admitindo a formação e decomposição do "complexo de sulfōnio" $\underline{5}, j a ̈$ assinalado por Grignard (pag.11).

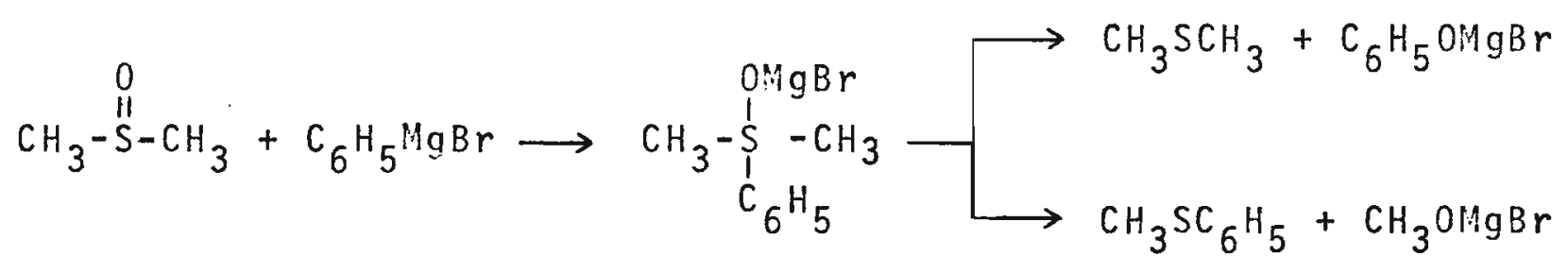

Para explicar a formação do benzeno, do etil fenil sulfeto e do metil benzil sulfeto, os autores propuseram um mecanismo segundo o qual o complexo formado por adição do organomagnesiano ao sulfôxido perde um pröton para uma segunda molēcula do composto de Grignard formando uma ilida (E) que sofre um deslocamento posterior.

$$
\begin{aligned}
& \mathrm{CH}_{3}-\mathrm{SOCH}_{3}+\mathrm{C}_{6} \mathrm{H}_{5} \mathrm{MgBr} \longrightarrow \underset{\mathrm{C}_{6} \mathrm{H}_{5}}{\stackrel{\mathrm{OHgBr}}{\mathrm{I}-\mathrm{CH}_{3}}} \stackrel{\mathrm{CH}_{6} \mathrm{H}_{5} \mathrm{MgBr}}{\longrightarrow}
\end{aligned}
$$

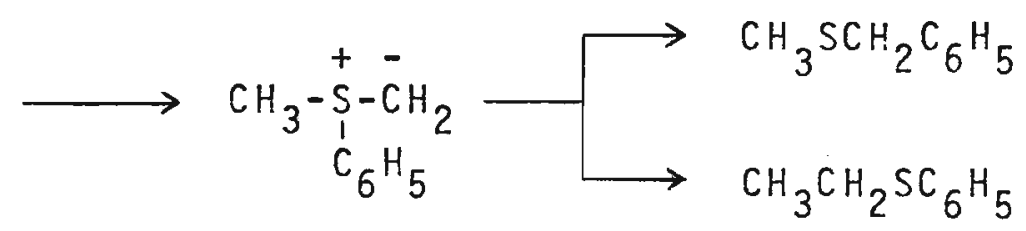


Entretanto, em um trabalho posterior, em colaboração com Manya ${ }^{27}$, os autores, na base dos resultados experimentais ob tidos, chegaram a uma conclusão diferente. Quando os metil aril sulfőxidos $\underline{7}$ e $\underline{8}$ foram tratados com os brometos de arilmagnésio, - produto principal obtido era sempre o sulfeto $\underline{9}$ ou 10 resultan te da fixação, no carbono alfa ao enxōfre, do grupo que provinha do reagente de Grignard. Os autores concluiram que, se a reação ocorresse, como proposto por eles anteriormente, atravës da formação de um "complexo de sulfōnio", os dois sulfetos $\underline{9}$ e $\underline{10}$ deve riam ser obtidos em ambas reações, jâ que o intermediārio seria o mesmo.

$\mathrm{p}-\mathrm{CH}_{3} \mathrm{OC}_{6} \mathrm{H}_{4} \mathrm{SOCH}_{3}$

(

$\mathrm{C}_{6} \mathrm{H}_{5} \mathrm{SOCH}_{3}$

()

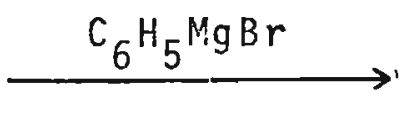

$\stackrel{\mathrm{p}-\mathrm{CH}_{3} \mathrm{OC}_{6} \mathrm{H}_{4} \mathrm{MgBr}}{\longrightarrow}$

$$
p-\mathrm{CH}_{3} \mathrm{OC}_{6} \mathrm{H}_{4} \mathrm{SCH}_{2} \mathrm{C}_{6} \mathrm{H}_{5}
$$

$\mathrm{C}_{6} \mathrm{H}_{5} \mathrm{SCH}_{2} \mathrm{C}_{6} \mathrm{H}_{4} \mathrm{OCH}_{3}-\mathrm{p}$

(10)

Para explicar estes resultados os autores sugeriram um mecanismo segundo o qual haveria um ataque inicial do organomagnesiano com retirada de um próton do carbono em alfa ao grupo sul finīico e coordenação do magnēsio ao oxigênio. A ilida (11) assim formada sofreria um ataque de uma segunda molēcula do reagen te de Grignard, conduzindo a produto principal.

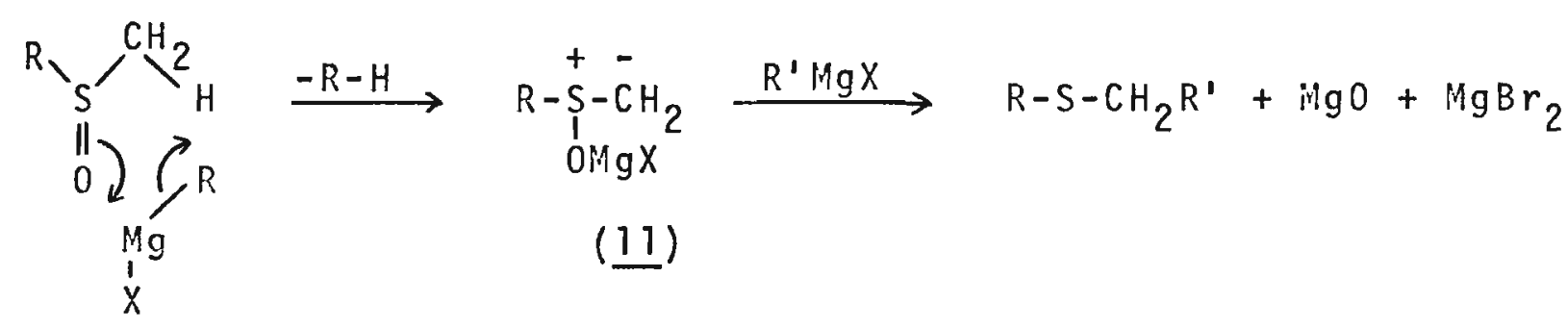


Em um estudo mais detalhado ${ }^{28}$ da reação do brometo de $p$-me toxifenilmagnésio com o metil fenil sulfóxido, realizado pelos mes mos autores alguns anos depois, foram identificados, ao lado do p-metoxibenzil fenil sulfeto, värios subprodutos. Com base nos resultados obtidos os autores apresentaram um esquema mecanistico ad mitindo a formação da ilida 11, capaz de sofrer, competitivamente, uma decomposição e uma transposição, dando origem aos intermediã rios instāveis 12, 13 e 14 . Por reação com outra molëcula do com posto de Grignard, os intermediärios 12 e 13 dariam origem aos com postos 15 e 16 , enquanto que o intermediärio 14 originaria o com posto 17 e os novos intermediärios 18 e $\underline{19}$. A reação entre 18 e 14 resultaria no composto 20 , e a do intermediärio $\underline{19}$ com outra molécu 1 a do composto de Grignard produziria o composto 21 .

$$
\left[\begin{array}{c}
0 . \operatorname{lgX} \\
1 \\
\mathrm{~s}-\mathrm{CH}_{2} \\
+--2
\end{array}\right]
$$

(11)

RSOHgX $+\mathrm{CH}_{2} \stackrel{\text { Decomposição }}{\text { Transposição }} \longrightarrow \mathrm{RSCH}_{2}$ OMgX

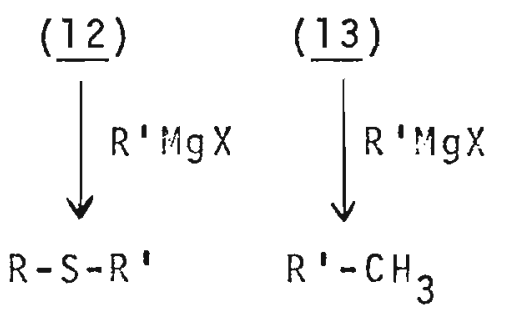

(15)
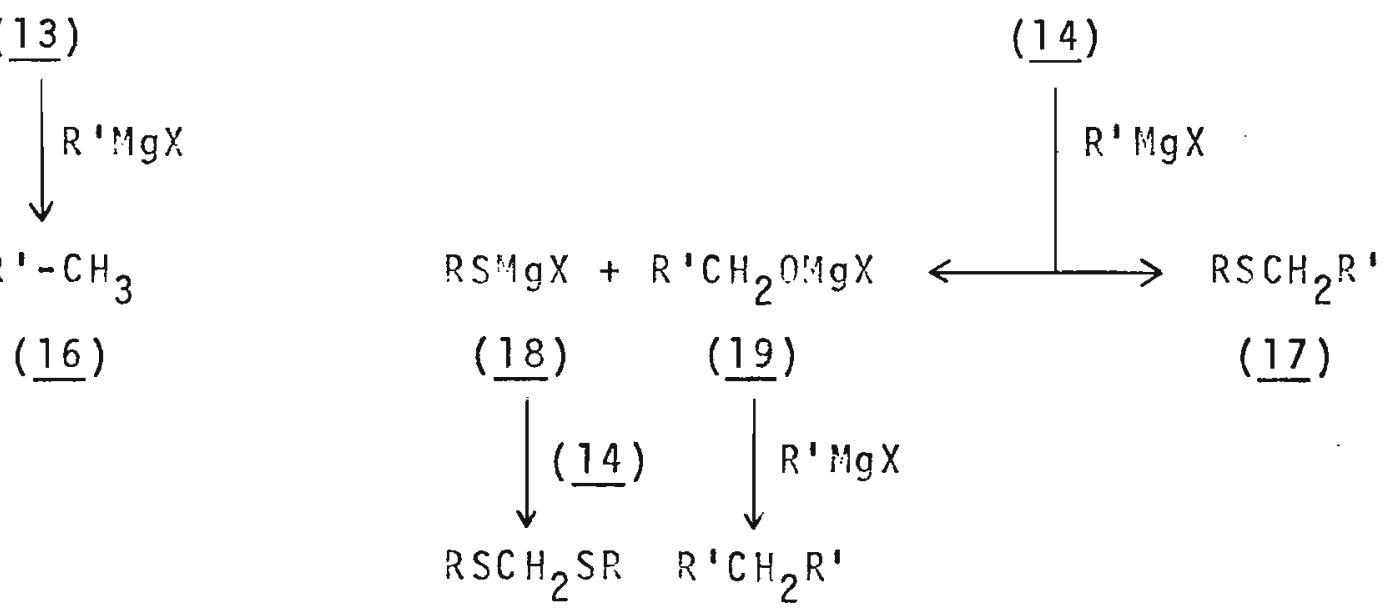

(17)

(20)

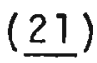


No caso da reação entre o metil fenil sulfôxido com o brometo de $p$-anisilmagnēsio ( $R=$ fenila e $R^{\prime}=p$-anisila) os compostos formados seriam: fenil p-anisil sulfeto, p-metilanisol, fenil p-metoxibenzil sulfeto, difenilmercaptal do formaldeido, e o bis (p-anisil)-metano.

De acordo com estes pesquisadores, a transposição do intermediärio 11 ocorreria por ataque intramolecular do carbânion ao oxigēnio:

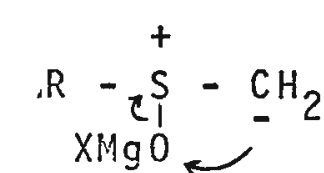

(11)

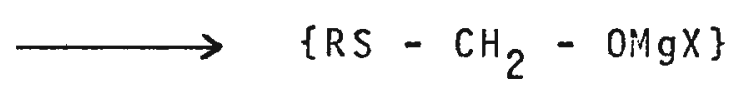

(14)

Ho mesmo trabalho foram relatadas as reações do metil fe nil sulföxido com o brometo de n-butilmagnēsio, e do metil n-butil sulfóxido com o brometo de fenilmagnēsio. Enquanto que na primeira os autores observaram o desprendimento de buteno-1, na segunda não foi observada qualquer evolução de olefina. Por outro lado, a reação do metil n-butil sulfôxido com o brometo de etilmagnësio produziu eteno e nenhum traço de buteno-1. 0 mesmo foi observado na reação do n-butil fenil sulföxido com o brometo de etilmagnésio. 0 último sulfóxido reagiu com o iodeto de metil magnësio sem formar olefina. Estes resultados indicaram que a olefina obtida não resultava da degradação de um cātion de sulfónio intermediārio.

Alguns sulföxidos cỉclicos foram, mais recentemente, sub metidos a reações com compostos de Grignard, por Nesmeyanov e col. ${ }^{29}$. O trimetilenosulföxido, quando tratado com diferentes com postos de Grignard alifäticos, sob refluxo em éter,conduziu a 
uma expansão do anel:

$$
\begin{aligned}
& \bigcup_{S=0}+\mathrm{RCH}_{2} \mathrm{MgX} \underset{\mathrm{e} \text { ter }}{\longrightarrow}{ }_{\mathrm{S}}^{\longrightarrow} \\
& \mathrm{R}(25 \%) ; \mathrm{CH}_{3}(18 \%) ; \mathrm{C}_{6} \mathrm{H}_{5}(33 \%) ; \quad 0-\mathrm{CH}_{3} \mathrm{C}_{6} \mathrm{H}_{4}(51 \%)
\end{aligned}
$$

Entretanto, quando o tetrametilenosulföxido foi tratado com haletos de metil e benzilmagnêsio, foram obtidos, respectivamente, o $\alpha$-metil e o $\alpha$-benziltetrahidrotiofeno, não se obser vando os produtos de expansão do ane1.

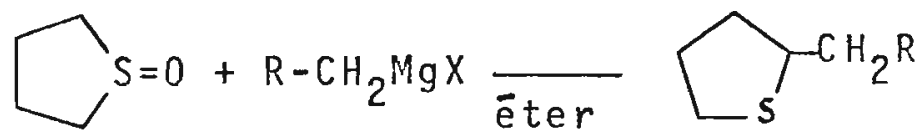

$$
\begin{aligned}
& \mathrm{R}=\mathrm{H} \text { e } \mathrm{C}_{6} \mathrm{H}_{5}
\end{aligned}
$$

Em 1976, Nesmeyanov e col. ${ }^{30}$ realizaram um estudo visando esclarecer a natureza do precipitado resultante da adição do dimetilsulföxido ao iodeto de metilmagnësio em ëter, a frio. observando a evolução do metano tanto na formação como na hidrólise do precipitado, e a recuperação quase quantitativa do dimetilsulfóxido, os autores imaginaram dois processos ocorrendo con juntamente: a metalação do sulfōxido e a formação do aduto 22 .

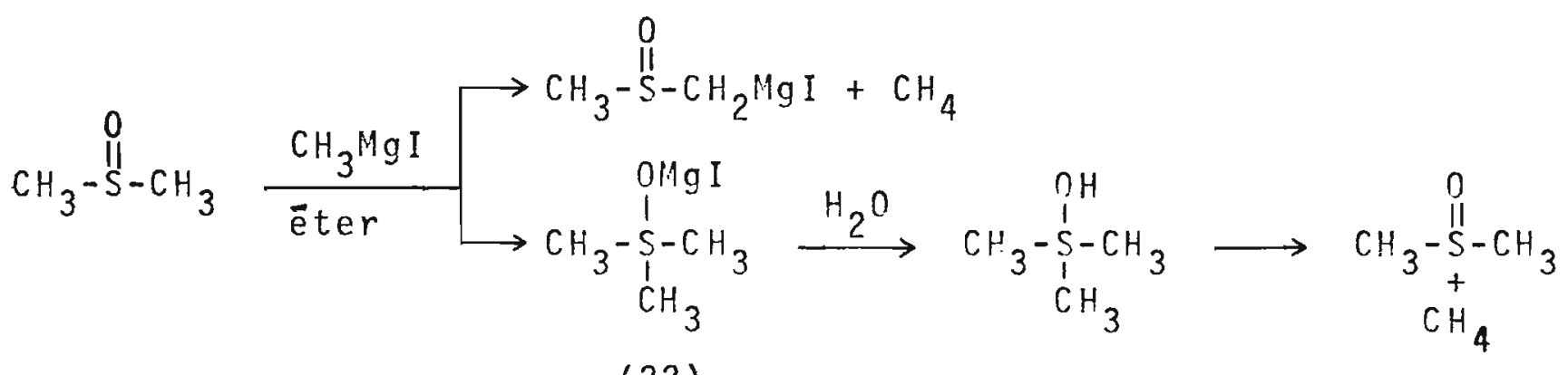


Medindo a quantidade de metano desenvolvida em cada $\underline{e}$ tapa, os autores avaliaram a percentagem de metalação e de forma ção do aduto, em experiências nas quais foram variadas as propor ções e a ordem de adição dos reagentes. 0 maior grau de metalação foi de $74 \%$, obtido quando o magnesiano foi adicionado sobre quatro equivalentes do sulfóxido. Quando foi adicionado o dime tilsulföxido sobre um equivalente do composto de Grignard, obser vou-se apenas $7 \%$ de metalação. 0 maior grau de formação do aduto foi de $27 \%$, obtido quando dois equivalentes do sulföxido foram adicionados sobre o iodeto de metilmagnēsio.

Em 1974, Kunieda e co1. 32 obtiveram 90-100\% de metalação da $\alpha-(p-t o l i l s u l f i n i l)$-acetofenona (23) por tratamento com um equivalente de diferentes reagentes de Grignard. Esta percenta gem foi determinada por hidrōlise da mistura da reação em $\mathrm{D}_{2} \mathrm{SO}_{4}{ }^{\prime}$ $\mathrm{D}_{2} \mathrm{O}$. Pelo emprego de dois equivalentes do organomagnesiano, os autores obtiveram os correspondentes a-sulfinil-ālcoois (24)

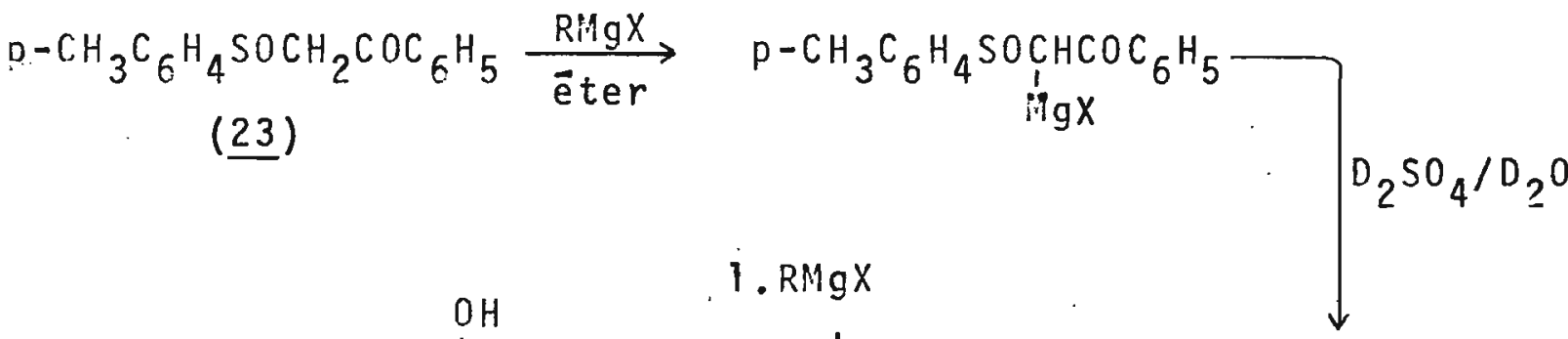

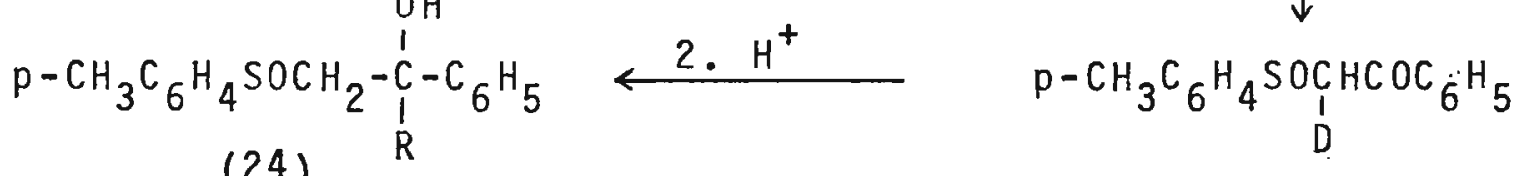

$$
R=\mathrm{CH}_{3}(90 \%) ; \mathrm{C}_{2} \mathrm{H}_{5}(97 \%) ; n-\mathrm{C}_{3} \mathrm{H}_{7}(76 \%) ; \mathrm{C}_{6} \mathrm{H}_{5} \mathrm{CH}_{2}(88 \%)
$$

A metalação foi tambểm conseguida em rendimentos quan titativos, pelos mesmos autores ${ }^{32}$, por tratamento do a-fenilsul- 
finil-acetato de etila (25) com um equivalente do brometo ou 10deto de etilmagnểio. 0 novo composto de Grignard (26) assim for mado foi utilizado em reações de adição à carbonila de diferen tes aldeidos e cetonas.

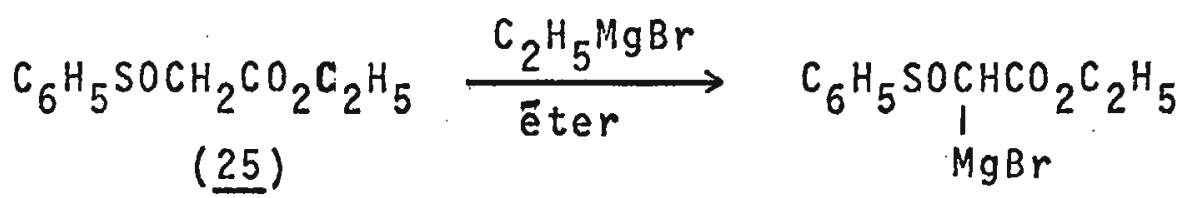

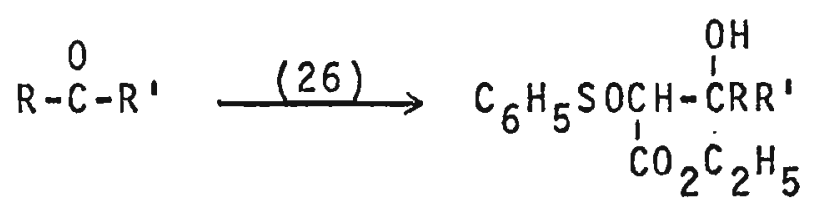

Os autores observaram que o carbanion formado pelo emprê go de bases como hidreto de sōdio e butil litio, em tetrahidrofú rano, dimetilsulfōxido ou dimetilformamida, não reagia com os al deidos e cetonas. 
CAPITULO 2

\section{APRESENTAÇAO DOS RESULTADOS E DISCUSSAO}

\subsection{MEDIDAS COMPARATIVAS DE BASICIDADE PELO EMPREGO DO METODO DE RESSONANCIA MAGNETICA NUCLEAR}

Foram realizados, no nosso laboratōrio, vārios trabaIhos ${ }^{33-37}$ que visavam estudar a influencia do ätomo de enxôfre em posição alfa, sobre a basicidade do grupo carbonila ou ciano, em $\alpha-a l q u i l t i o-c e t o n a s,-e \overrightarrow{s t e r e s,}$-amidas, -tioesteres ou -nitrilas. Era de interesse verificar se haveria alguma modificação na basicidade do grupo sulfinila em sulfōxidos alifäticos $\beta$-tia-substi tuidos, em comparação com os sulföxidos não substituidos corres pondentes.

Os nossos estudos consistiram na determinação de constan tes de associação entre alguns sulfōxidos e um doador de prōtons, que seriam diretamente relacionadas com a energia livre ( $\Delta G^{\ominus}$ ) para o equilibrio do complexo doador-aceptor. Da mesma maneira como nos trabalhos anteriores, empregamos, como doador de prōtons, o fenol, e como solvente, o tetracloreto de carbono.

Escolhemos, para as nossas medidas comparativas, dois pa res de sulföxidos: 27 e $28 ; 29$ e 30 (Tabela IV pag.23).

0 metil n-propil sulfōxido (27), metil metiltiometil sul föxido (28) e etil etiltiometil sulfōxido (으) foram por nōs preparados pela oxidação do sulfeto e dos mercaptais correspondentes pelo emprēgo de perhidrol em äcido acētico glacial (secções 3.6.l. a 3.6.3., pag. 70 a 73). 
Foram efetuadas medidas de sistemas ternärios fenol-sul föxido-tetracloreto de carbono. Com a finalidade de minimizar a auto-associação do doador sua concentração era mantida tão bafxa quanto possĩvel. As concentraçōes de sulfōxido eram variadas den tro de tal faixa que um excesso do aceptor era sempre mantido pa ra garantir a associação $1: 1$.

Para cada sistema ternārio foram efetuadas de 6 a 8 medidas do deslocamento quîmico do prōton hidroxilico $\left(\nu_{O H}\right)$ refe rentes às diversas concentrações molares de sulfōxido (secção. 3 . 2.2.). Destes valores, foi subtraido o valor de $v_{1(O H)}$ do fenol livre, obtendo-se, assim, os deslocamentos devidos à associação $\left(\Delta v_{O H}\right)$. A partir destes e das respectivas concentraçöes de aceptor foram determinadas, gráficamente, para cada composto, as constantes de associação, pelo emprēgo dos mētodos de Carper $^{38}$ e de Mathur $^{39}$ (seç̧ão 3.2,4.1. a 3.2.4.4., pag.41a47). Os valores de constantes de associação obtidos acham-se reunidos na tabela IV.

\section{TABELA IV}

\begin{tabular}{|c|c|c|c|}
\hline NO & Sulföxido: & Kass & \\
\hline & & Carper & Mathur \\
\hline 27 & $\mathrm{CH}_{3} \mathrm{SOCH}_{2} \mathrm{CH}_{2} \mathrm{CH}_{3}$. & $85,3 \pm 1,8$ & $86,0 \pm 2,0$ \\
\hline 28 & $\mathrm{CH}_{3} \mathrm{SOCH}_{2} \mathrm{SCH}_{3}$ & $51,4 \pm 1,6$ & $51,7 \pm 1,7$ \\
\hline 29 & $\mathrm{CH}_{3} \mathrm{CH}_{2} \mathrm{SOCH}_{2} \mathrm{CH}_{2} \mathrm{CH}_{2} \mathrm{CH}_{3}$ & $86,3 \pm 1,5$ & $86,5 \pm 1,6$ \\
\hline 30 & $\mathrm{CH}_{3} \mathrm{CH}_{2} \mathrm{SOCH}_{2} \mathrm{SCH}_{2} \mathrm{CH}_{3}$ & $61,7 \pm 1,5$ & $67,8 \pm 1,6$ \\
\hline
\end{tabular}


A inspeção destes resultados indica que os sulfõxidos B-tia-substituidos (28 e $\underline{30}$ ) são menos bãsicos que os não subst tuidos ( 27 e $\underline{29})$.

A considerāvel diminuição de basicidade em $\beta$-tia-sulfó xidos, que ē maior quando comparada com a das $\beta-t i a-c e t o n a s " ~ e \underline{s}$ tã de acōrdo com a observação de szmant ${ }^{41}$ sobré a grande senstbí lidade da basicidade do grupo sulfinila quanto aos efeitos dos substituintes. Parece-nos dificil supor que a.causa desta dimi nuição de basicidade seja devida ao efeito da eletronegatividade do enxofre, normalmente considerado fraco. Esta diminuição de basicidade ë de interesse, e serä investigada oportunamente, con forme programa de estudos de interações eletrōnicas, em desenvolvimento no nosso laboratōrio, Paralelamente, estão sendo investigadas as alteraçōes da reatividade dos mesmos sulföxidos, causa das por estes efeitos.

2.2. REACOES DE B-TIA-SULFOXIDOS COM COMPOSTOS DE GRIGNARD

No decorrer de nossos estudos de reatividade de $\beta-t i a-$ sulföxidos pareceu-nos de interesse investigar o comportamento dos mesmos em relação aos compostos de Grignard.

Desde que a reação de sulföxidos não substituidos com compostos de Grignard alifāticos conduzia ä formação de olefinas (pag.14), os compostos de Grignard aromäticos, pareciam mais adequados para o nosso estudo. Era de se esperar que em nossas rea çōes ocorreria, em analogia com os sulfōxidos não substituidos (pag, 13), a redução do sulföxido e concomitante substituição do 
hidrogênio em alfa pelo grupo arila do organomagnestano. Parecia-nos mals provävel que esta substituição ocorresse no grupo metilena situado entre os dois ätomos de enxofre, conduzindo. assim, ã formação de mercaptais de aldeidos aromäticos.

$$
\mathrm{RSCH}_{2} \mathrm{SOR} \stackrel{\mathrm{ArMgBr}}{\longrightarrow} \operatorname{ArCH}(\mathrm{SR})_{2}
$$

Numa experiência preliminar (secção 3.3.2.1. pag.56) verificamos que a reação entre quantidades equimolares de etil etiltiometil sulföxido e brometo de fenilmagnêsio, em ëter eţlico, forneceu o dietilmercaptal do benzaldeido, identificado, e o seu rendimento $(30 \%)$ determinado, por ressonāncia magnëtica nuclear e por cromatografia de gãs. Este resultado estava de acordo com os da literatura para a reação do dimetilsulfōxido com compostos de Grignard, nas mesmas condições (pag.14). Entretanto - rendimento do mercaptal aumentou para $60 \%$ quando repetimos a reação acima mencionada utilizando dois equivalentes do brometo de fenilmagnësio (seç̧ão 3.3.2.2. pag.57).

Prosseguindo o nosso estudo, efetuamos a reação do mesmo sulfōxido com dois equivalentes do brometo de p-tolil-magnē sio ( $\operatorname{secção~} 3.3,2.3$, pag.58). O espectro de ressonância magnētica nuclear e a cromatografla de găs do produto bruto indicaram a presença, como produto principal, do dietil-mercaptal do p-tolualdeido, o seu rendimento, determinado por cromatografia de găs, foi de $65 \%$.

Em continuação, fizemos reagir o etil etiltiometil sulfóxido, nas condições acima mencionadas, com o brometo de p-anisilmagnêsio (seç̧ão 3.3.2.4. pag.58). Constatamos, atravēs da 
ressonância magnëtica nuclear e da cromatografta de gās, que hou ve formação do dietilmercaptal do p-anisaldeido em $63 \%$ de rendimento.

Era de interesse verificar se a introdução de grupos fenila no sulföxido modificaria os rendimentos destas reaçöes. Dois sulfóxidos foram, então, estudados: o etil feniltiometil sul föxido (31) e o fenil feniltiometil sulföxido (르), ambos por nōs obtidos em 51 e $70 \%$, respectivamente, pela oxidação dos mercap tais do formaldeido correspondentes (secção 3.6 .4 e 3.6 .5 pag.73 e 75 ).

$$
\begin{array}{cc}
\mathrm{C}_{6} \mathrm{H}_{5} \mathrm{SCH}_{2} \mathrm{SC}_{2} \mathrm{H}_{5} \stackrel{\mathrm{H}_{2} \mathrm{O}_{2} / \mathrm{HOAC}}{\longrightarrow} \mathrm{C}_{6} \mathrm{H}_{5} \mathrm{SCH}_{2} \mathrm{SOC}_{2} \mathrm{H}_{5} \\
\mathrm{C}_{6} \mathrm{H}_{5} \mathrm{SCH}_{2} \mathrm{SC}_{6} \mathrm{H}_{5} \stackrel{\text { (31) }}{\longrightarrow} \stackrel{\mathrm{H}_{2} \mathrm{O}_{2} / \mathrm{HOAC}}{\longrightarrow} \mathrm{C}_{6} \mathrm{H}_{5} \mathrm{SCH}_{2} \mathrm{SOC}_{6} \mathrm{H}_{5}
\end{array}
$$

O sülfóxido $\underline{31}$ ainda não descrito na literatura, apös purificação por cromatografia em coluna, foi identificado por ressonāncia magnêtica nuclear. A posição do oxigênio neste composto foi determinada pela comparação do seu espectro de res sonäncia magnêtica nuclear com o do fenil etiltiometilsulfóxido, disponível em nosso laboratörio. A oxidação seletiva do enxofre Tigado ao grupo etila era por nōs esperada.

As reações dos sulföxidos $\underline{31}$ e $\underline{32}$ com brometo de fe nilmagnësio nas condiçöes empregados anteriormente (pag.25) con duziram ao etil fenilmercaptal e difenilmercaptal do benzaldeido em rendimento de 45 e $53 \%$, respectivamente, ambos identifica dos atravēs da ressonāncia magnētica nuclear e cromatografia de 
gãs, por comparação com os produtos autênticos (seção 3.3.2.5. e 3.3.2.6., pag. 60).

A reação de sulfôxidos $\beta$-tia-substftuidos com os compostos de Grignard aromäticos fol, tambēm, por nōs experimentada na sërie cîclica. Entretanto, quando se fêz reagir o 1,3-d1tiolano-1-öxido (33) com o brometo de fenilmagnësio, (secção 3 . 3.2.7., pag.61) obteve-se o 2-fenil-1,3-ditiolano em apenas 20\% de rendimento,

A tabela $V$ reüne as reações acima descritas, indicando os rendimentos dos mercaptais, obtidos.

\section{TABELA $V$}

Reaçōes de $\beta$-tia-sulfōxidos com compostos de Grignard aromätico:

Nọ Sulföxidos

Reagentes de. Mercaptais

Rend. Grignard

\begin{tabular}{lllll}
$\underline{30}$ & $\mathrm{C}_{2} \mathrm{H}_{5} \mathrm{SCH}_{2} \mathrm{SOC}_{2} \mathrm{H}_{5}$ & $\mathrm{C}_{6} \mathrm{H}_{5} \mathrm{MgBr}$ & $\mathrm{C}_{6} \mathrm{H}_{5} \mathrm{CH}\left(\mathrm{SC}_{2} \mathrm{H}_{5}\right)_{2}$ & 60 \\
$\underline{30}$ & $\mathrm{C}_{2} \mathrm{H}_{5} \mathrm{SCH}_{2} \mathrm{SOC}_{2} \mathrm{H}_{5}$ & $\mathrm{p}-\mathrm{CH}_{3} \mathrm{C}_{6} \mathrm{H}_{4} \mathrm{MgBr}$ & $\mathrm{p}-\mathrm{CH}_{3} \mathrm{C}_{6} \mathrm{H}_{4} \mathrm{CH}\left(\mathrm{SC}_{2} \mathrm{H}_{5}\right)_{2}$ & 65 \\
$\underline{30}$ & $\mathrm{C}_{2} \mathrm{H}_{5} \mathrm{SCH}_{2} \mathrm{SOC}_{2} \mathrm{H}_{5}$ & $\mathrm{p}-\mathrm{CH}_{3} \mathrm{OC}_{6} \mathrm{H}_{4} \mathrm{MgBr}$ & $\mathrm{p}-\mathrm{CH}_{3} \mathrm{OC}_{6} \mathrm{H}_{4} \mathrm{CH}\left(\mathrm{SC}_{2} \mathrm{H}_{5}\right)_{2}$ & 63 \\
$\underline{31}$ & $\mathrm{C}_{6} \mathrm{H}_{5} \mathrm{SCH}_{2} \mathrm{SOC}_{2} \mathrm{H}_{5}$ & $\mathrm{C}_{6} \mathrm{H}_{5} \mathrm{Mg} \mathrm{Br}$ & $\mathrm{C}_{6} \mathrm{H}_{5} \mathrm{CH}\left(\mathrm{SC}_{6} \mathrm{H}_{5}\right)\left(\mathrm{SC}_{2} \mathrm{H}_{5}\right)$ & 45 \\
$\underline{32}$ & $\mathrm{C}_{6} \mathrm{H}_{5} \mathrm{SCH}_{2} \mathrm{SOC}_{6} \mathrm{H}_{5}$ & $\mathrm{C}_{6} \mathrm{H}_{5} \mathrm{MgBr}$ & $\mathrm{C}_{6} \mathrm{H}_{5} \mathrm{CH}\left(\mathrm{SC}_{6} \mathrm{H}_{5}\right)_{2}$ & 53 \\
$\underline{33}$ & $\mathrm{CH}_{2} \mathrm{SCH}_{2} \mathrm{CH}_{2} \mathrm{SO}$ & $\mathrm{C}_{6} \mathrm{H}_{5} \mathrm{MgBr}$ & $\mathrm{C}_{6} \mathrm{H}_{5} \mathrm{CHSCH}_{2} \mathrm{CH}_{2} \mathrm{~S}$ & 20 \\
\hline
\end{tabular}

Os cromatogramas dos produtos brutos destas reações in dicaram que, ao lado dos mercaptais, houve formação de vărios produtos secundärios. No caso da reação do etil etiltiometil sul 
f.öxido com brometo de p-anisilmagnësio, identificamos, pela compa ração com os produtos autēnticos, alēm dos compostos provenientes do reagente de Grignard, o anisol, etil fenil sulfeto, e o etil bis (p-anisil)-metil sulfeto (34) seção 3.3.2.4., pag.58).E.digno de nota que o pico no cromatograma correspondente ao composto 34, que aparece logo depois do pico do mercaptal, acha-se presente nos produtos brutos de todas as reações com compostos de Grignard por nōs estudaḍas.

$$
\left(\mathrm{p}-\mathrm{CH}_{3} \mathrm{OC}_{6} \mathrm{H}_{4}\right)_{2} \mathrm{CH}-\mathrm{SC}_{2} \mathrm{H}_{5}
$$

Pelo que foi exposto no capĩtulo anterior, vārias hipōteses mecanisticas, às vezes contraditörias, foram aventadas para esclarecer a reação de sulföxidos com compostos de Grignard. Alēm disto as condições experimentais variavam, impossibilitando a com paração entre os rendimentos dos produtos principais, e os tipos de produtos secundärios obtidos. Assim, os pesquisadores franceses (pag.15) sugerem, nos trabalhos iniciais, um processo intramo lecular ocorrendo atravës da adição do composto de Grignard ao grupo sulfinila, com formaçāo de um aduto, seguido por metalação e transposição posterior. Entretanto, posteriormente, os mesmos autores (pag.17) admitem um outro processo, intermolecular, pelo qual haveria uma metalação e coordenação simultãnea, seguida por uma transposição e substituição nucleofĩlica do OMgX pelo grupo proveniente do composto de Grignard.

A formaçäo inicial de adutos ( $\underline{35}$ e $\underline{36})$ ẽ tambēm sugerida pelos pesquisadores russos (pag.19). A expansäo do anel por eles observada parecenos indicar a ocorrēncia de um processo in tramolecular no carbānion 37, igualmente aplicāvel à reação com 
- carbanion 38, sem expansão do anel. Os mecanismos abaixo apre sentados indicam, em ambos os casos, a formação de intermediärios ( 37 e 38 ) que poderiam ser considerados como ilidas de íons de sulfōnio incipientes.

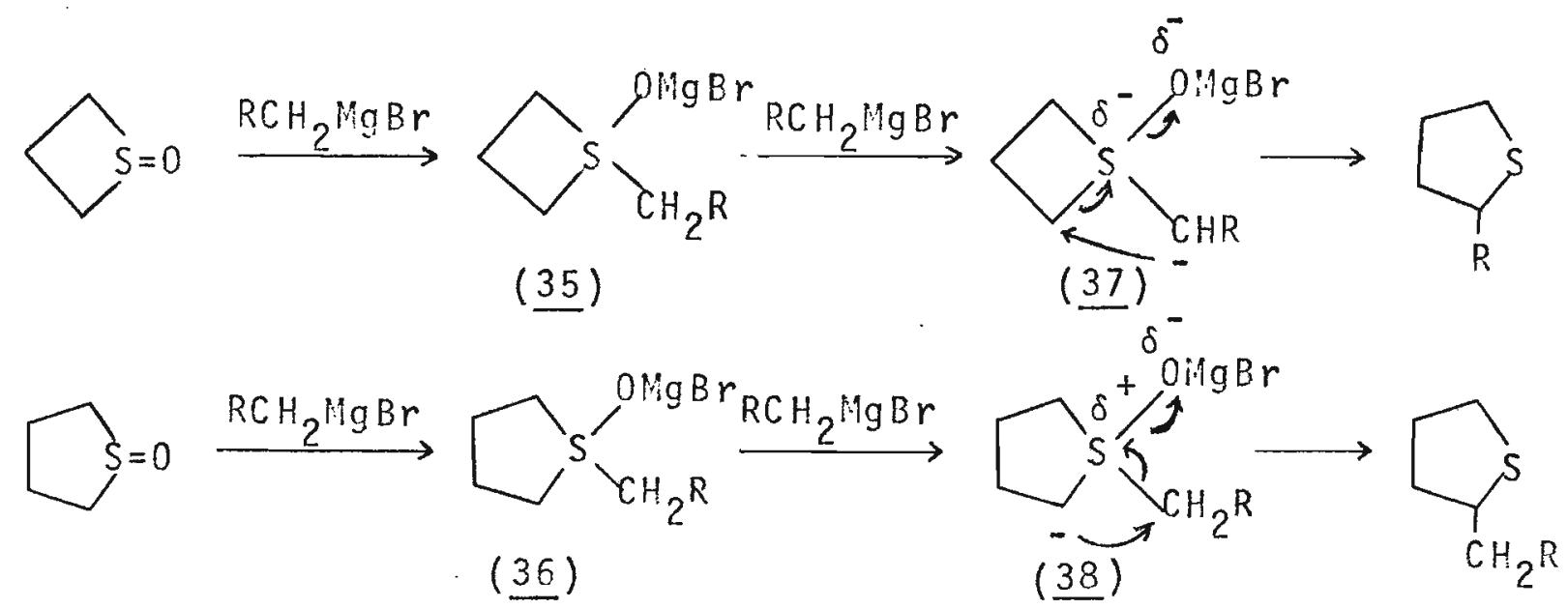

A ocorrēncia do processo intramolecular ë tambēm sugerida pela inspeção dos resultados obtidos por Oda e Yamamoto (pag.14). A obtenção do metil-o-metilbenzil sulfeto a partir do dimetilsulfōxido com o brometo de benzilmagnēsio pressupōe a for mação de um aduto (39), semelhante aos anteriores, cujo carbānion (40), neste caso, sofreria um rearranjo do tipo stevens ${ }^{4}$.

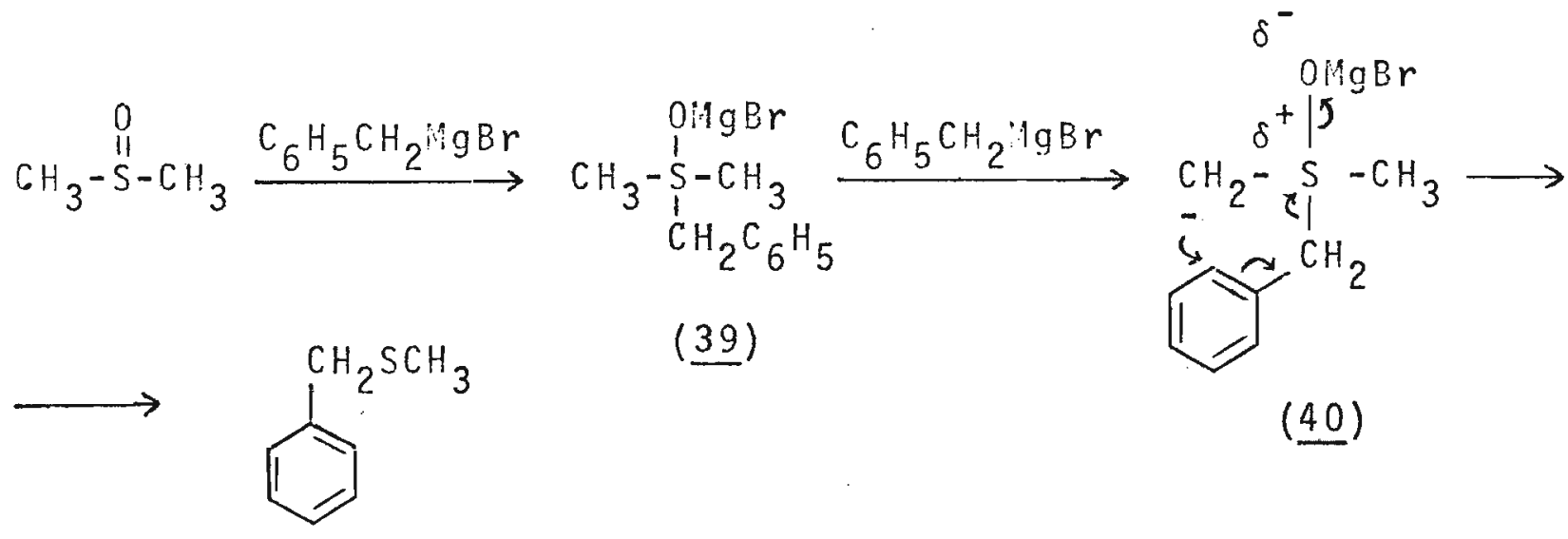

Em resumo, dois mecanismos alternativos pareciam-nos possīveis na reação de sulföxidos com compostos de Grignard: 
A) Coordenação e metalação simultânea do sulfōxido por uma molécu la do reagente de Grignard (pag.16), formando 4l, seguida de uma transposição com formação do intermediärio 42 e reação intermolecular do mesmo com outra molëcula do composto de Grignard. B) For mação inicial do aduto 43, sua transformação em carbānion (44), e formação do produto final atravēs de um processo intramolecular. Entretanto, parece-nos que, no mecanismo A, apōs a coordenação e metalação, poderia tambēm ocorrer uma transformação da ilida 41 , em uma outra (45) que forneceria o produto final atra vēs de um processo intramolecular.

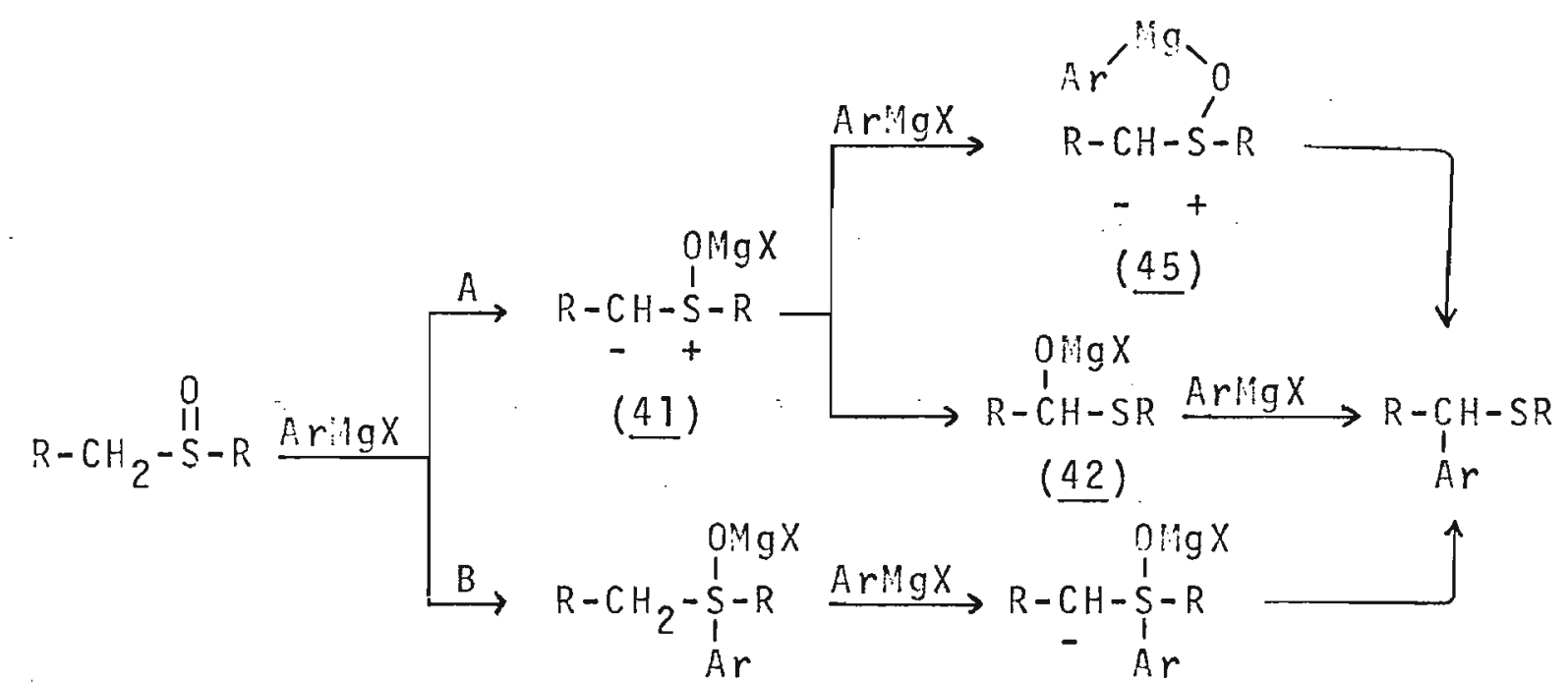

$(\underline{43})$

$(\underline{44)}$

No caso dos sulfōxidos $\beta$-tia-substituidos por nōs estudados, obtivemos alguma indicação do mecanismo operante quando, na reação do etil etiltiometil sulfōxido (으) com o brometo de p-meto xifenilmagnësio, identificamos, ao lado do mercaptal (46), alguns produtos secundärios tais como o anisol, etil fenil sulfeto e o etil bis (p-anisil)-metil sulfeto (pag.28). 0 fato de se ter 
formado o anisol em quantidade muito maior que a esperada pela de composição do excesso do reagente de Grignard indica que èle ē proveniente da metalação. A formação do etil bis (p-anisil)-metil sulfeto (34) deve resultar do ataque do composto de Grignard sobre 0 grupo etiltio do mercaptal formado ${ }^{43}$.

$\mathrm{CH}_{3} \mathrm{OC}_{6} \mathrm{H}_{4} \mathrm{CH}\left(\mathrm{SC}_{2} \mathrm{H}_{5}\right)_{2} \stackrel{\mathrm{CH}_{3} \mathrm{OC}_{6} \mathrm{H}_{4} \mathrm{MgBr}}{\longrightarrow}\left(\mathrm{CH}_{3} \mathrm{OC}_{6} \mathrm{H}_{4}\right)_{2} \mathrm{CH}-\mathrm{SC}_{2} \mathrm{H}_{5}+\mathrm{C}_{2} \mathrm{H}_{5} \mathrm{SHgBr}$

A existēncia de pequena quantidade do etil p-metoxifenil sulfeto poderia ser um indĩcio de que a reação ocorre pelo meca nismo $A$, pois este composto seria proveniente da decomposição da i1ida 47, (pag.17). Entretanto, nesta decomposição, deveria, também, ter-se formado o carbeno 48 que, na presença de excesso do composto de Grignard ou do aniso1, forneceria o etil p-metoxibenzil sulfeto (49). Entretanto, provamos a ausēncia déste ültimo com posto, na mistura reacional (secção 3.3.2.4., pag.58).

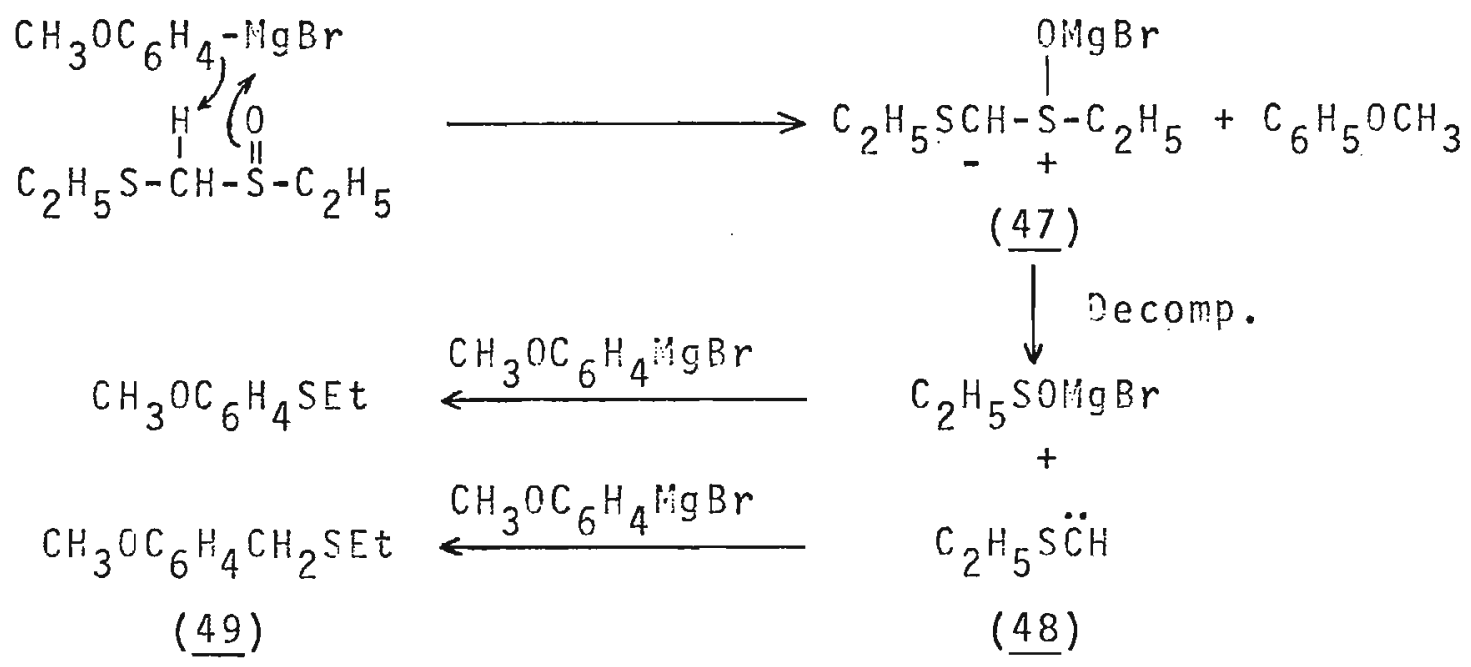

Em vista disto pode-se concluir que a formação do etil pmetoxifenil sulfeto deve ter uma outra origem. Parece-nos que ele poderia ser formado por decomposição do aduto 50 (pag.11). 


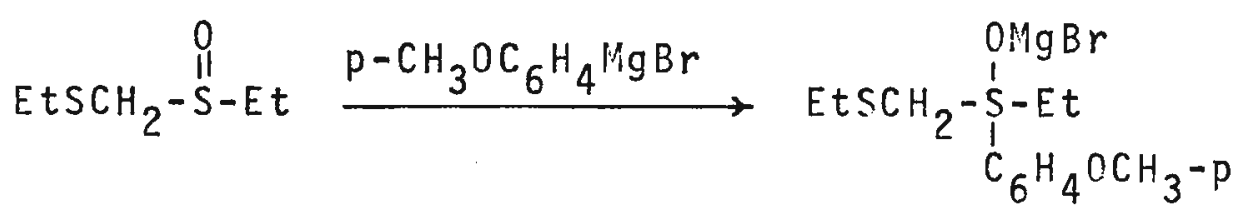

$$
\mathrm{EtSCH} \mathrm{OHgBr}_{2} \mathrm{OHESC} \mathrm{H}_{4} \mathrm{OCH}_{3}-\mathrm{p}
$$

Achamos que uma possīvel maneira de comprovar que, na rea ção de sulföxidos com compostos de Grignard, não ocorre a metala ção e coordenação inicial, seria preparar o sulfinilcarbãnion e tratá-10, em seguida, com o composto de Grignard. Se a metalação e coordenação simultānea fosse o passo inicial na reação, esta seria facilitada em presença de bases fortes. E digno de nota que os rear ranjos de Pummerer, em que uma das fases consiste em perda de pró ton, mostraram-se induzidos por bases ${ }^{44}$. Quando submetemos, inicialmente, o etil etiltiometil sulfóxido (므) à reação com o n-butil litio e tratamos o carbānion formado (51) com um equivalente de brometo de fenilmagnésio, obtivemos o dietilmercaptal do benzaldei do em apenas $11 \%$ de rendimento (secção 3.4.1.2., pag.62). Repetindo a mesma experiência em presença de brometo de magnēsio (secção 3.4.1.4., pag.63), obtivemos novamente o mercaptal em baixo rendimento $(8,5 \%)$. Semelhantes resultados foram obtidos quando adiciona mos um excesso do composto de Grignard aos produtos da reação do etil etiltiometil sulföxido com n-butil litio, tanto na presençaco mo na ausēncia de brometo de magnësio, obtendo rendimentos do mercaptal de 15 e $11 \%$, respectivamente. 


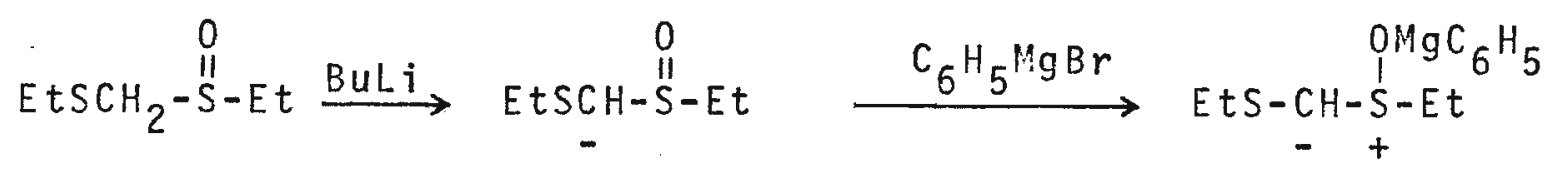

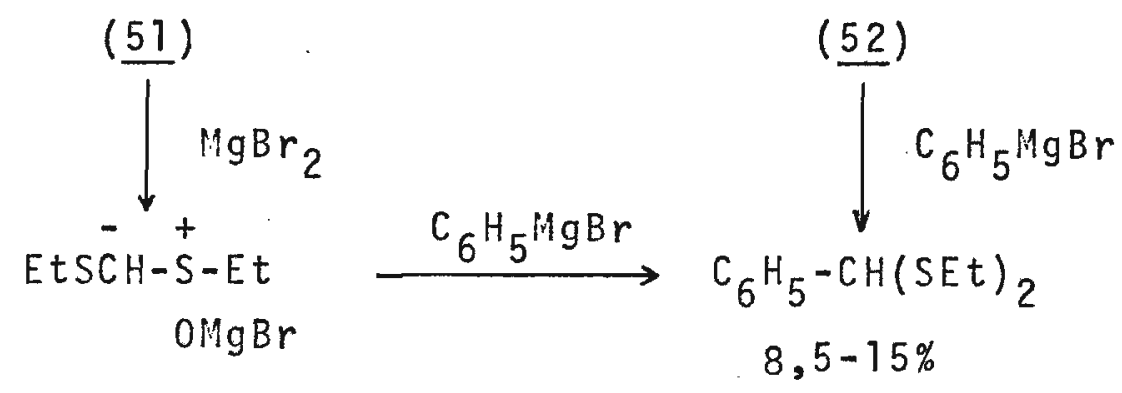

(3)

Fornecemos uma prova da formação do sulfinilcarbānion, na reação entre etil etiltiometil sulföxido com n-butil litio, quan do, numa outra experiência, verificamos que houve incorporação de deutêrio no sulfōxido recuperado, ao adicionarmos ägua deuterada à mistura reacional (secção 3.4.1.5., pag.65).

Devemos ressaltar que os rendimentos de mercaptais obtidos nas reaçőes em presença de butil 17̄tio são muito mais baixos que o rendimento da reação do etil etiltiometil sulföxido com um equivalente do composto de Grignard (pag.25). Este fato parece indicar que as ilidas $\underline{52}$ e $\underline{53}$ não são intermediārias nas reações de B-tia-sulföxidos com reagentes de Grignard aromäticos. Desde que es tas ilidas correspondem às ilidas 41 e 45 (pag.3n), a ocorrēncia da coordenação e metalação simultānea; que precede a formação das mesmas, torna-se, assim, pouco provāvel, e, com isto, o mecanismo A $(\operatorname{pag} .30)$

A formação inicial do aduto 54, pelo ataque do grupo arila sōbre o enxofre do sulfōxido 30 (mec. B) parecenos bastante viā vel. Ela seria dificultada na presença da carga negativa do carbo no vizinho quando a reação ē efetuada em prosença de n-butil 1 itio. 
A retirada do pröton ocorreria no passo posterior, quando o grupo arila jā se acharia ligado ao enxōfre, com formação do intermediärio 55. Neste passo interviria uma segunda molēcula do composto de Grignard. A transformação de $\underline{55}$ no mercaptal 56 ocorreria atravēs de um processo intramolecular.

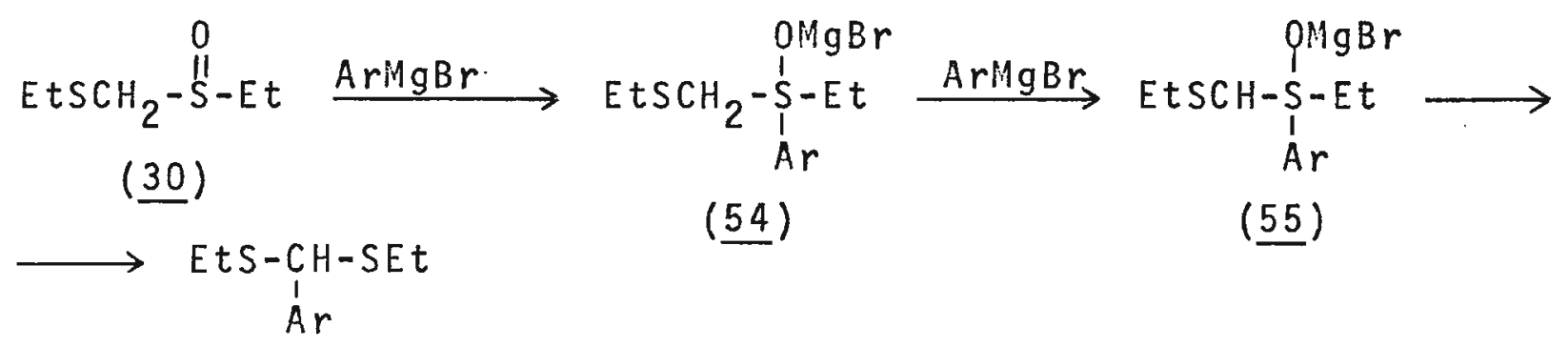

$(\underline{56})$

Entretanto, quando, numa experiēncia (secção 3.4.4., วag.68), adicionamos āgua deuterada à mistura da reação entre um 101 do sulfōxido 30 e um mol do composto de Grignard, verifica mos que não houve incorporação de deutērio no sulfōxido parcialmente recuperado. Este fato depõe contra a formação do intermedi ārio 55. Além disto, o mecanismo acima sugerido, ocorrendo em três passos consecutivos, atravēs dos intermediārios $\underline{54}$ e $\underline{55}$, não explicaria a migração preferencial do grupo que se origina do composto de Grignard (pag.16). Parece-nos que èste ūitimo fato seria explicado assumindo-se que todos èstes passos ocorreriam concomitantemente, envolvendo um estado de transição cíclico (57). Assim, a migração do anel aromätico ocorreria antes dele se fi xar ao enxofre. 


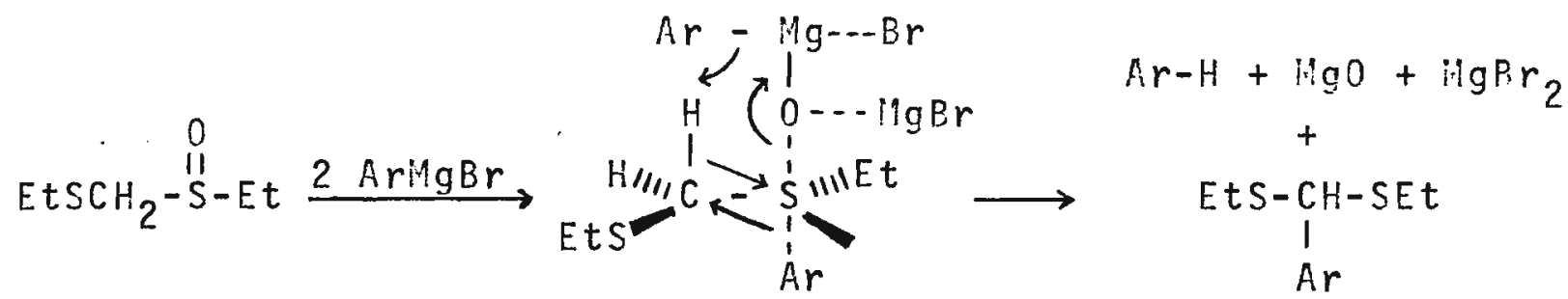

$\underline{(57)}$

E digno de nota que, na formação do mercaptal 56 a migra ção do grupo arita com seu par de elëtrons para o carbono deficiente em elëtrons parece-nos mais plausĩvel que o rearranjo do tipo Stevens (pag.29) que, envolvendo o ataque nucleofílico do carbono ao anel, seria pouco provāvel.

Estudos futuros introduzindo-se outros substituintes em posição alfa dos sulfōxidos permitirão esclarecer melhor o meca nismo destas reações.

Convēm ressaltar que a reação de a-alquitio-sulfōxidos com reagentes de Grignard aromāticos, conduzindo aos mercaptais, constitue-se num novo mëtodo de obtenção de aldeidos aromäticos ${ }^{45}$. 


\section{CAPITULO 3}

\section{PARTE EXPERIMENTAL}

\subsection{INSTRUMENTOS}

ESPECTROMETRO DE RESSONANCIA MAGNETICA NUCLEAR - Foi empregado um espectrōmetro "Varian" mode10 "T-60", com fonte de radiofrequēncia de $60 \mathrm{MHz}$.

ESPECTROFOTOMETRO HO INFRAVERIAELHO - Foi utilizado um espectrofotōmetro "Perkin Elmer", modelo "457-A".

CROIIATJGRAFO DE GITS - FOi empregado um cromatōgrafo "Varian" modelo "1868-40", equipado com integrador digital eletrōnico. Utilizou-se o detector de ionização de chama, e o nitrogēnio como gás de arraste.

BALANÇA - Foi utilizada uma balança "Hettler H-34".

3.2. DETERIIIIAÇAO DE CONSTANTES DE ASSOCIACRTO DE SULFTXIDOS COH FENOL, EM TETRACLORETO DE CARBONO

3.2.1. Notações

Os deslocamentos quïmicos se referem à posição do sinal considerado, em relação ã posição do sinal de referéncia, ciclohexano. 
$\nu_{1}$ Deslocamento quīmico do prōton do fenol livre (em $\mathrm{Hz}$ )

$v$ Deslocamento quĩmico do prōton do fenol (em Hz), quando em presença do aceptor.

$\Delta v$ Variação do deslocamento químico do prōton do fenol, em pre sença do aceptor.

$\Delta c$ Variação do deslocamento quïmico do pröton do fenol quando em presença do aceptor ã concentração mäxima.

[OH $\}$ Concentração do fenol utilizada nas medidas (em mol/litro)

\{so\} Concentração de sulföxido utilizada nas medidas (em mol/1itro)

Kass Constante de associação do sulfōxido com fenol (em 1/mol)

$r$ Coeficiente de correlação linear

3.2.2. Descrição geral do método empregado nas medidas dos deslo camentos quimicos.

\subsubsection{Preparação das amostras}

Foram preparadas soluções-mãe de fenol, 0,04:4 (1mmol / $25 \mathrm{ml})$ e de sulföxido $0,6 M(6$ moles/10ml), em tetracloreto de car bono. Antes de se completar o volume da solução-mãe do doador. adicionava-se cerca de $1 \mathrm{ml}$ de ciclohexano (referēncia interna). Destas soluções foram feitas as diluições necessärias para as me didas.

Na tabela VI apresentamos os volumes utilizados e as concentrações resultantes, quando as soluções-mãe tinham as con- 
centrações referidas acima.

\section{TABELA VI}

Volumes utilizados na preparação das amostras e con centrações obtidas com as diluições.

\begin{tabular}{ccccc}
\hline $\begin{array}{l}\text { Volume do } \\
\text { doador, } \mathrm{m} 1\end{array}$ & $\begin{array}{l}\text { Volume do } \\
\text { aceptor, } \mathrm{m}\}\end{array}$ & $\begin{array}{l}\text { Volume de } \\
\mathrm{CCl}_{4}, \mathrm{~m} 1\end{array}$ & $\{\mathrm{OH}\}$ & $\{\mathrm{SO}\}$ \\
\hline 1,0 & 1,0 & 0 & 0,02 & 0,30 \\
1,0 & 0,9 & 0,1 & 0,02 & 0,27 \\
1,0 & 0,8 & 0,2 & 0,02 & 0,24 \\
1,0 & 0,7 & 0,3 & 0,02 & 0,21 \\
1,0 & 0,6 & 0,4 & 0,02 & 0,18 \\
1,0 & 0,5 & 0,5 & 0,02 & 0,15 \\
1,0 & 0,4 & 0,6 & 0,02 & 0,12 \\
1,0 & 0,3 & 0,7 & 0,02 & 0,09 \\
\hline
\end{tabular}

3.2.2.2. Hedidas dos deslocamentos químicos $(\nu)$

Pegistro

Cada amostra era transferida para o tubo de ressonāncia, e protegida com "parafilme". Registrava-se o espectro em um tempo de varredura de $250 \mathrm{seg}$. e largura de varredura de $500 \mathrm{~Hz}$. Em todas as medidas o sinal do pröton hidroxīlico aparecia em campo mais baixo que o dos prōtons aromäticos, não havendo dificulda de na sua identificação. Âpös localização dos sinais do prōton hidroxîlico e da referēncia (ciclohexano), escolhiam-se as sensi 
bilidades adequadas do detector para que fossem obtidos com in tensidades semelhantes. Registravam-se, sōmente, estes dois sinais, deslocava-se o campo cerca de $20 \mathrm{~Hz}$, e repetia-se a operação por mais quatro vezes.

Leitura

Traçavam-se duas perpendiculares à linha base, uma na pó sição do sinal do hidrogēnio äcido do doador e a outra na dos hidrogēnios de referéncia. Media-se com um paquímetro a distāncia (em $\mathrm{mm}$ ) entre os dois sinais, obtendo-se, para cada amostra, um valor mëdio das leituras de cinco registros. 0 valor de $\nu$ (em $\mathrm{Hz}$ ) corresponde ao dobro do valor encontrado em $\mathrm{mm}$, para a largura de varredura de $500 \mathrm{~Hz}(2 \mathrm{~Hz} / \mathrm{mm})$.

3.2.2.3. Determinação da variação do deslocamento quĩmico do pröton fenōitico $(\Delta \nu)$.

0 valor de $\Delta v$ era obtido da expressão: $\Delta \nu=v-v_{1}$, onde $\nu_{1}$ é o deslocamento quỉmico do prōton do fenol livre, tambēm em relação ao ciclohexano. o valor de $v_{1}$ utilizado foi de $168,5 \mathrm{~Hz}$, determinado por Trufem ${ }^{40}$ atravēs da extrapolação, à diluição infinita, dos valores encontrados para diferentes concentrações.

3.2.2.4. Determinação da variação do deslocamento químico do pröton fenōlico quando em presença de concentraçāo māxima do aceptor $(\Delta c)$.

o valor de $\Delta c$ corresponde à variação do deslocamento quĩ 
mico quando todas as molëculas do doador estão na forma complexada. Era determinado utilizando-se as expressões (1) e (2) da secção 3.2 .3 .

Pela expressão (1), $\Delta c$ era obtido determinando-se a in tersecção, na abcissa, da reta construida dos valores de $\Delta \nu /\{S 0\}$ em função de $\Delta v$.

Pela expressão (2), $\Delta c$ era obtido calculando-se 0 inver so do coeficiente linear da reta construida dos valores de $1 / \Delta \nu$ em função de $1 /\left\{\mathrm{SO}_{0}\right\}$.

3.2.2.5. Relações entre os deslocamentos descritos

0 esquema I ilustra as relações existentes entre os deslocamentos descritos nas ültimas secções.

\section{ESQUEMA I}

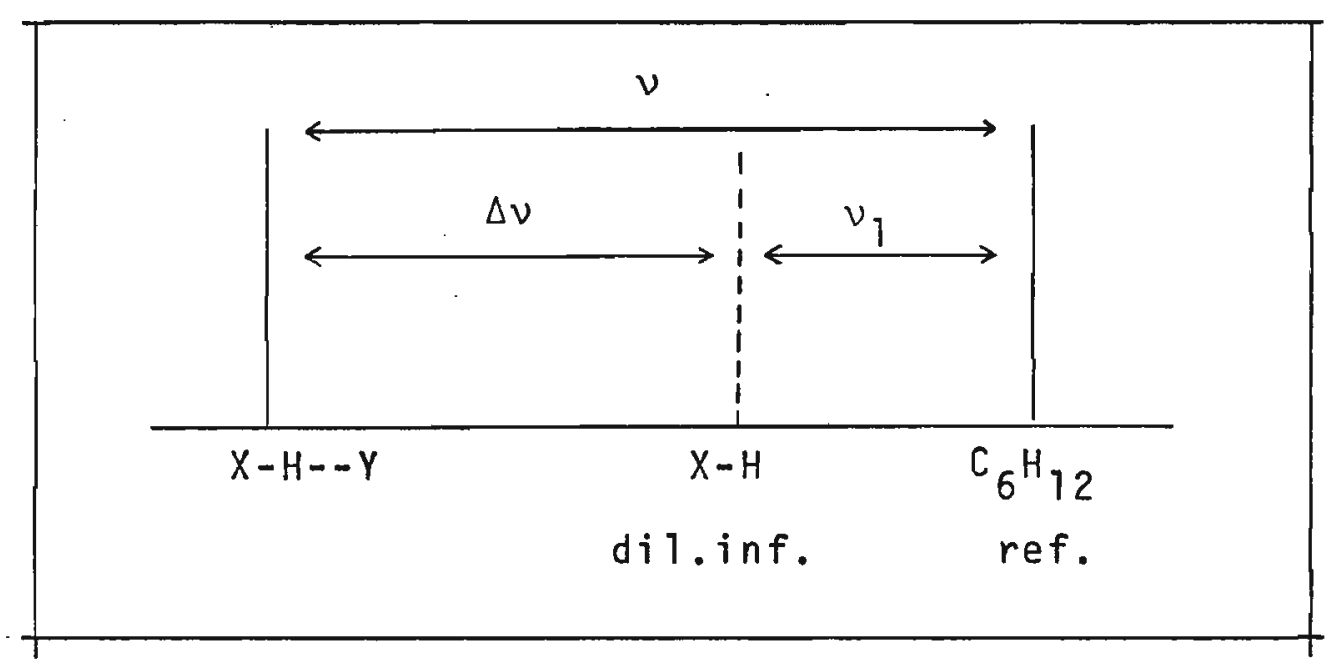


3.2.3. Determinação das constantes de associação ( $K_{a s s}$ )

Mëtodo de Carper e col. ${ }^{38}$

Utilizando a expressão (1), construia-se o grāfico de $\Delta v /\{S 0\}$ em função de $\Delta v$. Obtinha-se o valor da constante de asso ciação diretamente do coeficiente angular da reta.

$$
\frac{\Delta v}{\{s 0\}}=-k_{a s s} \cdot \Delta v+k_{a s s} \cdot \Delta c(1)
$$

Mëtodo de Mathur e col.

Utilizando a expressão (2), construia-se o grāfico de $1 / \Delta v$ em função de $1 /\{S 0\}$. A divisão do coeficiente linear pelo coeficiente angular da reta fornecia o valor da constante de associação.

$$
\frac{1}{\Delta v}=\frac{1}{\Delta c \cdot k_{\text {ass }}} \cdot \frac{1}{\{s 0\}}+\frac{1}{\Delta c}
$$

3.2.4. Experiências Realizadas

3.2.4.1. Determinação da constante de associação do metil metiltiometil sulfóxido com fenol, em tetracloreto de carbono, a $350 \mathrm{C}$.

Procedendo como descrito em 3.2.2., obtiveram-se os 
resultados indicados na tabela VII.

\section{TABELA VII}

Deslocamentos quĩmicos para o sistema fenol-metil metiltiometil sulfōxido, em $\mathrm{CCl}_{4}$, a diferentes concentrações do sul fōxido.

\begin{tabular}{llll}
\hline$\{\mathrm{OH}\}$ & $\{\mathrm{SO}\}$ & $\nu(\mathrm{Hz})$ & $\Delta \nu(\mathrm{Hz})$ \\
\hline 0,02 & 0,30 & 398,8 & 230,3 \\
0,02 & 0,27 & 397,0 & 228,5 \\
0,02 & 0,24 & 394,4 & 225,9 \\
0,02 & 0,21 & 391,8 & 223,3 \\
0,02 & 0,18 & 388,4 & 219,9 \\
0,02 & 0,15 & 384,4 & 215,9 \\
0,02 & 0,12 & 378,6 & 210,1 \\
0,02 & 0,09 & 370,2 & 201,7 \\
\hline
\end{tabular}

Método de Carper ${ }^{38}$

Construiu-se o gräfico de $\Delta \nu /\{$ So\} em função de $\Delta \nu$ (figura I-A). A reta que melhor se ajustou ao conjunto de pontos $(r=0,9979)$ apresentou os seguintes parâmetros:

$$
\begin{aligned}
\text { coeficiente angular } & =-51,4 \\
\text { intersecção na abcissa } & =244,5 \text { correspondendo a } \\
K_{\text {ass }} & =51,4 \pm 1,61 / \mathrm{mol} \\
\Delta \mathrm{c} & =244,5 \pm 0,6 \mathrm{~Hz}
\end{aligned}
$$


0 gräfico de $1 / \Delta \nu$ em função de $1 /\left\{S_{0}\right\}$ (figura II-A)pro duz uma reta $(r=0,9984)$ com os parâmetros que seguem:

$$
\begin{aligned}
\text { coeficiente angular } & =7,889 \times 10^{-5} \\
\text { coeficiente linear } & =409,5 \times 10^{-5} ; \text { a partir dos quais } \\
\text { obtiveram-se: Kass } & =51,9 \pm 1,7 \mathrm{~T} / \mathrm{mol} \\
\Delta \mathrm{C} & =244,2 \pm 0,6 \mathrm{~Hz}
\end{aligned}
$$

3.2.4.2. Determinação da constante de associação do metil propil sulfóxido com fenol, em tetracloreto de carbono, a 350.

Procedendo como descrito em 3.2.2., obtiveram-se os resuttados indicados na tabela VIII.

\section{$\underline{\text { TABELA VIII }}$}

Deslocamentos químicos para o sistema fenol-metil propil sulfóxido, em $\mathrm{CCl}_{4}$, a diferentes concentraçōes do sulfōxido.

\begin{tabular}{llll}
\hline$\{\mathrm{OH}\}$ & $\{\mathrm{SO}\}$ & $v(\mathrm{~Hz})$ & $\Delta v(\mathrm{~Hz})$ \\
\hline 0,016 & 0,244 & 412,4 & 243,9 \\
0,016 & 0,220 & 411,2 & 242,7 \\
0,016 & 0,195 & 409,2 & 240,7 \\
0,016 & 0,171 & 407,2 & 238,9 \\
0,016 & 0,146 & 404,2 & 235,7 \\
0,016 & 0,122 & 401,0 & 232,5 \\
0,016 & 0,098 & 396,6 & 228,1 \\
0,016 & 0,073 & 388,8 & 220,3 \\
\hline
\end{tabular}


Mētodo de Carper ${ }^{38}$

Construiu-se o grāfico de $\Delta \nu /\{S O\}$ em função de $\Delta \nu$ (figura I-B) e calculou-se a reta que melhor se ajustou ao conjunto de pontos $(r=0,9988)$. Obtiveram-se os seguintes parämetros:

$$
\begin{aligned}
\text { coeficiente angular } & =-85,3 \\
\text { intersecção na abcissa } & =255,3 \text { correspondendo a } \\
K_{\text {ass }} & =85,3 \pm 1,8 \mathrm{1} / \mathrm{mol} \\
\Delta \mathrm{c} & =255,3 \pm 0,4 \mathrm{~Hz}
\end{aligned}
$$

Mêtodo de Mathur ${ }^{39}$.

o grãfico de $1 / \Delta \nu$ em função de $1 /\{$ SO\} (figura II-B) prọ duz uma reta $(r=0,9984)$ com os parâmetros que seguem,

$$
\begin{array}{rl}
\text { coeficiente angular } & =4,564 \times 10^{-5} \\
\text { coeficiente linear }=391,9 \times 10^{-5} ; \text { a partir dos quais } \\
\text { calcularam-se: Kass }=86,0 \pm 2,01 / \mathrm{mol} \\
\Delta \mathrm{c} & 255,2 \pm 0,4 \mathrm{~Hz}
\end{array}
$$




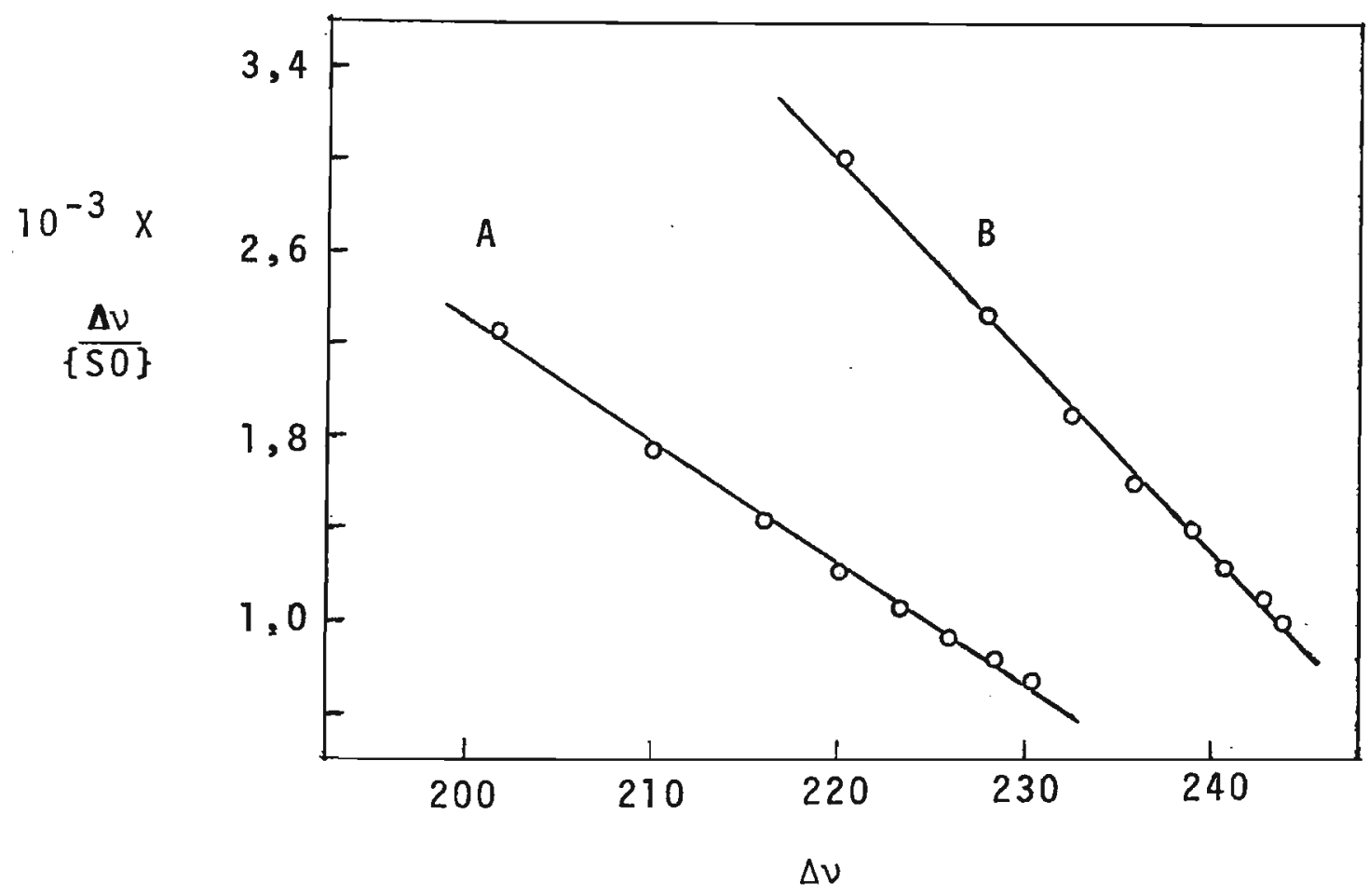

Figura I - Correlações entre os valores de $\Delta v /\{S 0\}$ e $\Delta v, p a-$ ra determinação de constantes de associação dos sulfóxidos:

A) metil metiltiometil sulfóxido; B) metil propil sulfóxido Método de Carper.

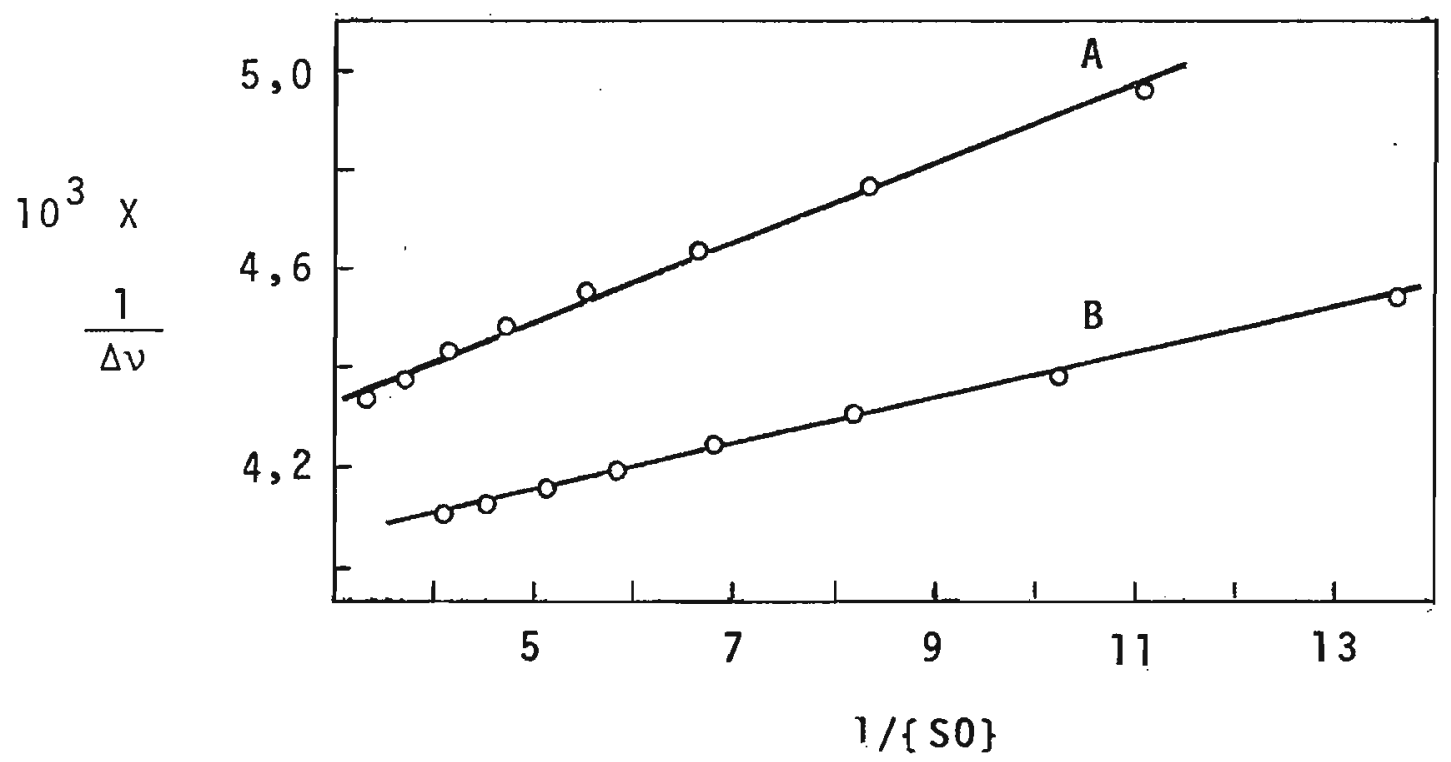

Figura II - Correlações entre os valores de $1 / \Delta \nu$ e $1 /\{S O\}$, para determinação de constantes de associação dos sulfōxi dos: A) metil metiltiometil sulfóxido; B) metil propil sul fóxido. Método de Mathur. 
3.2.4.3. Determinação da constante de associação do etil etiltiometil sulfóxido com fenol, em tetracloreto de carbono, a 350 . C.

Procedendo como descrito em 3.2.2., obtiveram-se os re sultados apresentados na tabela IX.

TABELA IX

Deslocamentos quĩmicos para o sistema fenol etil etiltio metil sulfōxido, em $\mathrm{CCl}_{4}$, a diferentes concentrações do sulföxido.

\begin{tabular}{llll}
\hline$\{0 \mathrm{H}\}$ & $\{\mathrm{SO}\}$ & $\nu(\mathrm{Hz})$ & \multicolumn{1}{c}{$\Delta \nu(\mathrm{Hz})$} \\
\hline 0,021 & 0,30 & 400,7 & 232,2 \\
0,021 & 0,27 & 399,4 & 230,9 \\
0,021 & 0,24 & 397,2 & 228,7 \\
0,021 & 0,21 & 295,2 & 226,7 \\
0,021 & 0,18 & 392,0 & 223,5 \\
0,021 & 0,15 & 388,8 & 220,3 \\
0,021 & 0,12 & 383,2 & 214,7 \\
0,021 & 0,09 & 376,2 & 207,7 \\
\hline
\end{tabular}

Mêtodo de Carper ${ }^{38}$

Construiu-se o gräfico de $\Delta v /\{S O\}$ em função de $\Delta v$ (figura III-A) e calculou-se a reta que melhor se ajustou ao con- 
junto de pontos $(r=0,9993)$. Obtiveram-se os seguintes parâmetros:

$$
\begin{aligned}
\text { coeficiente angular } & =-61,7 \\
\text { intersecção na abcissa } & =244,3 \text { correspondendo a } \\
\mathrm{K}_{\text {ass }} & =61,7 \pm 1,51 / \mathrm{mol} \\
\Delta c & =244,3 \pm 0,5 \mathrm{~Hz}
\end{aligned}
$$

Mëtodo de ilathur ${ }^{39}$

0 gräfico de $1 / \Delta \nu$ em função de $1 /$ \{SO\} (figura IV-A ) produz uma reta com $r=0,9995$. Desta reta, foram obtidos os parā metros:

$$
\begin{aligned}
\text { coeficiente angular } & =6,625 \times 10^{-5} \\
\text { coeficiente linear } & =409,4 \times 10^{-5} \text { a partir dos quais } \\
\text { calcularam-se: Kass } & =61,8 \pm 1,6 \mathrm{1} / \mathrm{mol} \\
\Delta c & =244,3 \pm 0,5 \mathrm{~Hz}
\end{aligned}
$$

3.2.4.4. Determinação da constante de associação do etil butil sulfóxido com fenol, em tetracloreto de carbono, a 350 C.

Procedendo como descrito em 3.2.2., obtiveram-se os re sultados indicados na tabela $X$. 
TABELA X

Deslocamentos químicos para o sistema fenol-etil butil sulfōxido, em $\mathrm{CCl}_{4}$, a diferentes concentrações do sulfōxido.

\begin{tabular}{llll}
\hline$\{\mathrm{OH}\}$ & $\{\mathrm{SO}\}$ & $\nu(\mathrm{Hz})$ & $\Delta \nu(\mathrm{Hz})$ \\
\hline 0,02 & 0,30 & 421,0 & 252,5 \\
0,02 & 0,27 & 419,8 & 251,3 \\
0,02 & 0,24 & 418,2 & 249,7 \\
0,02 & 0,18 & 414,4 & 245,9 \\
0,02 & 0,12 & 407,2 & 238,7 \\
0,02 & 0,09 & 401,8 & 232,3 \\
\hline
\end{tabular}

Mêtodo de Carper

Construiu-se o gräfico de $\Delta \nu /\{S O\}$ em função de $\Delta v$ (figura III-B) obtendo-se uma reta $(r=0,9995)$ com os seguintes para metros:

$$
\begin{aligned}
\text { coeficiente angular } & =-86,3 \\
\text { intersecção na abcissa } & =262,0 \text { correspondendo a } \\
\mathrm{K}_{\mathrm{ass}} & =86,3 \pm 1,5 \mathrm{1} / \mathrm{mol} \\
\Delta \mathrm{c} & =262,0 \pm 0,3 \mathrm{~Hz}
\end{aligned}
$$

Método de Mathur ${ }^{39}$

0 gräfico de $1 / \Delta \nu$ em função de $1 /\{S O\}$ (figura IV-B)prọ 
duz uma reta $(r=0,9996)$ com os parāmetros que seguem:

$$
\begin{aligned}
\text { coeficiente angular } & =4,415 \times 10^{-5} \\
\text { coeficiente linear } & =381,8 \times 10^{-5} ; \text { a partir dos quais } \\
\text { calcularam-se: } \quad \mathrm{K}_{\text {ass }} & =86,5 \pm 1,61 / \mathrm{mol} \\
\Delta \mathrm{c} & =261,9 \pm 0,3 \mathrm{~Hz}
\end{aligned}
$$




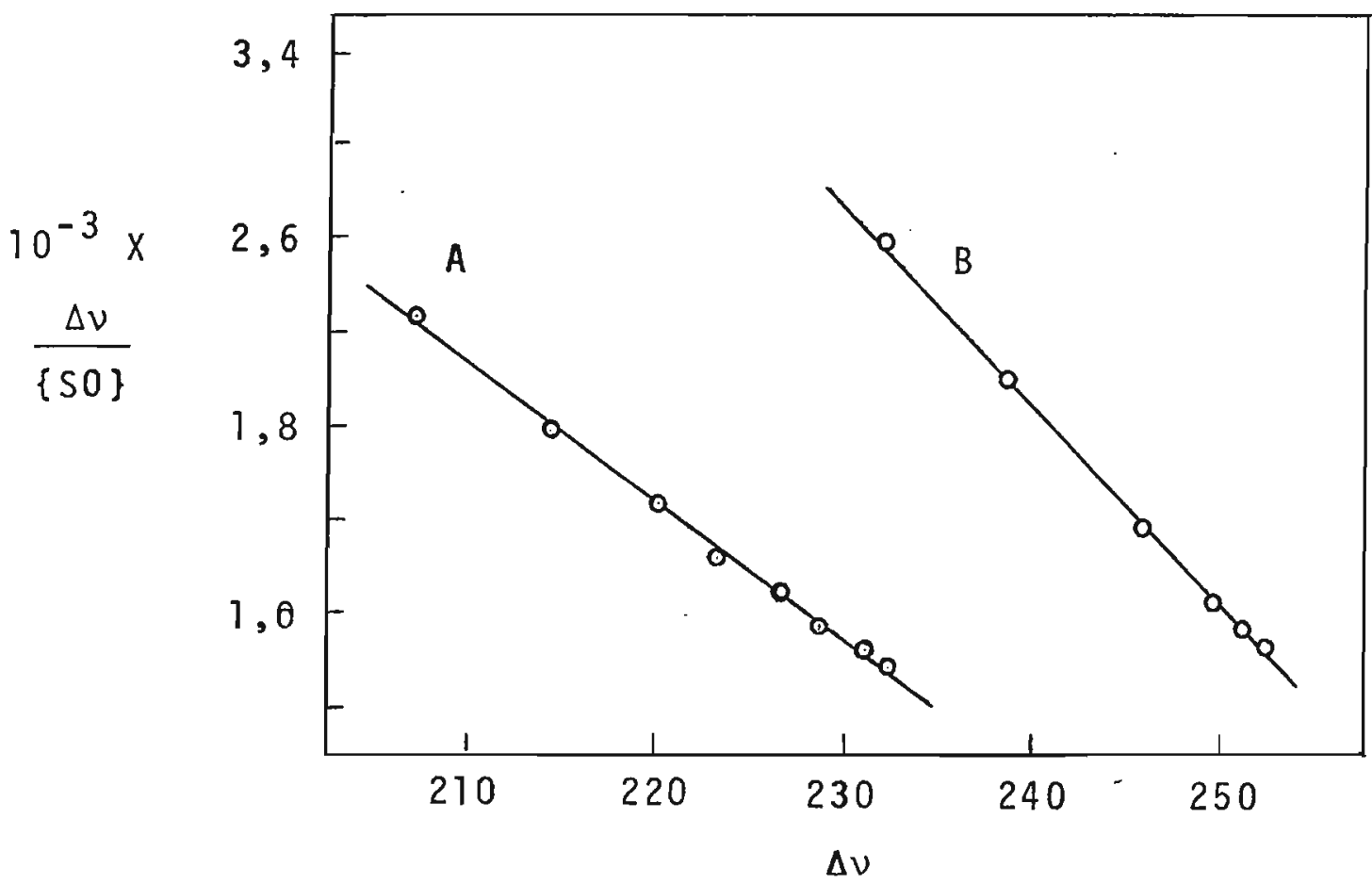

Figura III - Correlações entre os valores de $\Delta \nu /\{S 0\}$ e $\Delta \nu$, para determinação de constantes de associação dos sulfóxidos:

A) etil etiltiometil sulfóxido; B) etil butil sulfóxido. Método de Carper.

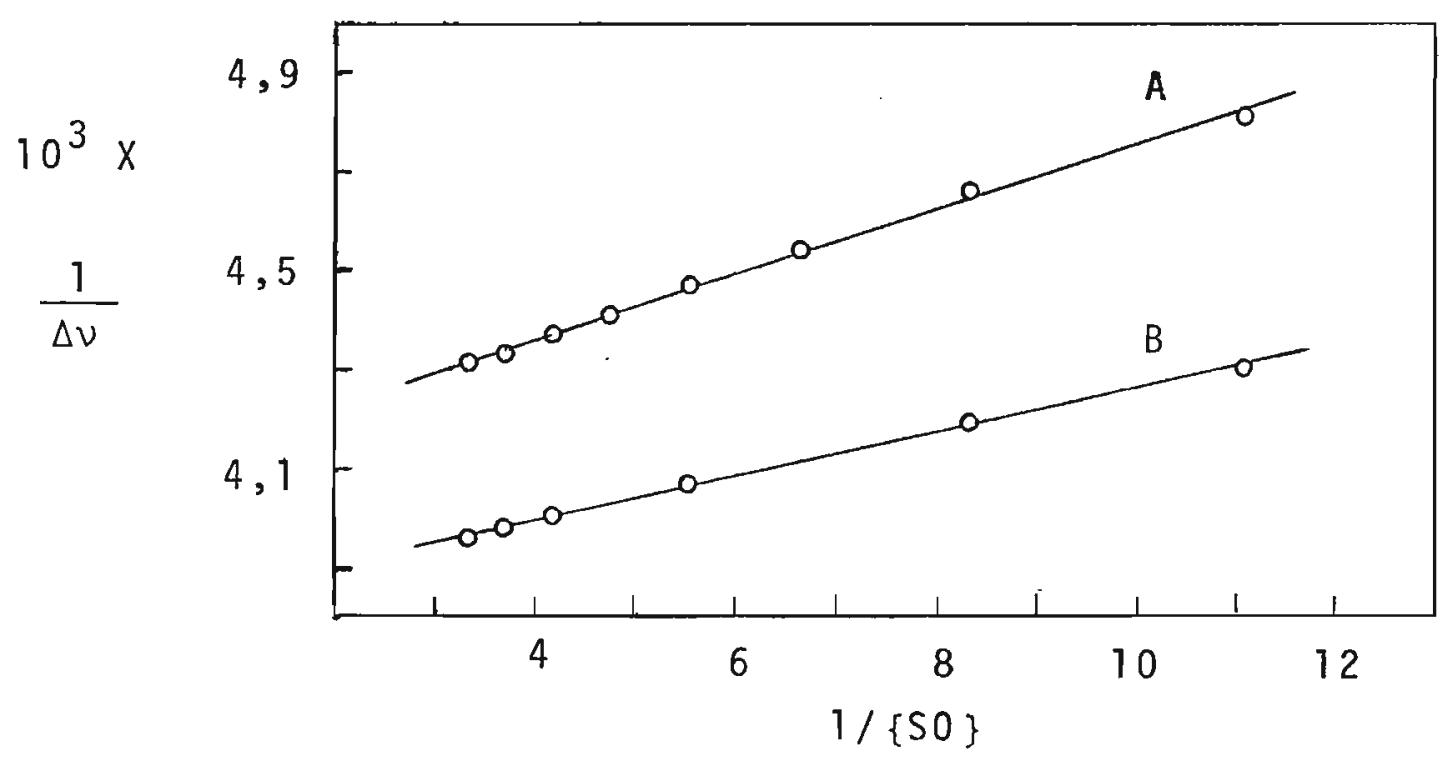

Figura IV - Correlações entre os valores de $1 / \Delta \nu$ e $1 /\{\$$ O para determinação de constantes de associação dos sulfóxidos: A) etil etiltiometil sulfóxido; B) etil butil sulfóxido. Método de Mathur. 


\subsection{REAÇOES DE SULFOXIDOS COM COMPOSTOS DE GRIGNARD}

\subsubsection{Procedimentos gerais}

\subsubsection{1- Preparação e dosagem dos compostos de Grignard}

Preparação ${ }^{46}$

Utilizava-se uma aparelhagem seca, constituida de um balāo de três tubuladuras ao qual foram adaptados um agitador me cānico, um condensador com tubo de cloreto de cālcio, e um funil conta-gotas com tubo equalizador de pressão.

No balão colocava-se o magnẻsio, e, no funil, uma quan tidade equivalente de uma solução $1 M$ do haleto em ēter anidro. Sobre o magnësio, adicionava-se, inicialmente, cerca de um décimo da solução do haleto, esperáva-se começar a reagir agitando levemente, e resfriava-se quando necessärio. Continuava-se a adi ção, ãs gotas, com agitação mais forte, mantendo um refluxo suave. Terminada a adição, completava-se a reação aquecendo sob refluxo e agitando, durante meia hora.

Dosagem $^{47}$

Tranferia-se, com o auxīio de uma pipeta seca, toda a solução do reagente de Grignard para o funil conta-gotas graduado, e media-se o volume total. Uma alíquota de $1 \mathrm{ml}$ desta solução era retirada e adicionada sobre $25 \mathrm{ml}$ de uma solução $0,1 \mathrm{~N}$ de äcido clorídrico. A mistura era aquecida em banho-maria por 10 
minutos e titulada com uma solução $0,1 \mathrm{~N}$ de hidrōxido de sōdio, usando fenolftaleîna como in dicador.

o cālculo da quantidade obtida do reagente de Grig nard(em mmoles) era feito utilizando a expressão: mmoles do reagente de Grignard $=(2,5-0,1 \mathrm{~V}) \mathrm{V}_{\mathrm{t}}$ onde $V \bar{e}$ o volume da base gasto na tituração (em ml), e $v_{t} \bar{e}$ o volume total da solução do reagente de Grignard (em $\mathrm{ml}$ ).

3.3.1.2. Reaçōes de sulföxidos com compostos de Grignard ${ }^{25}$

Utilizava-se a mesma aparelhagem descrita em 3.3.1.1. Uma quantidade adequada de uma solução $1 M$ do sulföxido em ēter seco era adicionada, ās gotas, com agitação mecânica e resfriamento em gelo, sobre um ou dois equivalentes do composto de Grignard. Aquecia-se sob refluxo durante trēs horas, com agitação, e deixava-se em repouso, ã noite.

A mistura era, então, jogada sobre uma solução de ācị do clorīdrico $10 \%$ em ägua gelada, o produto era extraido com ēter, e o extrato lavado com ägua e seco com sulfato de sỏdio anidro. 0 sal era separado por filtração e o solvente evaporado à trompa. 0 produto bruto era analisado por cromatografia de gās para identificação e determinação do rendimento (ver 3.3 .1 .3$. ).

3.3.1.3. Identificações e anālises dos produtos das reações de sulföxidos com compostos de Grignard.

Identificações

Por ressonāncia magnëtica nuclear do produto bruto em 
tetracloreto de carbono, usando tetrametilsilano como referéncia interna, obtinha-se uma indicação da presença do mercaptal na mistura comparando-se as posições dos sinais obtidos com as dos mercaptais autēnticos. 0 espectro de ressonāncia de substāncias isoladas ê apresentado indicando-se a posição de cada sinal em relação ao tetrametilsilano, seguida pelo desdobramento e nümero de hidrogênios correspondentes.

Por cromatografia de gäs identificava-se o produto inje tando-se o bruto em mistura com o autēntico. Utilizavam-se as du as colunas que apresentaram maior efieiência na separação dos componentes destas misturas: $3 \%$ SE-52 sobre Varaport $30,100 / 120$ mesh, com $3,18 \mathrm{~mm} \times 1,52 \mathrm{~m} ;$ e $3 \%$ XE-60 sobre Varaport $30,100 / 120$ mesh, com $3,18 \mathrm{~mm} \times 1,52 \mathrm{~m}$. As condiçōes de operação estão indicadas em cada caso, abreviando-se, entre parênteses, a pressão de gâs de arraste $\left(N_{2}\right)$, a temperatura do injetor (INJ) e a programa ção da temperatura da coluna (COL).

Anāilises dos produtos

Ds produtos brutos eram analisados por cromatografia de gās para a determinação dos rendimentos utilizando-se o procedimento $A$ ou $E$, descritos mais adiante nesta secção.

0 procedimento A foi utilizado para as experiēncias em que o produto era o etilmercaptal do benzaldeido. Nestes casos o cromatograma do bruto apresentava um pico simētrico corresponden te ao produto bem separado de outros picos de subprodutos, facilitando a utilização de um padrão interno conveniente. 
Para as experiências em que o produto era outro mercap tal, utilizava-se o procedimento B. Nestes casos era difícil con seguir um cromatograma em que o pico do produto principal apresentasse simetria adequada para a añ̄ise, e, ao mesmo tempo, fosse afastado o bastante dos picos mais pröximos para que pu desse ser usado um padrão interno.

Determinações de rendimento

Procedimento A - Prepararam-se misturas com quantida des conhecidas do produto autēntico (mercaptal) e de uma subs tāncia padrão (benzilfenil sulfeto) com tempo de retenção prōxi mo. Das misturas, diluidas com $1 \mathrm{ml}$ de tolueno para melhor homo geneização, foram tomadas alíquotas de $0,5 \mu 1$ para injecção no cromatōgrafo. Construia-se um gräfico (figura V) das relações obtidas entre ārea da substāncia e ārea do padrão ( $\left.A / A^{\prime}\right)$, em função das relações conhecidas entre massa da substāncia e massa do padrão $\left(\mathrm{m} / \mathrm{m}^{\prime}\right)$.

Para a determinação do rendimento preparava-se uma so 1 uçāo com quantidades pesadas do produto bruto e do padrão, e in jetavam-se alíquotas no cromatōgrafo, obtendo-se, do cromato grama, o valor de $A / A^{\prime}$. A massa de mercaptal contida na quantida de pesada do bruto era, então calculada, verificando-se no gräfi co o valor correspondente de $\mathrm{m} / \mathrm{m}^{\prime}$, e multiplicando este valor pe la massa pesada do padrão $\left(m^{\prime}\right)$. Calculava-se a massa de mercap tal contida no total do bruto, e o rendimento da reação. 


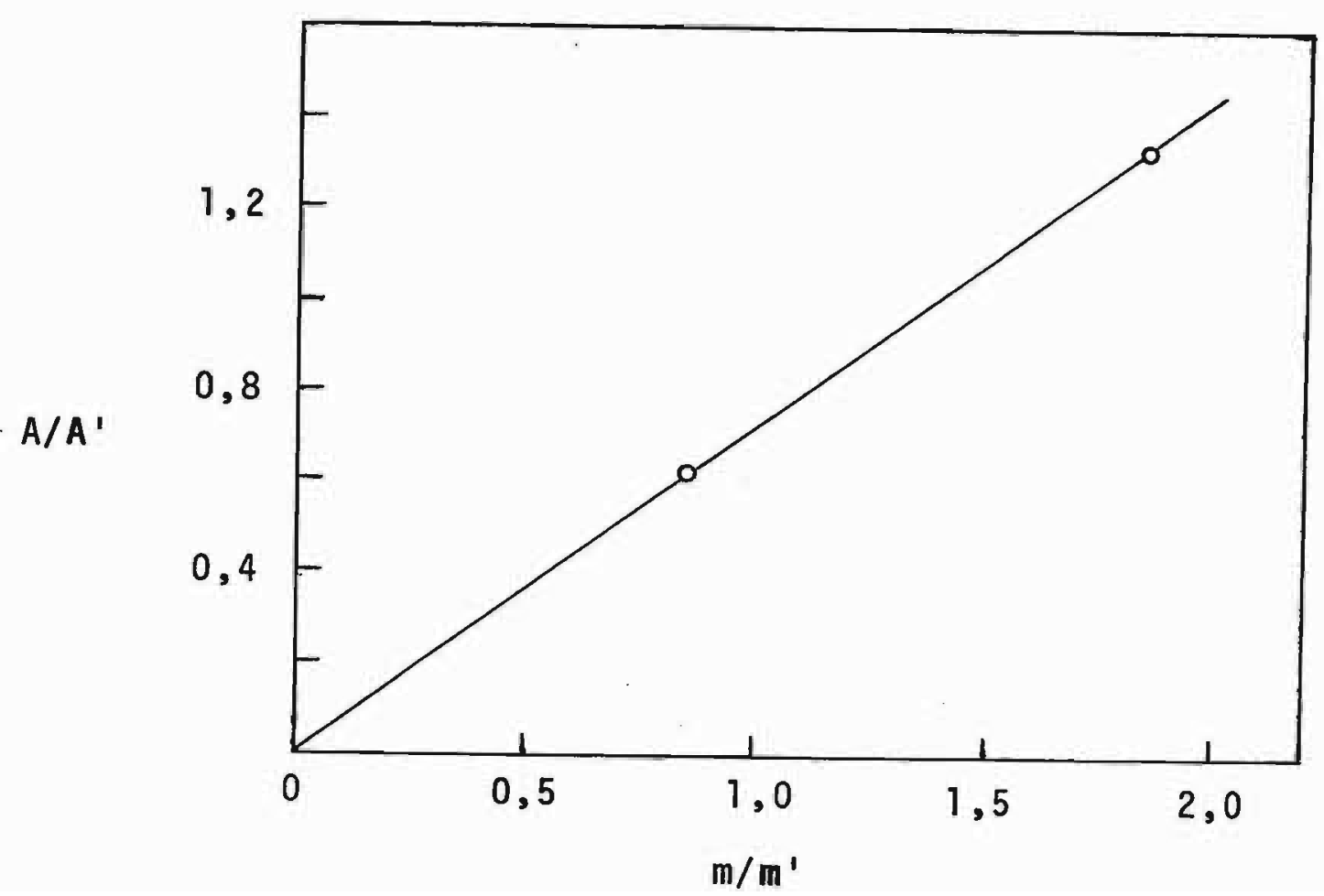

Figura V - Curva padrão utilizada na determinação de rendimentos do etiTmercaptal do benzaldeido, pelo procedimento $A$

Procedimento B - Preparavam-se soluçōes com quantidades semelhantes do bruto $\left(m_{b}\right)$ e diferentes quantidades do produto autêntico (m) em tolueno. Injetavam-se alĩquotas de $1 \mu 1$ no cromatō grafo, obtendo-se, do cromatograma, os valores das äreas do produ to (A) para cada amostra. Escolhia-se a ārea de um pico mais prōximo ao do produto como referência $\left(A^{\prime}\right)$ e determinavam-se as rela çōes entre ärea do produto e ārea da referēncia ( $A^{\prime} A^{\prime}$ ) para cada amostra.

Construia-se um gräfico de $A / A^{\prime}$ em funçāo de $\mathrm{m} / \mathrm{m}_{b}$ (figura VI) obtendo-se, por extrapolação, o valor de $m_{0} / m_{b}$, onde $m_{0}$ 
è a massa de mercaptal na quantidade $m_{b}$ do bruto. Calculava-se a massa do mercaptal obtida na reaçäo, multiplicando $m_{0} / m_{b}$ peTa massa do produto bruto.

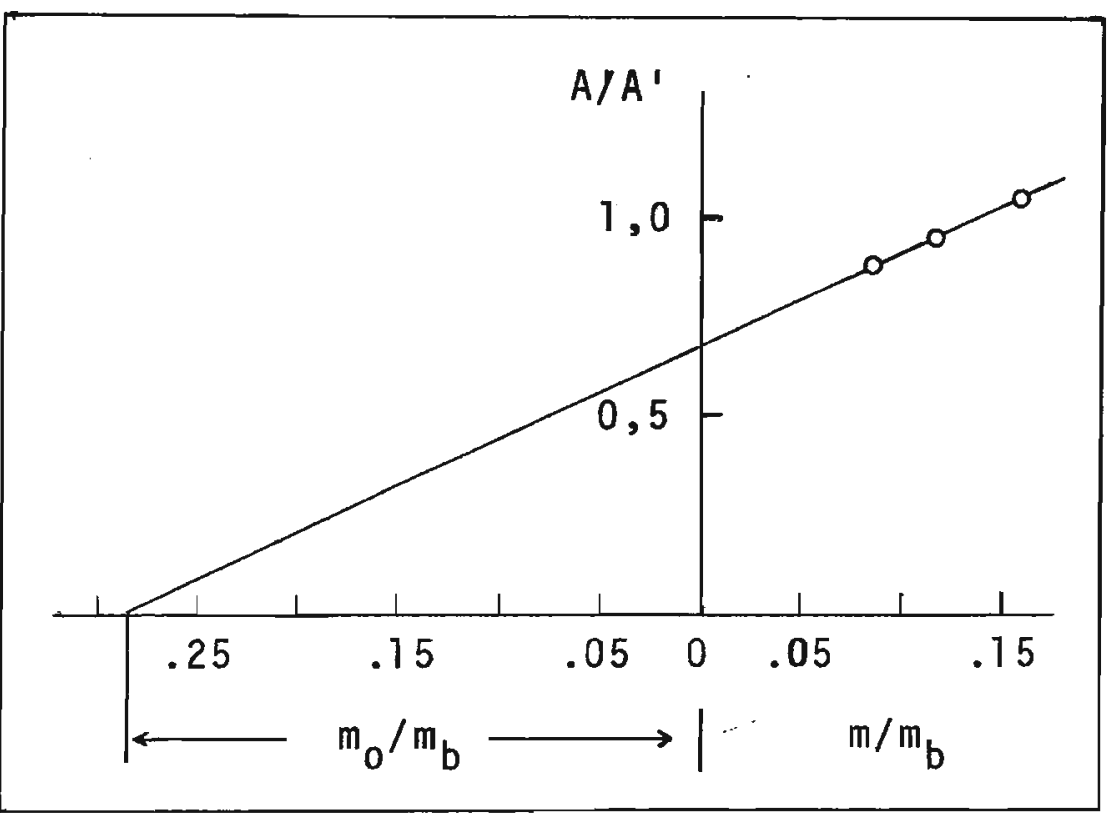

Figura VI - Exemplo de curva obtida para determinação de rendimentos de mercaptais, pelo procedimento $B$

3.3.2. Experiëncias realizadas

3.3.2.1. Reaçäo do etil etiltiometil sulföxido com um equivalente de brometo de fenilmagnésio.

Procedendo como descrito em 3,3.1.2., adicionaram-se 6,58 mmoles do etil etiltiometil sulföxido (1,0g em $7 \mathrm{ml}$ de ēter) 
sôbre uma solução de 6,6 mmoles do brometo de fenilmagnēsio em $6,5 \mathrm{ml}$ de éter (ver 3.3 .1 .1$. ), obtendo-se $0,68 \mathrm{~g}$ do produto bruto.

0 mercaptal do benzaldeido foi identificado no bruto por cromatografia de gäs (ver 3.3.1.3.), utilizando-se as colu nas: $3 \%$ SE $-52\left(N_{2}: 20\right.$ psi; INJ.: $240^{\circ} \mathrm{C}$; COL.: $1009 \mathrm{C} 2$ min; $150 \mathrm{C} / \mathrm{min} .10 \mathrm{~min} ; 2500 \mathrm{C} 10 \mathrm{~min}$.$) , e 3 \% \mathrm{XE}-60\left(\mathrm{~N}_{2}: 20 \mathrm{psi}\right.$; INJ.: 2400 C; COL.: $1100 \mathrm{C} 1,5 \mathrm{~min} ; 12,50 \mathrm{C} / \mathrm{min} 12 \mathrm{~min}$; $2600 \mathrm{C} 9 \mathrm{~min}$.$) .$

A quantidade do etilmercaptal do benzaldeido contida no bruto $(0,42 \mathrm{~g} ; 1,98$ mmoles $)$, correspondendo a um rendimento de $30 \%$, foi determinada por cromatografia de gãs (ver procedimento A em 3.3.1.3.), utilizando-se a coluna de $3 \%$ SE-52 nas condições indicadas acima para esta coluna.

\subsubsection{Reação do etil etiltiometil sulfóxido com dois equiva- lentes de brometo de fenilmagnēsio.}

Utilizaram-se 6,58 mmoles do sulfóxido $(1 \mathrm{~g}$ em $5 \mathrm{ml}$ de éter) e 14,5 mmoles do reagente de Grignard em $15 \mathrm{~m} 1$ de ēter.Pro cedendo como descrito em 3.3.1.2., obtiveram-se 1,4 gramas do produto bruto.

0 mercaptal do benzaldeido foi identificado no bruto por cromatografia de găs (ver 3.3.1.3.), utilizando-se as colunas: $3 \%$ SE-52 (N 2 : 20 psi; INJ.: 2400C; COL.: 1000C 2 min $150 \mathrm{C} / \mathrm{min} 10 \mathrm{~min} ; 2500 \mathrm{C} 10 \mathrm{~min})$, e $3 \% \mathrm{XE}-60\left(\mathrm{~N}_{2}: 20 \mathrm{psi}\right.$; INJ.; 2400C; COL.: $1100 \mathrm{C} 1,5 \mathrm{~min} ; 12,50 \mathrm{C} / \mathrm{min} 12 \mathrm{~min} ; 2600 \mathrm{C} 9 \mathrm{~min})$. A quantidade do etilmercaptal do benzaldeido contida no bruto $(0,843 \mathrm{~g} ; 3,97$ mmoles $)$, correspondendo a um rendimento 
de $60 \%$, foi determinada por cromatografia de gãs (ver procedimen to A em 3.3.1.3.), utilizando-se a coluna.de $3 \%$ SE-52 nas condições indicadas acima para identificação.

3.3.2.3. Reação do etil etiltiometil sulföxido com o brometo de p-tolilmagnésio.

Procedendo como descrito em 3.3 .1 .2 , adicionaram-se 5,0 mmoles do etil etiltiometil sulföxido $10,76 \mathrm{~g}$ em $5 \mathrm{ml}$ de ēter seco) sōbre solução de 12,9 mmoles do brometo de p-tolilimagnēsio em $15 \mathrm{~m} 1$ de ëter (ver 3.3 .1 .1$.$) , obtendo-se 1.35 \mathrm{~g}$ do produto bru to.

Identificou-se o mercaptal no bruto, por cromatografia de gäs (ver 3.3.1.3.), utilizando-se as colunas: $3 \%$ SE-52 ( $\mathrm{N}_{2}: 20$ psi; INJ.: 2409C; COL.: 1509C $2 \mathrm{~min} ; 12,50 \mathrm{C} / \mathrm{min} 6 \mathrm{~min} ; 2230 \mathrm{C} /$ min 8 min.), e $3 \%$ XE-60 (N 2 : 20 psi; INJ.; $2409 \mathrm{C} ; \mathrm{COL} .: 1109 \mathrm{C} 1,5$ min; $12,50 \mathrm{C} / \mathrm{min} 10,5 \mathrm{~min} ; 2409 \mathrm{C} 13,5 \mathrm{~min})$.

A quantidade do etilmercaptal do p-tolualdeido contida no bruto $(0,735 \mathrm{~g} ; 3,25$ mmoles $)$, correspondendo a um rendimento de $65 \%$, foi determinada por cromatografia de gás (ver procedimen to $B$, em 3.3 .1 .3$.$) , em uma coluna de 3 \%$ SE-52 nas mesmas condi ções indicadas para a identificação acima.

3.3.2.4. Reação do etil etiltiometil sulfōxido com brometo de p-metoxifenil magnésio.

Procedendo como descrito em 3.3 .1 .2 , adicionaram-se 
11,5 mmoles do etil etiltiometil sulföxido $(1,75 \mathrm{~g}$ em $10 \mathrm{ml}$ de éter seco (sōbre solução de 25,3 mmoles do brometo de p-metoxifenilmagnēsio em $25 \mathrm{~m} 1$ de ēter (ver 3.3.1.1.), obtendo-se $4,1 \mathrm{~g}$ do produto bruto.

A identificação do mercaptal no bruto por cromatografia de gäs (ver $3.3,1,3$, ) foi realizada utilizando-se as colu nas: $3 \%$ SE-52 (N 2 : 20 psi; INJ.: 2409C; COL.: 909C 2 min; $23,30 \mathrm{C} /$ min $2 \mathrm{~min} ; 12,50 \mathrm{C} / \mathrm{min} 10 \mathrm{~min} ; 2620 \mathrm{C} 12 \mathrm{~min}$.$) , e 3 \% \mathrm{XE}-60\left(\mathrm{~N}_{2}: 20\right.$

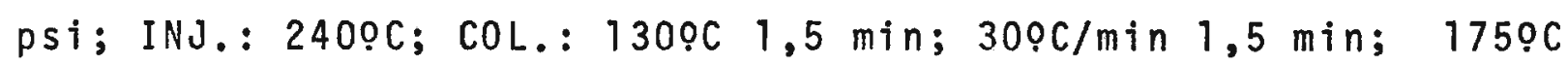
$3 \mathrm{~min} ; 23,30 \mathrm{C} / \mathrm{min} 3 \mathrm{~min} ; 2450 \mathrm{C} 12 \mathrm{~min}$.$) . Do mesmo modo, outros$ componentes do bruto foram identificados (pequenas quantidades de p-bromoanisol, etil p-metoxifenil sulfeto, e maior quantidade de anisol), constatando-se a auséncia do etil p-metoxibenzil sulfeto e do etil mercaptal do o-anisaldeido.

A quantidade do etilmercaptal do p-anisaldeido contida no bruto $(1,75 \mathrm{~g} ; 7,25$ mmoles $)$, correspondendo a um rendimento de $63 \%$, foi determinada por cromatografia de gās (ver procedimento $B$, em 3.3 .1 .3$.$) , na coluna de 3 \% \mathrm{SE}-52$, utilizando as mesmas condi çōes indicadas acima para esta coluna.

Por cromatografia em coluna, usando $40 \mathrm{~g}$ de gel de sili $\mathrm{ca}, 3,5 \mathrm{~g}$ do bruto, e tetracloreto de carbono como eluente, foram separadas $1,16 \mathrm{~g}(42 \%)$ do etilmercaptal do anisaldeido. RMN $\left(\mathrm{CCl}_{4}{ }^{-}\right.$ TMS ): $\delta 6,7-7,4(\mathrm{~m}, 4 \mathrm{H}) ; 4,83(\mathrm{~s} .1 \mathrm{H}) ; 3,73(\mathrm{~s} .3 \mathrm{H}) ; \quad 2,50$ $(q .4 H) ; 1,18(t, 6 H)$.

Uma fração posterior contendo $0,06 \mathrm{~g}(2 \%)$ de um 1 ĩquido incolor, apresentou o seguinte espectro de RMN ( $\mathrm{CCl}_{4}$-TMS): $\delta$ 6,63$7,33(\mathrm{~m} .8 \mathrm{H}) ; 5,01(\mathrm{~s} .1 \mathrm{H}) ; 3,73(\mathrm{~s} .6 \mathrm{H}) ; 2,33(\mathrm{q} .2 \mathrm{H}) ; 1,18$ (t. $3 \mathrm{~h}$ ), indicativo da estrutura do (etiltio)bis(p-metoxifenil)- 
metano.

Este $\bar{u}$ timo composto, quando injetado no cromatōgrafo de gãs junto com o produto bruto da reação, permitiu a identifi cação do pico posterior ao do mercaptal do anisaldeido.

3.3.2.5. Reação do etil feniltiometil sulföxido com o brometo de fenilmagnésio.

Utilizando 7 moles do etil feniltiometil sulfōxido $(1,4 \mathrm{~g}$ em $1.0 \mathrm{ml}$ de éter) e 18 mmoles do brometo de fenilmagnēsio em $15 \mathrm{ml}$ de ëter, e procedendo como descrito em 3.3.1.2., obtiveram-se $2,4 \mathrm{~g}$ do produto bruto.

A identificação do mercaptal foi realizada (ver 3.3.1. 3.) Utilizando-se as colunas: $3 \%$ SE-52 $\left(N_{2}: 20\right.$ psi; INJ.; 180OC; COL.: $1100 \mathrm{C} 2,5 \mathrm{~min} ; 300 \mathrm{C} / \mathrm{min} 5 \mathrm{~min} ; 2600 \mathrm{C} 20 \mathrm{~min})$, e $3 \% \mathrm{XE}-60$ $\left(\mathrm{N}_{2}: 20 \mathrm{psi} ; \mathrm{INJ} .: 1709 \mathrm{C} ; \mathrm{COL} . ; 1109 \mathrm{C} 1,5 \mathrm{~min} ; 12,50 \mathrm{C} / \mathrm{min} 12 \mathrm{~min}\right.$; 2600 ( 12 min).

0 rendimento do etil fenil mercaptal do benzaldeido foi de $45 \%(0,98 \mathrm{~g} ; 3,78$ mmoles $)$, determinado por normalização das àreas dos picos do cromatograma do produto bruto. A coluna utilizada foi de $3 \%$ SE-52, nas mesmas condiçōes usadas na identificação.

3.3.2.6. Reação do fenil feniltiometil sulfỏxido com o brometo de fenilmagnësio.

Utilizando 4,5 mmoles do fenil feniltiometil sulfōxido $(1,12 \mathrm{~g}$ em $5 \mathrm{mll}$ de ēter) e 11,3 mmoles do brometo de fenilmagnē sio em $10 \mathrm{~m} 1$ de ëter e procedendo como descrito em 3.3.1.2., ob- 
tiveram-se $1,75 \mathrm{~g}$ do produto bruto.

Para a identificação do mercaptal por cromatografia de gās (ver 3.3.1.3.), utilizaram-se as colunas: $3 \%$ SE-52 $\left(\mathrm{N}_{2}: 20\right.$ psi; INJ.: 1709C: COL.: 1109C 2 min; 20 $\mathrm{C} / \mathrm{min} 2 \mathrm{~min} ; 1509 \mathrm{C} 2 \mathrm{~min}$; $259 \mathrm{C} / \mathrm{min} 4 \mathrm{~min} ; 2500 \mathrm{C} 12 \mathrm{~min})$, e $3 \% \mathrm{XE}-60\left(\mathrm{~N}_{2}: 20 \mathrm{psi}\right.$; INJ. : 1709C; COL,: $1109 \mathrm{C} 1,5 \mathrm{~min} ; 12,50 \mathrm{C} / \mathrm{min} 12 \mathrm{~min}$; $2609 \mathrm{C} 12 \mathrm{~min})$. Da anălise por cromatografia de gās (ver procedimento $B$, em 3.3.1.3.) determinou-se um rendimento de $53 \%$ do fenilmercap tal do benzaldeido $(0,73 \mathrm{~g} ; 2,37$ mmoles $)$, utilizando a coluna de $3 \%$ SE-52 nas condições indicadas acima.

3.3.2.7. Reação do 1,3-ditiolano-1-öxido com o brometo de fenilmagnēsio.

Procedendo como descrito em 3.3.1.2., e utilizando 7 mmoles do 1,3-ditiolano-1-ōxido (0,86g em $10 \mathrm{ml}$ de THF) e 17,5 mmoles do brometo de fenilmagnésio, obtiveram-se $2,0 \mathrm{~g}$ do produto bruto.

Identificou-se o produto (ver 3.3.1.3.) utilizando a coluna de $3 \%$ SE-52 (N 2 : 20 psi; INJ.: 2400C; COL.; $1809 \mathrm{C} 8 \mathrm{~min}$; $300 \mathrm{C} / \mathrm{min} 2 \mathrm{~min} ; 2400 \mathrm{C} 8 \mathrm{~min})$.

Por cromatografia de gās (ver procedimento B em 3.3.1.3.) determinou-se o rendimento de $20 \%(0,26 \mathrm{~g} ; 1,4$ mmoles $)$ utilizando a coluna e as condições indicadas acima para identificação. 


\subsection{PREPARAÇOES E REAÇOES DE CARBANIONS DO ETIL ETILTIOMETIL} SULFOXIDO.

\subsubsection{Pelo emprêgo do n-butil 1itio}

3.4 .1 .1 Preparação do carbânion ${ }^{48}$

Uma solução $0,5 M$ do sulfōxido em tetrahidrofurano era colocada en balão de três tubuladuras munido com septo de borra cha, tubo de entrada para nitrogēnio, termōmetro, e barra magnê tica. Resfriava-se o balão com banho de gelo-sal e adicionava-se ãs gotas e com agitação, um equivalente de uma solução $2 M$ de bu til litio em n-hexano. A mistura era mantida sob nitrogênio, com a temperatura interna entre -8 e $-50 \mathrm{C}$, durante a adição, e usada logo em seguida.

3.4.1.2. Reação com um equivalente de brometo de fenilmagnësio.

Preparou-se, como descrito em 3.3 .1 .1 , uma solução de 11,0 mmoles do brometo de fenilmagnēsio em $15 \mathrm{mt}$ de ēter. Conservou-se o funil conta-gotas da aparelhagem, e substituiu-se o con densador por um tubo para admissão de nitrogênio.

Uma solução do carbānion do etil etiltiometil sulfōxido foi preparada, como descrito em 3.4 .1 .1 , a partir de $10 \mathrm{mmo-}$ les do sulföxido $(1,52 \mathrm{~g}$ em $20 \mathrm{ml}$ de THF) e 10 mmoles de butil 1ํ tio (5 ml BuLi 2 M em hexano), e transferida, por meio de uma p $\underline{i}$ peta seca, para o funil conta-gotas adaptado na aparelhagem onde foi preparado o composto de Grignard. Para a transferência, ap $1 \underline{\mathbf{j}}$ cava-se uma pressão positiva de nitrogênio em cada aparelhagem 
que estava sendo aberta

Adicionou-se a solução do carbānion, às gotas, sobre a solução do brometo de fenilmagnēsio, com agitação e resfriamento em banho de gêlo. A reação foi continuada, e o tratamento da mis tura foi efetuado, do mesmo modo como descrito em 3.3.1.2. para as reações de sulfōxidos com compostos de Grignard. Foram obti das $1,68 \mathrm{~g}$ do produto bruto.

Determinou-se a quantidade do etilmercaptal do benzaldeido no bruto $(0,237 \mathrm{~g} ; 1,1$ mmoles $)$, correspondente a um rendi mento de $11 \%$, procedendo-se como descrito para a anāise do bruto da experiéncia 3.3 .2 .1 .

3.4.1.3. Reação com dois equivalentes de brometo de fenilmagnësio.

Procedendo como descrito na secção anterior (3.4.1.2.), partiu-se de 4,73 mmoles do carbānion do etil etiltiometil sulfóxido em $10 \mathrm{ml}$ de THF, e 10,1 mmoles do brometo de fenilmagnësio em $10 \mathrm{ml}$ de ëter, obtendo-se $0,94 \mathrm{~g}$ do produto bruto, com um conte üdo em dietilmercaptal do benzaldeido $(0,16 \mathrm{~g} ; 0,75$ mmoles) corres pondendo a um rendimento de $15,5 \%$.

\subsubsection{Reação com brometo de fenilmagnësio, em presença de bro- meto de magnësio.}

0 brometo de magnēsio foi obtido ${ }^{49}$ em uma aparelhagem protegida contra umidade, adicionando-se, ãs gotas e com agitação magnētica, uma solução de 6 mmoles $(2,16 \mathrm{~g})$ de brometo mercūrio em 
$10 \mathrm{ml}$ de THF, sobre 12 mmoles $(0,3 \mathrm{~g})$ de magnēsio. A mistura, apōs adição, foi agitada sob refluxo por 3 horas, resultando em uma so lução clara contendo uma suspensão fina de um sōlido cinzento. 0 sőlido foi separado por filtração rāpida sob nitrogênio, utili zando-se um funil seco de vidro sinterizado. A solução do brometo de magnēsio foi recolhida diretamente em um funil conta-gotas jă adaptado na aparelhagem a ser utilizada em seguida.

A solução do brometo de magnësio foi adicionada; ãs gotas, com agitação magnētica, e resfriamento em gelo, sobre uma so 1 ução do carbānion do etil etiltiometil sulfōxido recentemente pre parada (ver 3.4.1.1.) a partir de 6 mmoles do sulföxido $(0,91 \mathrm{~g}$ em $10 \mathrm{ml}$ de THF) e 6 mmoles de butil 17tio (3 $\mathrm{ml}$ de BuLi 2 M em hexa no). Esta mistura foi deixada agitando à temperatura ambiente por 1 hora, e transferida, sob nitrogênio, para um funil conta-gotas. Adicionou-se a mistura sôbre uma solução de 6 moles de brometo de fenilmagnēsio em $10 \mathrm{~m} 1$ de ëter (preparada como descrito em 3.3 .1 .1$.$) , às gotas, com resfriamento em gelo, e com agita-$ ção mecânica. A continuação da reação e o tratamento da mistura resultante foram efetuados do mesmo modo como descrito em 3.3.1.2. para as reações de sulfōxidos com compostos de Grignard, obtendose $0,9 \mathrm{~g}$ do produto bruto.

A quantidade do etil mercaptal do benzaldeido contida no bruto $(0,108 \mathrm{~g} ; 0,51$ mmoles $)$, correspondendo a um rendimento de $8,5 \%$, foi determinada procedendo-se como descrito para a añ̄ise do bruto da experiēncia 3.3 .2 .1 .

Repetiu-se a experiēncia utilizando 1,5 equivalentes do reagente de Grignard ( 9 mmoles), obtendo-se $1,19 \mathrm{~g}$ do bruto, contendo $0,134 \mathrm{~g}(0,63$ mmoles $)$ do mercapta 1 , o que corresponde a um 
rendimento de $10,5 \%$.

\section{$3.4 \cdot 1.5$. Reação com ãgua deuterada}

Uma solução de 6 mmoles do carbānion do etil etiltiometil sulfōxido em $12 \mathrm{ml}$ de THF, foi preparada como descrito em 3.4.1.1. A esta solução, resfriada entre -8 e -50 C, adicionou-se às gotas e com agitação, uma solução de $0,4 \mathrm{ml}$ de ācido sulfürico $\left(20 \% \mathrm{SO}_{3}\right)$ em $1 \mathrm{ml}$ de āgua deuterada. Separou-se a fase orgāni ca e secou-se com sulfato de sōdio anidro. 0 solvente foi evaporado à trompa, obtendo-se $0,51 \mathrm{~g}$ do sulföxido deuterado.

IV (filme; $\mathrm{NaCl}$ ): $2220 \mathrm{~cm}^{-1}$ (fraca); $2170 \mathrm{~cm}^{-1}$ (fraca); $1040 \mathrm{~cm}^{-1}$ (for te )

$\operatorname{RMN}\left(\mathrm{CCl}_{4}\right.$-TMS $): \delta 3,63(\mathrm{~s}, 1 \mathrm{H}) ; 2,81(\mathrm{q}, 4 \mathrm{H}) ; 1,32(t .5 \mathrm{H})$.

A fase aquosa foi extraida com ēter, e o extrato foi la vado com solução saturada de sulfato de sódio e seco com sulfato de sōdio anidro. Apōs evaporação do solvente, obtiveram-se mais $0,21 \mathrm{~g}$ do sulfōxido deuterado.

\subsubsection{Pelo emprēgo de hidreto de sōdio}

3.4 .2 .1 . Preparação do carbānion ${ }^{50}$

Utilizava-se um balão de trés tubuladuras, ao qual fo ram adaptados um condensador com tubo de cloreto de cālcio, um tubo para admissão de nitrogēnio, e um septo de borracha.

Colocava-se, no balão, 6,58 mmoles $(0,158 \mathrm{~g})$ de hidre 
to de sôdio, correspondendo a $0,316 \mathrm{~g}$ de uma emulsão oleosa contendo $50 \%$ do hidreto. O hidreto era liberado do öleo por lava gem com värias porçōes de hexano anidro. Cada porção de hexano era injetada, por meio de uma seringa, sob nitrogênio, e retira da apõs agitação e deposição do sōlido. Os traços finais de hexano eram eliminados a väcuo. Adicionava-se, então, $10 \mathrm{ml}$ de ēter seco. À suspensão de hidreto resultante, adicionava-se, ãs gotas e com agitação magnētica, uma solução de 6,58 mmoles $(1,0 \mathrm{~g})$ do etil etiltiometil sulfōxido em $5 \mathrm{ml}$ de ëter. Completava-se a rea ção agitando-se sob refluxo durante 3 horas.

3,4.2.2. Reação com um equivalente de brometo de fenilmagnêsio.

Preparou-se, como descrito em 3.4.2.1, uma suspensäo de 6,58 mmoles do carbãnion em $15 \mathrm{ml}$ de ëter.

A esta suspensão, resfriada em banho de gêlo e com agitação mecânica, adicionou-se, ãs gotas, uma solução de $6,7 \mathrm{mmo}$ les do brometo de fenilmagnësio em $8 \mathrm{ml}$ de ëter (ver 3.3.1.1.).

A reação e o tratamento da mistura foram efetuados do mesmo modo como descrito em 3.3.1.2. para as reações de sulföxi dos com compostos de Grignard. Obtiveram-se $0,76 \mathrm{~g}$ do produto bru to.

A quantidade de etilmercaptal do benzaldeido contida no bruto $(0,426 \mathrm{~g} ; 2,0$ mmoles $)$, determinada como descrito para a experiēncia 3.3 .2 .1 , corresponde a um rendimento de $30 \%$. 
3.4.2.3. Reação com dois equivalentes de brometo de fenilmagnésio

Procedendo como descrito na secção anterior (3.4.2.2.), partiu-se de 6,58 mmoles do carbānion e de 14,5 mmoles do brometo de fenilmagnēsio, obtendo-se, $1,4 \mathrm{~g}$ do produto bruto, com um conteúdo em dietilmercaptal do benzaldeido $(0,843 \mathrm{~g} ; 3,97$ mmoles) correspondente a um rendimento de $60 \%$.

\subsubsection{Reação com ägua deuterada}

A uma suspensão de 3,5 mmoles do carbānion em $10 \mathrm{ml}$ de Ëter, preparada como descrito em 3.4.2.1.. adicionou-se, ãs go tas, com agitação magnētica e resfriamento em gelo, uma solução de $0,2 \mathrm{ml}$ de àcido sulfúrico $\left(20 \% \mathrm{SO}_{3}\right)$ em $2 \mathrm{ml}$ de āgua deuterada. Extraiu-se a fase orgânica com éter, secou-se o extrato com sulfato de sōdio anidro e evaporou-se o solvente, recuperando-se $0,34 \mathrm{~g}$ do sulfōxido.

0 sulfōxido recuperado não era deuterado, como evidenci ado pela ausēncia de absorção entre 2000 e $2500 \mathrm{~cm}^{-1}$ no espectro do infravermelho, e pela relação de intensidadesdos sinais na ressonância magnētica nuclear: $\operatorname{RMN}\left(\mathrm{CCl}_{4}-\mathrm{TMS}\right) \delta 3,63(\mathrm{~s} .2 \mathrm{H}) ; 2,81$ $(q .4 \mathrm{H}) ; 1,32(t, 6 \mathrm{H})$.

3.4.3, Pelo emprégo do brometo de etilmagnēsio

3.4.3.1. Preparação e reação com ãgua deuterada.

Uma solução de brometo de etilmagnēsio $(10,8$ mmoles $)$ em $12 \mathrm{~m} 1$ de ēter, preparada como descrito em 3.3.1.1.. foi adiciona 
da, ãs gotas, com agitação e resfriamento em gelo, sobre uma so1 ução do etil etiltiometil sulfōxido (10 mmoles) em 10 ml de ēter Formou-se um sōlido viscoso durante a adição. A mistura foi agitada sob refluxo por 3 horas, e deixada em repouso à noite. Adicionou-se, em seguida, às gotas, com agitação e resfriamento em gelo, uma solução de $0,4 \mathrm{ml}$ de ācido sulfürico $\left(20 \% \mathrm{SO}_{3}\right)$ em $2 \mathrm{ml}$ de āgua deuterada. A mistura foi saturada com sulfato de sōdio, extraida com ēter, e o solvente eliminado à trompa, com banho a 409 C. 0 produto bruto $(0,6 \mathrm{~g})$ foi analizado, constatando-se a pre sença do etil etiltiometil sulfōxido não deuterado.

$\operatorname{RMN}\left(\mathrm{CCT}_{4}{ }^{-T M S}\right): \delta 3,63(\mathrm{~s}, 2 \mathrm{H}) ; 2,81(\mathrm{q} .4 \mathrm{H}) ; 1,32(\mathrm{t} .6 \mathrm{H})$

IV (filme; $\mathrm{NaCl}$ ): $1040 \mathrm{~cm}^{-1}$ (não absorve entre $2000-2500 \mathrm{~cm}^{-1}$ ).

\subsubsection{Pelo emprẻgo do brometo de fenilmagnësio}

\subsubsection{Preparação e reação com āgua deuterada}

Partindo-se de 10 mmoles do brometo de fenilmagnēsio e 10 mmoles do etil etiltiometil sulföxido e procedendo-se nas mesmas condições empregadas em 3.4.3.1., obtiveram-se $1,16 \mathrm{~g}$ do produto bruto contendo o etil etiltiometil sulföxido não deuterado. $\operatorname{RMN}\left(\mathrm{CCl}_{4}\right.$-TMS $): \delta 3,63(\mathrm{~s} .2 \mathrm{H}) ; 2,81(\mathrm{q} .4 . \mathrm{H}) ; 1,32(\mathrm{t} .6 \mathrm{H})$ IV (filme; NaCl): $1040 \mathrm{~cm}^{-1}$ (não absorve entre $2000-2500 \mathrm{~cm}^{-1}$ ) 


\subsection{COMPOSTOS DISPONIVEIS}

\subsubsection{Solventes e reagentes não purificados}

Ciclohexano (Merck, uvasol); Diclorometano (Merck); Tetracloreto de carbono (Merck, uvasol); Acido acētico glacial (QEEL); Perhidrol 30\% (May \& Baker); Formalina 40\% (Quimibrās); Metanotiol (Eastman Kodak); N-Clorosuccinimida (Merck); n-Butil 17 tio $2 M$ em hexano (Ventron); Hidreto de sōdio $57 \%$ em dispersão oleosa (Ventron); Magnēsio (Carlo Erba).

\section{5 .2 . Solventes e reagentes purificados}

Tetrahidrofurano (Aldrich), Refluxado e destilado sōbre hidreto de 1 îtio e aluminio 51 .

Fenol (Merck). Destilado, coletando-se a fração de Eb. = 91,0$91,50 \mathrm{C} / 25 \mathrm{mmHg}$. Seco em dessecador ã pressão reduzida, com pentó xido de fósforo, durante três dias 51 b.

Iodometano (QEEL). Destilado. Eb. $=39-409 \mathrm{C}$

Bromoetano $(B D H)$, Destilado. $\mathrm{Eb} .=38-390 \mathrm{C}$

Sulfato de etila (L. Light \& Co. Ltd;). Destilado. Eb. = 969C / $15 \mathrm{~mm} \mathrm{Hg}$.

Cloreto de benzila (Riedel). Destilado, Eb. $=75-770 \mathrm{C} / 22 \mathrm{mmHg}$. Bromobenzeno (Kodak). Destilado. Eb. $=148-1490 \mathrm{C}$

p-Bromotolueno (Kodak). Destilado. Eb. $=176-1790 \mathrm{C}$. o-Bromoanisol (Aldrich. Destilado. Eb. $=730 \mathrm{C} / 4 \mathrm{mmHg}$. Etanotiol (Eastman Kodak). Destilado. Eb. $=35-36$ QC Propanotiol (Kodak). Destilado. Eb. $=67-680 \mathrm{C}$ 
Etilenotiol (Aldrich). Destilado. Eb. $=450 \mathrm{C} / 13 \mathrm{mmHg}$. Benzenotiol (Kodak). Destilado. Eb. $=62-630 \mathrm{C} / 15 \mathrm{mmHg}$ p-Metoxibenzenotiol (Aldrich). Destilado. Eb. $=89-900 \mathrm{C} / 5 \mathrm{mmHg}$ p-Anisaldeido (Aldrich). Destilado. Eb. $=86-880 \mathrm{C} / 2 \mathrm{mmHg}$ o-Anisaldeido (Aldrich). Recristalizado (ēter de petrōleo). F=37$380 \mathrm{C}$.

p-Tolualdeido (Merck). Destilado. Eb. $=78-790 \mathrm{C} / 9 \mathrm{~mm} \mathrm{Hg}$.

\subsection{PREPARAÇOES DE SULFOXIDOS}

\subsubsection{Preparação do metil metiltiometil sulfōxido}

$3.6 \cdot 1.1$. Metilmercaptal do formaldeido ${ }^{52}$

Em um balão de três tubuladuras, munido de um dedo frio para refluxo refrigerado com gềlo seco e acetona, adaptado a um tú bo em $U$ com mercúrio, adicionaram-se $25 \mathrm{~g}$ ( $0,52 \mathrm{~mol})$ de metanotiol e $22,5 \mathrm{~g}$ de formaldeido $35 \%(0,26$ mol $)$. Nesta mistura, resfriada em gelo e sal, introduziu-se, lentamente e com agitação magnētica,uma corrente de ảcido clorîdrico seco atē saturação. 0 material toi deixado em repouso por uma noite. A fase orgānica foi extraida com ēter, e o extrato lavado com ägua, com cinco porçōes de uma solu ção de $\mathrm{NaOH} 2 \%$, e novamente com ăgua. A solução foi seca com carbo nato de potãssio, filtrada, e o solvente eliminado à trompa, obten do-se $25 \mathrm{~g}$ do produto bruto. Por fracionamento, coletou-se $22,1 \mathrm{~g}$, do metil mercaptal do formaldeido entre 147-1480C. (Lit. ${ }^{52}$ : Eb. = $148-149 \% \mathrm{C})$. Rendimento: $80 \%$.

RMN $\left(\mathrm{CCl}_{4}\right.$-TMS): $\delta 3,57(\mathrm{~S} .2 \mathrm{H}) ; 2,12(\mathrm{~s}, 6 \mathrm{H})$. 
3.6.1.2. Metil metiltiometil sulfōxido ${ }^{53}$

A uma solução de $12,5 \mathrm{~g}$ (116 mmoles) do metilmercaptal do formaldeido em $25 \mathrm{ml}$ de äcido acētico glacial, adicionou-se, ãs gotas, com agitação magnētica e resfriamento em gelo e sal. $12,5 \mathrm{ml}$ de ägua oxigenada $30 \%$ ( 120 mmoles), mantendo-se a temperatura da mistura entre 0 e $100 \mathrm{C}$. A agitação foi continuada com resfriamento por uma hora, e ã temperatura ambiente por meia hora. Adicionaram-se $150 \mathrm{~m} 1$ de diclorometano, e $30 \mathrm{~g}$ de carbonato de potāssio. Agitou-se a mistura por uma hora. o sōlido foi remo vido por filtração e o filtrado seco com sulfato de sôdio anidro. o solvente foi eliminado à trompa e o material bruto foi destila do, coletando-se $7,4 \mathrm{~g}$ do metil metiltiometil sulföxido com Eb.= $92-930 \mathrm{C} / 2,5 \mathrm{mmHg}$. (Lit. $\left.{ }^{53}: \mathrm{Eb} .=92-930 \mathrm{C} / 2,5 \mathrm{~mm} \mathrm{Hg}\right)$. Rendimento: $51 \%$.

RMN $\left(\mathrm{CCl}_{4}\right.$-TMS $): \delta 3,73(\mathrm{s.2H}) ; 2,63(\mathrm{s.3H}) ; 2,32(\mathrm{s.3H})$.

IV (filme; $N a C 1): 1040 \mathrm{~cm}^{-1}$ (forte)

\subsubsection{Preparação do etil etiltiometil sulfōxido}

3.6.2.1. Etilmercaptal do formaldeido

Procedendo como descrito para a preparação do metilmercaptal do formaldeido (ver 3.6.1.1.), partiu-se de $124 \mathrm{~g}$ de etanotiol ( 2 moles) e $83,6 \mathrm{~g}$ de formaldeido $35 \%$ ( 1 mol), obtendo-se $132,3 \mathrm{~g}$ do produto bruto. Por destilação a vácuo, coleta ram-se $121,6 \mathrm{~g}$ do etilmercaptal do formaldeido a $629 \mathrm{C} / 10 \mathrm{~mm} \mathrm{Hg}$. (Lit. ${ }^{54}: \mathrm{Eb} .=74-760 \mathrm{C} / 11 \mathrm{mmHg}$ ). Rendimento: $89 \%$. 
$\operatorname{RMN}\left(\left(\mathrm{CCl}_{4}-\right.\right.$ TMS $): \delta 3,63(\mathrm{~s}, 2 \mathrm{H}) ; 2,63(\mathrm{q}, 4 \mathrm{H}) ; 1,30(\mathrm{t} .6 \mathrm{H})$

3.6.2.2. Etil etiltiometil sulföxido ${ }^{53}$

Procedendo como descrito para a preparação do metil metiltiometil sulföxido (ver 3.6.1.2.), partiu-se de $16,02 \mathrm{~g}$ ( 118 mmoles) do etilmercaptal do formaldeido e de $13,5 \mathrm{ml}$ de ägua oxi genada $30 \%$ (118 mmoles), obtendo-se $16,7 \mathrm{~g}$ do produto bruto. Por destilação obtiveram-se $12,6 \mathrm{~g}$ do etil etiltiometil sulfōxido com $\mathrm{Eb} .=94 \mathrm{OC} / 2 \mathrm{mmHg} \cdot\left(\mathrm{Lit}^{53}: \mathrm{Eb} .=95-970 \mathrm{C} / 2,5 \mathrm{mmHg}\right)$. Rendimento: $70 \%$.

$\operatorname{RMN}\left(\mathrm{CCl}_{4}\right.$-TMS $): \delta 3,63(\mathrm{~s}, 2 \mathrm{H}) ; 2,81(\mathrm{q}, 4 \mathrm{H}) ; 1,32(\mathrm{t}, 6 \mathrm{H})$

IV (filme; $\mathrm{NaCl}$ ); $1040 \mathrm{~cm}^{-1}$ (forte)

3.6.3. Preparação do metil propil sulfōxido

3.6 .3 .1 . Metil propil sulfeto ${ }^{55}$

Em um balão de três tubuladuras munido com agitador mecānico, condensador e funil conta-gotas, colocou-se uma solução de $20,5 \mathrm{~g}$ (512 mmoles) de hidrōxido de sōdio em $125 \mathrm{~m} 1$ de ãgua. Adicionaram-se às gotas, com agitação e resfriamento em gelo e $\mathrm{sal}, 45,3 \mathrm{ml}$ (38g; $500 \mathrm{mmoles})$ de propanotiol. Apōs adição, o ba nho foi retirado, e adicionaram-se, ās gotas e com agitação, $31,2 \mathrm{ml}$ ( $71 \mathrm{~g} ; 500 \mathrm{mmoles}$ ) de iodometano. A mistura foi aquecida em banho a 509 C durante 3,5 horas e, em seguida, destilada por arraste a vapor. A fase orgānica separada do destilado foi lavada com āgua e tratada com $40 \mathrm{~m} 1$ de uma solução de hidrōxido de 
sődio 10\% agitando-se durante meia hora. Apōs lavagem com āgua, secagem sobre cloreto de cālcio e separaçāo do sōilido, o produto bruto (37g) foi fracionado sōbre hidreto de 17tio e aluminio, coletando-se $34,5 \mathrm{~g}$ do metil propil sulfeto a 90-929C (Lit. ${ }^{55}:$ Eb. $=$ $95,60 \mathrm{C})$. Rendimento: $77 \%$.

$\operatorname{RMN}\left(\mathrm{CCl}_{4}\right.$-TMS $): \delta 2,45(t .2 \mathrm{H}) ; 2,05(\mathrm{~s} .3 \mathrm{H}) ; 1,57(\operatorname{sex} .2 \mathrm{H}) ; 1,00$

$$
(t .3 \mathrm{H}) \text {. }
$$

3.6 .3 .2 . Metil propil sulfōxido ${ }^{53}$

Procedendo como descrito para a preparação do metil metiltiometil sulföxido (ver 3.6.1.2.), partiu-se de $9,0 \mathrm{~g}$ (100 mmo les) do metil propil sulfeto e de $11,4 \mathrm{~m} 1$ de ägua oxigenada $30 \%$ (101 mmoles) obtendo-se $10,6 \mathrm{~g}$ do produto bruto. Por destilação foram obtidas $6,97 \mathrm{~g}$ do metil propil sulfóxido com $\mathrm{Eb} .=730 \mathrm{C} / 3 \mathrm{~mm}$ Hg. (Lit. ${ }^{56}$ : Eb. $=1020 \mathrm{C} / 15 \mathrm{mmHg}$ ). Rendimento: $65 \%$. RMN $\left(\mathrm{CCl}_{4}\right.$-TMS): $\delta 2,67(\mathrm{t}, 2 \mathrm{H}) ; 2,50(\mathrm{~s} .3 \mathrm{H}) ; 1,73(\operatorname{sex} .2 \mathrm{H})$; $1,07(t .3 \mathrm{H})$.

IV (filme; $\mathrm{NaCl}): 1040 \mathrm{~cm}^{-1}$ (forte)

3.6.4. Preparação do fenil feniltiometil sulfōxido

3.6 .4 .1 . Fenilmercaptal do forma1deido 57

Numa mistura de $20 \mathrm{ml}(21,7 \mathrm{~g}) ; 200$ mmoles) de benzeno tiol, $8 \mathrm{ml}$ de formaldeido $40 \%$ (107 mmoles de $\mathrm{CH}_{2}{ }^{\circ}$ ) e $20 \mathrm{ml}$ de ācido acētico glacial, introduziu-se uma corrente rāpida de āci 
do clorídrico gasoso, sem resfriamento. Observou-se desprendimen to de calor, e, em 15 minutos, separação de fase oleosa, indicada por turvação da mistura. 0 ācido foi borbulhado por mais uma hora. A fase oleosa foi extraida com ēter, e o extrato lavado com āgua, em seguida com solução de hidrōxido de potássio $5 \%$, e nova mente com āgua. Apōs secagem com sulfato de sōdio anidro e separação do sōlido, eliminou-se o solvente a vācuo, e destilou-se o produto bruto, coletando-se, a $158-1600 \mathrm{C} / 0,6 \mathrm{mmHg}, 15,4 \mathrm{~g}$ de um liquido incolor que solidificou com o resfriamento. $F=34-350 \mathrm{C}$ (Lit. ${ }^{57}: F=369 \mathrm{C}$ ). Rendimento: $66 \%$. RMN $\left(\mathrm{CCl}_{4}{ }^{-T M S}\right): \delta 7,1-7,5(\mathrm{~m} .10 \mathrm{H}) ; 4,27(\mathrm{~s}, 2 \mathrm{H})$.

3.6.4.2. Fenil feniltiometil sulföxido ${ }^{53}$

A uma solução de $5,3 \mathrm{~g}(22,8$ mmoles $)$ do fenilmercaptal do formaldeido em $17,5 \mathrm{ml}$ de äcido acêtico glacial, adicionaram-se, às gotas, com resfriamento em banho de ägua e agitação, 2,6 m1 de água oxigenada $30 \%(22,8$ mmoles $)$. Agitou-se por duas horas. Adici onaram-se $200 \mathrm{~m} 1$ de diclorometano, $21 \mathrm{~g}$ de carbonato de potässio e $5 \mathrm{~m} 1$ de àgua, agitando-se atē cessar efervescēncia. A fase orgāni ca foi separada e seca com sulfato de sôdio anidro. Apōs filtração e evaporação do solvente, obtiveram-se $6,3 \mathrm{~g}$ do produto bruto. o sulföxido puro foi separado em uma coluna com $80 \mathrm{~g}$ de gel de sīlica usando-se diclorometano como eluente. Foram obtidas $4 \mathrm{~g}$ do fe nil feniltiometil sulföxido. Rendimento: $70 \%$ 
RMN $\left(\mathrm{CCl}_{4}{ }^{-T M S}\right): \delta 7,1-7,8(\mathrm{~m}, 10 \mathrm{H}) ; 4,05(\mathrm{~s}, 2 \mathrm{H})$.

IV (filme; NaCl): $1050 \mathrm{~cm}^{-1}$ (forte)

3.6.5. Preparação do etil feniltiometil sulfōxido

3.6 .5 .1 Etil clorometil sulfeto ${ }^{58}$

Em um balão de trēs tubuladuras munido com um condensador com tubo de cloreto de cālcio foram misturadas $5 \mathrm{~g}$ (160 mmo les) de paraformaldeido com 10,3g (160 mmoles) de etanotiol. Introduziu-se nesta mistura, resfriando-se com gelo e sal, uma cor rente de äcido clorīdrico seco atē saturaçāo. Adicionaram $30 \mathrm{~g}$ de cloreto de cālcio anidro e se deixou a mistura em repouso à noite.

Apōs adição de $50 \mathrm{ml}$ de ēter, filtrou-se rāpidamente pa ra um balão de duas tubuladuras. Adaptou-se um tubo de cloreto de cālcio e se fềz passar uma corrente de nitrogênio atē elimina ção do äcido clorídrico. Por destilação do material bruto, obtiveram-se $9,0 \mathrm{~g}$ do clorometil sulfeto, com Eb. $=126-1280 \mathrm{C}$ (Lit. ${ }^{58}$ : Eb. $=128-1310$ C) correspondendo a $50 \%$ de rendimento. $\operatorname{RMN}\left(\mathrm{CCl}_{4}-\right.$ TMS $): \delta 4,70(\mathrm{~s}, 2 \mathrm{H}) ; 2,77(\mathrm{q}, 2 \mathrm{H}) ; 1,33(\mathrm{t}, 3 \mathrm{H})$.

3.6.5.2. Etil feniltiometil sulfeto

Em um balão de trēs tubuladuras foram colocadas $1,04 \mathrm{~g}$ $(45,2$ at-g) de sōdio e $20 \mathrm{~m} 1$ de etanol absoluto. Adaptou-se um 
condensador de refluxo com tubo de cloreto de cālcioe, após dis soluçăo completa do sōdio, adicionaram-se $4,97 \mathrm{~g}(45,2$ mmoles $)$ de benzenotiol ãs gotas e com agitação magnêtica. A solução resul tante adicionaram-se, ās gotas, $5 \mathrm{~g}$ (45,2 mmoles) de etil clorome til sulfeto, com resfriamento e agitação. Em seguida aqueceu-se a mistura sob refluxo por meia hora. Destilou-se a maior parte do ãlcool, adicionou-se ãgua e extraiu-se o material orgânico com ēter. 0 extrato foi seco com sulfato de sōdio anidro e o produto bruto $(7,3 g)$, obtido apōs eliminação do solvente, foi fracionado, coletando-se $4,5 \mathrm{~g}$ do mercaptal a $1439 \mathrm{C} / 12 \mathrm{~mm} \mathrm{Hg}$. (Lit. ${ }^{52}: 1450 \mathrm{C}$ ) $12 \mathrm{~mm} \mathrm{Hg}$ ). Rendimento: $54 \%$.

RMN $\left(\mathrm{CCl}_{4}\right.$-TMS $): \delta 7,03-7,50(\mathrm{~m}, 5 \mathrm{H}) ; 3,90(\mathrm{~s}, 2 \mathrm{H}) ; 2,63(\mathrm{q} .2 \mathrm{H})$; $1,23(t, 3 H)$.

3.6.5.3. Etil feniltiometil sulfōxido

Procedendo como descrito em 3.6.1.2., utilizaram-se $4,27 \mathrm{~g}(23,2$ mmoles) de feniltiometil etil sulfeto em $5 \mathrm{ml}$ de āci do acētico, e $2,65 \mathrm{~g}$ de āgua oxigenada $30 \%(23,2$ mmoles) para a reação, $30 \mathrm{ml}$ de diclorometano para extração do produto e $6 \mathrm{~g}$ de carbonato de potāssio para a neutralização do äcido acētico. obtiveram-se $4,1 \mathrm{~g}$ do produto bruto. O feniltiometil etil sulfóxido foi separado do bruto por cromatografia em coluna, utilizando-se $80 \mathrm{~g}$ de gel de silica e, como eluente, uma mistura de $40 \%$ de acetona em hexano. O rendimento do sulfōxido foi de $2,4 \mathrm{~g}$ (51\%). $\operatorname{RMN}\left(\mathrm{CCl}_{4}\right.$-TMS $): \delta 7,06-7,60(\mathrm{~m}, 5 \mathrm{H}) ; 4,00(\mathrm{~s} .2 \mathrm{H}) ; 2,76$ e $2,70(\mathrm{~d} . \mathrm{q}$. $2 H) ; 1.20(t .3 H)$. 
IV (Filme $-\mathrm{NaCl}): 1040 \mathrm{~cm}^{-1}$ (forte)

Ressonância do fenil etiltiometil sulföxido:

$\operatorname{RMN}\left(\mathrm{CCl}_{4}\right.$-TMS $): \delta 7,4-7,8(\mathrm{~m}, 5 \mathrm{H}) ; 3,7(\mathrm{~s}, 2 \mathrm{H}) ; 2,71(\mathrm{q} .2 \mathrm{H}) ; 1,26$ (q. $3 \mathrm{H})$.

3.6.6. Preparação do 1,3-ditiolano-1-ōxido

$3.6 .6 .1 \cdot 1,3-$ Ditiolano $^{59}$

A uma solução de $3 g$ de ãcido p-toluenosulfōnico em 150 ml de clorofórmio adicionaram-se, com agitaçāo e resfriamento em gelo, $12 \mathrm{~g}$ (126 mmoles) de etilenotiol e $3,78 \mathrm{~g}$ (126 mmoles) de pa raformaldeido. A mistura foi deixada agitando com resfriamento em gelo por duas horas e em repouso em geladeira durante a noite. Jogou-se em ăgua, separou-se a fase orgânica, que em seguida foi lavada com ăgua, cinco vêzes com solução de hidrōxido de potās sio $5 \%$, e cinco vēzes com āgua. Apōs secagem con sulfato de sō dio anidro e filtraçāo do sölido, evaporou-se o solvente, obtendo-se $5,5 \mathrm{~g}$ do produto bruto. Por destilação em uma pequena colu na de Vigreaux obtiveram-se $4,5 \mathrm{~g}$ do 1,3 -ditiolano coletado a $649 \mathrm{C} / 14 \mathrm{mmHg}$ (Lit. ${ }^{60}=61 \mathrm{oC} / 11 \mathrm{mmHg}$ ). Rendimento: $34 \%$. RMN $\left(\mathrm{CCl}_{4}\right.$-TMS): $\delta 3,84(\mathrm{~s}, 2 \mathrm{H}) ; 3,14(\mathrm{~s}, 4 \mathrm{H})$.

$3,6,6,2,1,3-0 i t i o 1$ ano-1-ox $x i$ do 60

Uma solução de $2,5 \mathrm{ml}(24,5$ mmoles $)$ de ãgua oxigenada em $5 \mathrm{ml}$ de äcido ačetico foi adicionada, ãs gotas, com agitação 
e resfriamento em gelo, sobre solução de $3,07 \mathrm{~g}(28,9$ mmoles $)$ de 1,3-ditiolano em $5 \mathrm{ml}$ de äcido acētico, mantendo-se a temperatura interna entre 6 e $100 \mathrm{C}$. A mistura foi agitada a frio por mais meia hora, e deixada em repouso ã temperatura ambiente por três dias. O solvente foi eliminado ã trompa e depois na bomba de vācuo entre 11 e $1 \mathrm{~mm} \mathrm{Hg}$, com banho abaixo de $400 \mathrm{C}$, obtendo-se $4,8 \mathrm{~g}$ do produto bruto. Por destilação, coletaram-se $1.55 \mathrm{~g}$ do produto a $128-1329 \mathrm{C} / 3 \mathrm{~mm} \mathrm{Hg}$ (Lit. ${ }^{60}$ : Eb. $=115-1209 \mathrm{C} / 1 \mathrm{~mm} \mathrm{Hg}$ ), correspondendo a um rendimento de $51 \%$.

$\operatorname{RMN}\left(\mathrm{CCl}_{4}-\mathrm{TMS}\right): \delta 4,0(\mathrm{~s}, 2 \mathrm{H}) ; 3,0-3,8(\mathrm{~m} .4 \mathrm{H})$.

IV (fil me; $\mathrm{NaCl}): 1040 \mathrm{~cm}^{-1}$ (forte)

\subsection{PREPARAÇOES DE COMPOSTOS PARA FINS COMPARATIVOS}

3.7.1. Preparação do etilmercaptal do p-metoxibenzaldeido 52

Em um balão de três tubuladuras, ao qual foi adaptado um dedo frio contendo gelo seco e acetona, com tubo de cloreto de cālcio, e um tubo para admissão de ācido clorīdrico gașoso. foram misturadas $6,8 \mathrm{~g}$ (50 mmoles) de p-metoxibenzaldeido e 6,51 g (105 mmoles) de etanotiol. Nesta mistura, resfriada em gelo e sal, introduziu-se uma corrente de äcido clorīdrido gasoso atē saturação. Precipitou-se um sōlido branco. Oācido clorîdrico em excesso foi eliminado conservando-se a mistura sob väcuo, durante 24 horas, em um dessecador contendo hidrōxido de sódio. O pro duto foi recristalizado de etanol, e seco em dessecador contendo cloreto de câlcio anidro. Foi obtido um rendimento de $82 \%$ do 
p-metoxibenzaldeido $(10 \mathrm{~g})$ com $F=41-42,50 \mathrm{C}$. (Lit. $\left.{ }^{61}: F=42-439 \mathrm{C}\right)$. $\operatorname{RMN}\left(\mathrm{CCl}_{4}\right.$-TMS): $\delta 6,70-7,40(\mathrm{~m} .4 \mathrm{H}) ; 4,83(\mathrm{~s}, 1 \mathrm{H}) ; 3,73(\mathrm{~s} .3 \mathrm{H})$; $2,50(q, 4 H) ; 1,18(t, 6 H)$.

3. 7. 2. Preparação do etilmercaptal do o-metoxibenzaldeido

Em apareinagem idêntica à utilizada em 3.7.1. foram misturadas $6,8 \mathrm{~g}$ (50 mmoles) do o-metoxibenzaldeido e $6 ; 51 \mathrm{~g}$ (105 mmoles) de etanotiol. Nesta mistura, resfriada em gelo e sal, introduziu-se uma corrente de ācido clorīdrico gasoso atē saturação. Formou-se um ōleo. o àcido clorîdrico em excesso foi elị minado conservando-se a mistura sob vācuo, durante 24 horas, em um dessecador contendo hidrōxido de sōdio. o produto foi extrai do com ēter e o extrato foi lavado com āgua, depois com solução de hidrōxido de sōdio 10\%, e novamente com ägua. Agitou-se com solução saturada de bissulfito de sōdio durante uma hora, lavouse com ägua, secou-se com sulfato de sōdio anidro, filtrou-se e evaporou-se o solvente, obtendo-se $10 \mathrm{~g}$ do produto bruto. Destilou-se o bruto, coletando-se o mercaptal do o-metoxibenzaldeido $(7,5 \mathrm{~g})$ a $98-1000 \mathrm{C} / 0,02 \mathrm{~mm} \mathrm{Hg}$. Rendimento: $31,5 \%$.

$\operatorname{RMN}\left(\mathrm{CCl}_{4}\right.$-TMS $): \delta 6,65-7,65(\mathrm{~m}, 4 \mathrm{H}) ; 5,43(\mathrm{~s}, 1 \mathrm{H}) ; 3,77(\mathrm{~s} .3 \mathrm{H})$;

$$
2,50(q .4 \mathrm{H}) ; 1,17(\mathrm{t} .6 \mathrm{H}) \text {. }
$$

3.7.3. Preparação do etilmercaptal do tolualdeido

Partindo de $4,8 \mathrm{~g}$ ( 39 mmoles) de tolualdeido e $5 \mathrm{~g}$ ( 80 mmoles) de etanotiol, e procedendo como descrito em 3.7 .2 , ob- 
tiveram-se $6,77 \mathrm{~g}$ de etilmercaptal do tolualdeido, coletado, por destilação, a $123-1240 \mathrm{C} / 0,4 \mathrm{~mm} \mathrm{Hg}$ (Lit. ${ }^{62}$ : Eb. $=125-1300 \mathrm{C} / 0,35$ $\mathrm{mm} \mathrm{Hg})$. Rendimento: $74,3 \%$.

RMN $\left(\mathrm{CCl}_{4}\right.$-TMS $): \delta 6,9-7,4(\mathrm{~m} .4 \mathrm{H}) ; 4,87(\mathrm{~s}, 1 \mathrm{H}) ; 2,50(\mathrm{q} .4 \mathrm{H})$; $2,30(\mathrm{~s} .3 \mathrm{H}) ; 1,20(\mathrm{t} .6 \mathrm{H})$.

3.7.4. Preparação do fenilmercaptal do benzaldeido ${ }^{52}$

Partindo de $1,9 \mathrm{~g}$ ( 18 mmoles) de benzaldeido e de $4,2 \mathrm{~g}$ (37 mmoles) de tiofenol, obtiveram-se, procedendo como descrito em 3.7.1., 4,2g $(75,9 \%)$ do fenilmercaptal do benzaldeido com $F=48-51$ ọ apōs recristalização em etanol (Lit. ${ }^{63}: F=520 \mathrm{C}$ ). $\operatorname{RMN}\left(\mathrm{CC}_{4} 4^{-T M S}\right): \delta 7,0-7,5(\mathrm{~m}, 15 \mathrm{H}) ; 5,33(\mathrm{~s}, 1 \mathrm{H})$.

\subsubsection{Preparação do etilfenilmercaptal do benzaldeido}

\section{$3 \cdot 7 \cdot 5 \cdot 1$. Benzil fenil sulfeto ${ }^{64}$}

Em um balão munido de um funil conta-gotas e um conden sador para refluxo com tubo de cloreto de cālcio, colocou-se uma solução de hidrōxido de potāssio $(5,6 \mathrm{~g} ; 0,1 \mathrm{~mol})$ em etanol ( 50 m1). Adicionaram-se, às gotas e com agitação, $11 \mathrm{~g}(0,1 \mathrm{~mol})$ de benzenotiol e, em seguida, uma solução de cloreto de benzila $(12,65 \mathrm{~g} ; 0,1 \mathrm{~mol})$ em etanol (50 ml). A mistura foi aquecida sob refluxo por 5 horas. Eliminou-se a maior parte do solvente por destilação. 0 sōlido resultante foi misturado comãgua, extraido com ēter, e o extrato lavado com trēs porções de hidróxido de po tāssio $5 \%$, trēs vēzes com āgua, e seco com sulfato de sōdio ani- 
dro. Apōs filtração e eliminação do solvente, o produto bruto $(17,9 \mathrm{~g})$ foi recristalizado de metanol-āgua, obtendo-se $12 \mathrm{~g}$ (63\%) do benzil fenil sulfeto com $F=40-410 \mathrm{C}$. (Lit. ${ }^{64}$ : $F=41-420 \mathrm{C}$ ). $\operatorname{RMN}\left(\mathrm{CCl}_{4}\right.$-TMS $): \delta 7,0-7,4(\mathrm{~m}, 10 \mathrm{H}) ; 4,0(\mathrm{~s}, 2 \mathrm{H})$

Lit.:RMN (CCl ${ }_{4}$-TMS): $\delta 4,00(\mathrm{~s}$.

3.7.5.2. $\quad \alpha$-clorobenzil fenil sulfeto ${ }^{64}$

A uma solução de benzil fenil sulfeto $(5,45 \mathrm{~g} ; 25$ mmoles) em tetracloreto de carbono (50m1), contida em um balão com tubo de cloreto de cälcio, adicionou-se, com agitação, N-clorosuccinimida $(3,34 \mathrm{~g} ; 25$ mmoles), mantendo-se a temperatura entre 20 e $250 \mathrm{C}$. Apõs duas horas de agitação, o sôlido formado foi removido por filtração, obtendo-se uma solução de $\alpha$-clorobenzil fenil sulfeto. $\operatorname{RMN}\left(\mathrm{CC}_{4}\right.$-TMS $): \delta 7,0-7,5(\mathrm{~m}, 10 \mathrm{H}) ; 6,15(\mathrm{~s}, 1 \mathrm{H})$ Lit. $^{64}: \operatorname{RMN}\left(\mathrm{CCl}_{4}\right.$-TMS $): \delta 6,15(\mathrm{~s}$.

3.7 .5 .3 . Etil fenil mercaptal do benzaldeido ${ }^{52}$

A uma solução dé etōxido de sōdio, preparada a partir de $288 \mathrm{mg}(12,5$ mmoles $)$ de sôdio e $10 \mathrm{ml}$ de etanol absoluto, adicionaram-se, lentamente, $780 \mathrm{mg}(12,5$ mmoles $)$ de etanotiol. Esta soluçāo foi adicionada, às gotas, com agitaçāo e à temperatura ambiente, sobre uma solução de 12,5 mmoles de a-clorobenzil fenil sulfeto em $25 \mathrm{ml}$ de tetracloreto de carbono. A mistura foi 
deixada em repouso durante a noite e jogada em ãgua. A fase orgā nica foi lavada com solução de carbonato de potãssio, depois com āgua, e seca com sulfato de sōdio anidro. Por evaporação do solvente obtiveram-se $2,5 \mathrm{~g}$ do produto bruto.

Por cromatografia de gās do produto bruto nas mesmas condições indicadas em 3.3.2.5., observou-se a presença de trēs compostos na proporção de 1:4:1. Os compostos de menor quantidade foram identificados, por injecção em mistura com os autēnti cos, como sendo o dietilmercaptal do benzaldeido e o difenilmercaptal do benzaldeido. O de maior quantidade corresponde ao etil fenilmercaptal do benzaldeido, como evidenciado pelo espectro de ressonāncia magnētica nuclear do produto bruto, que apresenta si nais dos três mercaptais. Por cromatografia em coluna utilizan do=se $50 \mathrm{~g}$ de gel de sîlica, e $2 \%$ de acetona em hexano como eluen te, não foi possĩvel a separação dos mercaptais. o espectro de ressonāncia magnëtica nuclear do material recuperado da coluna apresenta os sinais:

RMN (CCl 4 -TMS): $\delta 7,0-7,5(\mathrm{~m}.) ; 5,36(\mathrm{~s}.) ; 5,10(\mathrm{~s}.) ; 4,87(\mathrm{~s}$.$) ;$

$$
2,58(q .) ; 2,45(q .) ; 1,16(t .) ; 1,13(t .) \text {. }
$$

3.7.6. Preparação do 2 -feni1-1,3-ditiolano

Uma solução de benzaldeido $(4,24 \mathrm{~g} ; 40$ mmoles $)$ e etile= noditiol ( $4 \mathrm{~g} ; 42$ mmoles) em clorofōrmio $(25 \mathrm{ml}$ ) foi saturada rãpidamente ( 5 min.) com äcido clorīdrico seco, resfriando-se com banho de ãgua. A solução foi lavada com ãgua, com cinco porções de $30 \mathrm{ml}$ de hidrōxido de sódio $4 \%$, novamente com āgua, e depois 
seca com sulfato de sōdio anidro. Apōs eliminação do solvente, o produto bruto $(7,34 \mathrm{~g})$ foi destilado a väcuo, obtendo-se $5 \mathrm{~g}(69 \%)$ do 2-fenil-1,3-ditiolano com $E_{0}=128-1290 \mathrm{C} / 0,8 \mathrm{~mm} \mathrm{Hg}$. (Lit. ${ }^{6}$ : Eb. $=129-1309 \mathrm{C} / 1,5 \mathrm{~mm} \mathrm{Hg})$.

RMN $\left(\mathrm{CCl}_{4}-\right.$ TMS $): \delta 7,1-7,6(\mathrm{~m}, 5 \mathrm{H}) ; 5,56(\mathrm{~s}, 1 \mathrm{H}) ; 2,96-3,60(\mathrm{~m} .4 \mathrm{H})$.

3.7.7. Preparação do etil p-metoxifenil sulfeto ${ }^{65}$

Sōbre uma solução de $2 \mathrm{~g}$ (50 mmoles) de hidrōxido de sọ dio em $20 \mathrm{ml}$ de ãgua adicionou-se, com agitação, $5,6 \mathrm{~g}$ ( 40 mmoles) de p-metoxibenzenotiol e, em seguida, 6,55g (42,5 mmoles) de sul fato de etila. A mistura foi aquecida em banho maria, com agitação, durante duas horas, separando-se a fase orgânica. Adicionouse ēter e lavou-se a solução etērea com āgua atē neutralização. Secou-se com carbonato de potässio anidro, evaporou-se o solvente e destilou-se a vācuo o produto bruto $(5,55 \mathrm{~g})$, coletando-se $3,5 \mathrm{~g}(52 \%)$ do etil p-metoxifenil sulfeto entre $87-880 \mathrm{C} / 2 \mathrm{~mm} \mathrm{Hg}$ $\left(\mathrm{Lit}^{66}\right.$ : Eb. $\left.=1039 \mathrm{C} / 5 \mathrm{~mm} \mathrm{Hg}\right)$. $\operatorname{RMN}\left(\mathrm{CCl}_{4}\right.$-TMS $): \delta 6,63-7,30(\mathrm{~m} .4 \mathrm{H}) ; 3,70(\mathrm{~s}, 3 \mathrm{H}) ; 2,75(\mathrm{q} .2 \mathrm{H})$; $1,20(t .3 H)$.

3.7.8. Preparação do etil p-metoxibenzil sulfeto ${ }^{65}$

Procedendo como em 3.7.7., partiu-se de $2 \mathrm{~g}$ de hidrōxido de södio, em $20 \mathrm{ml}$ de āgua, $6,16 \mathrm{~g}$ (40 mmoles) de p-metoxibenzị tiol e $6,55 \mathrm{~g}(42,5$ mmoles $)$ de sulfato de etila, obtendo-se $6,0 \mathrm{~g}$ do produto bruto. Por destilação a vācuo coletou-se o etil p-meto 
xibenzil sulfeto $(3,2 \mathrm{~g} ; 44 \%)$ a $1010 \mathrm{C} / 2 \mathrm{~mm} \mathrm{Hg}$.

$\operatorname{RMN}\left(\mathrm{CC}_{4}\right.$-TMS): $\delta 6,60-7,16(\mathrm{~m}, 4 \mathrm{H}) ; 3,70(\mathrm{~s}, 3 \mathrm{H}) ; 3,57(\mathrm{~s}, 2 \mathrm{H})$; $2,30(q .2 \mathrm{H}) ; 1,17(\mathrm{t} .3 \mathrm{H})$. 


\section{RESUMO}

o presente trabalho investiga alguns sulfōxidos B-tiasubstituidos quanto ā sua basicidade relativa e quanto à sua rea tividade em relação aos compostos de Grignard aromāticos.

0 conjunto de compostos investigados foi o seguinte: me til n-propil sulfōxido, metil metiltiometil sulföxido, etil bu tị sulfôxido, etil etiltiometil sulföxido, etil feniltiometil sulfóxido, fenil feniltiometil sulfōxido e 1,3-ditiolano-l-óxido.

E apresentada, inicialmente, uma revisão bibliogräfica sōbre dois ĩtens: 1 . basicidade de sulföxidos, e 2 . reações de sulfōxidos com compostos de Grignard.

Säo apresentados os valores de constantes de associação para dois sulfōxidos $\beta$-tia-substituidos e dois nāo substituidos correspondentes. Estes valores foram calculados a partir de medidas dos deslocamentos químicos dos prōtons do fenol em sistemas ternārios sulföxido -fenol-tetracloreto de carbono, pelo emprêgo dos métodos de Carper e de Mathur.

São apresentadas as reações de quatro sulföxidos com alguns compostos de Grignard aromāticos, tais como os brometos de feni1-, p-anisi1-, p-tolilmagnēsio, e descritos os mētodos de anä 1 ise dos compostos formados.

São descritas as preparações de cincos sulfōxidos e de alguns produtos autênticos.

São fornecidos os resultados de algumas experiências de reações de um sulfóxido $\beta$-tia-substituido com brometo de fenilmag nësio em presença de base.

E apresentada uma discussäo na qual se procura interpre- 
tar tanto os resultados da literatura como os nossos.

Os resultados obtidos demonstram que:

a) Hă diminuição de basicidade nos sulfōxidos $\beta$-tia-substituidos, em comparação com os não substituidos correspondentes.

b) A reação dos sulfôxidos $\beta$-tia-substituidos com compostos de Grignard aromãticos fornece os mercaptais dos aldeidos aromāti cos correspondentes.

c) A reação dos sulfōxidos $\beta$-tia-substituidos com reagentes de Grignard ē impedida por bases fortes. Os rendimentos dos mer captais são muito mais baixos do que na ausência de base.

d) A fixação do organomagnesiano ocorre inicialmente no grupo sul finila. Um mecanismo envolvendo um estado de transição cíclico $\bar{e}$ sugerido para explicar a migração preferencial do anel aromä tico proveniente do composto de Grignard. 


\section{ABSTRACT}

This thesis investigates some $B$-thia-substituted sulphoxides concerning their relative basicity and reactivity toward aromatic Grignard reagents. The following compounds were investigated: methyl n-propyl sulphoxide, methyl methylthiomethyl sulphoxide, ethyl n-butyl sulphoxide, ethyl ethylthiomethyl sulphoxide, ethyl phenylthiomethyl sulphoxide, phenyl phenylthiomethyl sulphoxide and 1,3-dithiolane-l-oxide.

A literature review, containing two topics, is presented: 1) basicity of sulphoxides, 2) reactions of sulphoxides with Grignard reagents.

The data of the association constants for two B-thiasubstituted and two corresponding unsubstituted sulphoxides are presented. These values were calculated from the chemical shifts of the phenol protons, measured in the ternary systems sulphoxide -phenol-carbon tetrachloride, by methods of Mathur and Carper.

The reactivity of four sulphoxides with some Grignard reagents, such as phenyl-, p-anisyl-, and p-tolylmagnesium bromides including the analyses of the resulting products is presented.

The preparation of five sulphoxides and of some authentic products are described.

Some experiments, in which the Grignard reaction is performed in basic conditions, are reported.

The obtained results are discussed in the light of the literature data. 
It is shown that:

a) There is a decrease in basicity going from the unsubstituted sulphoxides to the corresponding $\beta$-thia-substituted ones.

b) The reaction of $\beta$-thia-substituted sulphoxides lead to the corresponding aromatic aldehydes mercaptals.

c) The reaction of the B-thia-substituted sulphoxides is inhibited by the presence of a base. The yields of mercaptals are much lower than in the absence of base.

d) The attachment of the Grignard reagent occurs, initially, at sulphinyl group. A mechanism, envolving a cyclic transition state, is suggested, in order to explain the preferential migration of the aromatic ring, which belonged originally to the Grignard reagent. 


\section{REFERENCIAS BIBLIOGRAFICAS}

1. M.A. Andrade, "Tese de Mestrado", a ser apresentada ao Insti tuto de Qữmica da Universidade de São Paulo.

2. B. Wladislaw, L. Marzoratti, F. A. C. Andrade e M. A. Andrade, Phosphorus and Sulfur, $1979,6,333$.

3. B. Wladislaw, L. Marzoratti, F. A. C. Andrade, M. A. Andrade e M.B. Mathor, Cienc. Cu1t., 1977, 29, 405.

4. C. A. Streuli, Ana1, Chem., 1958, 30, 997.

5. K. K. Andersen, W. H. Edmonds, J. B. Biasotti e R. A. Strecker, J. Org. Chem., 1966, 31, 2859.

6. R. Stewart e K. Yates, J. Amer. Chem. Soc., 1958, 80, 6355.

7. P. Haake, R. Cook, Tetrahedron Letters, 1968, 427.

8. P. Haake, R. Cook e G. H. Hurst, J. Amer. Chem. Soc., 1967, 89,2650 .

9. D. Landini, G. Modena, G. Scorrano e F. Taddei, J. Amer. Chem. Soc., $1969, \underline{91,6703 .}$

10. C. T. Davis e T. A. Geissman, J. Amer. Chem. Soc., 1954, 76, 3507 .

11. J. F. Bunnett e F. P. 01 sen, Canad. J. Chem., 1966, 44, 1899. 
12. N. C. Marziano, G. Cimino, U. Romano e R. C. Passerini, Tetrahedron Letters, 1969, 2833.

13. L. P. Hammett e A. J. Deyrup, J. Amer. Chem. Soc., 1932, 54, 2721 .

14. K. Yates e R. A. McClelland, J. Amer. Chem. Soc., 1967, $\underline{89}$, 2686 .

15. S. Oae, K. Sakai e N. Kunieda, Bul1. Chem. Soc. Japan, 1969, 42, 1964 .

16. T. Gramstad, Spectrochimica Acta, 1963, 19, 829.

17. P. Biscarini, G. Galloni e S. Ghersetti, Bol1. Sci. Fac. Chim. Ind. Bologna, 1963, 21, 154.

18. R, H. Figueroa, E. Roig e H. H. Szmant, Spectrochimica Acta, $1966,22,1107$.

19. D, Gurka e R. W!. Taft, J. Amer. Chem. Soc., 1969, 91, 4794

20. V. Grignard e L. Zorn, Compt, rend., 1910, 150, 1177

21. H. Hepworth e H. W. Clapham, J. Chem. Soc. 1921, 119, 1188.

22. B, S. Wildi, S. W. Taylor e H. A. Potratz, J. Amer. Chem.Soc., $1951, \underline{73}, 1965$.

23. E. P. Kohler e H. Potter, J. Amer. Chem. Soc., 1935, 57, 1316. 
24. H. Potter, 137 th Meeting, American Chemical Society, Cleve1and, Ohio, Apri1 5-14, 1960, pag. 30 .

25. R. Oda e K. Yamamoto,J. Org. Chem,, 1961, 26, 4679.

26. A. Sekera, J. E. Fauvet e P. Rumpf, Ann. Chim., 1965, 10, 413.

27. P. Manya, A. Sekera e P. Rumpf, Compt, rend., 1967, 264, 1196.

28. P. Manya, A. Sekera e P. Rumpf, Tetrahedron, 1970, 26, 467.

29. N. A. Nesmeyanov, V. A. Kalyavin e 0. A. Reutov, Dok1. Akad. Nauk SSSR, 1975, 223, 1379.

30. N. A. Nesmeyanov, V. A. Kalyavin e 0. A. Reutov, Dokl. Akad. Nauk SSSR, 1976, 230, 1353.

31. N. Kunieda, J. Nokami e M. Kinoshita, Tetrahedron Letters, 1974, 3997 .

32. J. Nokami, N. Kunieda e M. Kinoshita, Tetrahedron Letters, 1975,2841 .

33. B. Wladislaw, R. Rittner e H. Viertler, J. Chem. Soc. (B), 1971 1859 ,

34. B. Wladislaw, R. Rittner, P. R, 01 ivato e C. C. Sancho, J. C. S. Chem. Comm., 1972, 236 . 
35. B. T. Buzzi, P. R. 01 ivato, R. Rittner, C. Trufem, H. Viertler, e B. Wladislaw, J. C. S. Perkin II, 1975, 1294.

36. M. T. Fabi, L. Marzoratti, P. R. 01ivato, R. Rittner, H. Viertler, e B. Wladislaw, J. C. S. Perkin II, 1976, 16.

37. K. C. Cole, C. Sandorfy, M. T, Fabi, P. R. 01 ivato, R. Rittner, C. Trufem, H. Viertler e B. Wladislaw,.J.C.S. Perkin II, $1977,1294$.

38. W. R. Carper, C. M. Buess e G. H. Hipp; J. Phys. Chem., 1970, 74, 4229 .

39. R. Mathur, E. D. Becker, R. B. Bradley e N. C. Li, J. Phys. Chem., 1963, 67, 2190.

40. C. Trufem, "Tese de Doutoramento", Instituto de Química da Universidade de Säo Paulo, São Paulo, 1976, pag. 93.

41. H. H. Szmant, em "Sulfur in Organic and Inorganic Chemistry", Alexander Senning (Ed.), Vol. I, Marcel Dekker Inc., New York, 1971, pag. 139.

42. H. 0. House, "Modern Synthetic Reactions", W. A. Benjamin, Inc, Men1o Park, California, 2a, ed., 1972, pag. 712.

43. M. F. Shostakovskii, M. R. Kulibekov e A. K. Gorban, J. Gene ral Chem. USSR, $1964, \underline{34}, 2870$.

44. G. A. Russe1 e E. T. Sabourin, J. Org. Chem., 1969, 34,2336. 
45. M. Hojo, R. Masuda, T. Saeki, K. Fujimori e S. Tsutsumi, Tetrahedron Letters, 1977, 3883.

46. A. I. Voge1, "A Textbook of Practical Organic Chemistry", Longman, London, 3a. ed., 1966, pag. 516.

47. H. Gilman, E. A. Zoeliner e J, B. Dickey, J. Amer. Chem.Soc., $1929, \underline{51}, 1576$

48. J. E. Richman, J. L. Herrmann e R. H. Schlessinger, Tetrahe dron Letters, 1973, 3267.

49. E. C. Ashby e R. C. Arnott, J. Organometal1ic Chem., 1968 , $\underline{14}, 1$.

50. K. Ogura e G. Tsuchihashi, Tetrahedron-Letters, 1971, 3151.

51. D. D. Perrin, W. L. F. Armarego, e D. R. Perrin, "Purification of Laboratory Chemicals", Pergamon Press, 0xford, 1966, a) pag. 262; b) pag. 136 .

52. H. Bohme e R. Marx, Chem. Ber., 1941, 74B, 1667.

53. K. Ogura e G. Tsuchihashi, Bu11. Chem. Soc. Japan, 1972, $\underline{45}$. 2203.

54. D. Welt e D, Whittaker, J. Chem, Soc., 1962, 4372.

55. D. T. McAlian, T. V. Cullum, R. A. Dean e F. A. Fidler, J. Amer, Chem. Soc, $1951,73,3627$. 
56. C. C. Price e R. Gillis, J. Amer, Chem. Soc., 1953, 75, 4750 .

57. H. H. Taylor, J. Amer. Chem. Soc., 1935, 57, 1065.

58. H. Bohme, Chem. Ber., 1936, 69, 1611

59. D. Seebach, B. W. Erickson e G. Singh, J. Org. Chem,, 1966, 31, 4303 ,

60. D. T. Gibson,J, Chem. Soc., 1930, 12.

61. P. R. 01 ivato, "Tese de Doutoramento", Instituto de Química da Universidade de São Paulo, São Paulo, 1972, pag. 77.

62. F, Bessette, J. Brault e J. M. Lalancetti, Canad. J. Chem., $1965, \underline{43}, 307$.

63. H. Hauptmann e B. Wladislaw, J. Amer. Chem. Soc., 1950, 72, 707.

64. D. L. Tuteen e V. C. Marcum, J. Org. Chem,, 1967, 32, 204.

65. H. Gilman e N. J. Beaber, J. Amer. Chem. Soc., 1925, 47 , 1449 .

66. C. M. Suter e H. L. Hansen, J. Amer. Chem. Soc., 1932, 54, 4100 . 